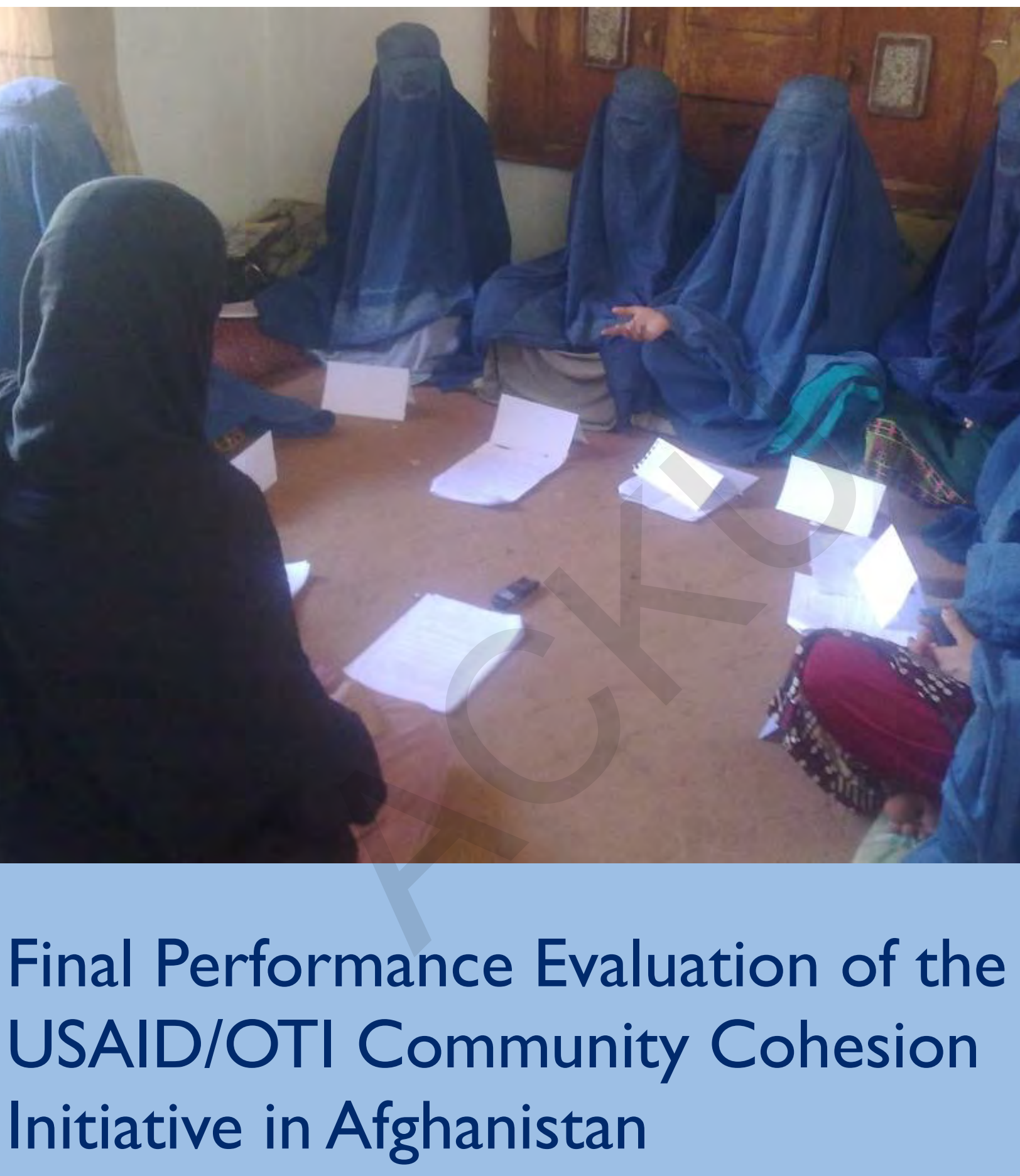

February 2016

This publication was produced at the request of the United States Agency for International Development. It was prepared independently by Social Impact. 


\footnotetext{
Cover photo: A focus group discussion with female participants in Kunar Province. Participant 3 told the group: "When the $\mathrm{CCl}$ project was implemented in Chandrawi village the relations between government and people were strengthened. The first activity of the project was to build a wall to protected [sic] people from floods. It solved many problems of the people. Fields and houses that were vulnerable before, now they are protected. Now people understand and they have trust in the government."
} 


\section{FINAL PERFORMANCE EVALUATION OF THE USAID/OTI COMMUNITY COHESION INITIATIVE IN AFGHANISTAN:}

A COMPREHENSIVE QUALITATIVE STUDY OF PROJECT PERFORMANCE, STRATEGY, AND THEORY OF CHANGE, ACTIVITY OUTCOMES, LEARNING PROCESSES, AND LESSONS LEARNED

February 18, 2016

AID-OAA-I-13-00006

Performance Evaluation Implemented by Social Impact under OTI Task Order \#II of the Program Development Quickly III (PDQ III) Indefinite Quantity Contract

DISCLAIMER

The author's views expressed in this publication do not necessarily reflect the views of the United States Agency for International Development or the United States Government. 


\section{CONTENTS}

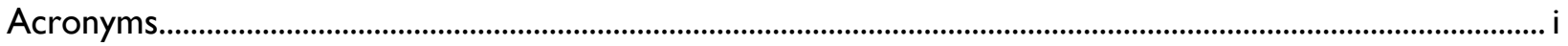

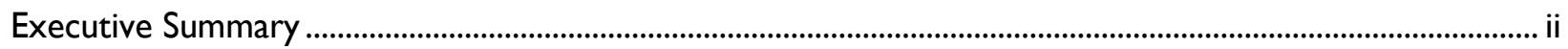

Evaluation Purpose and Evaluation Questions .............................................................................................. I

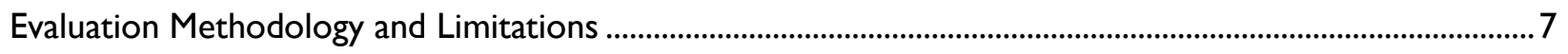

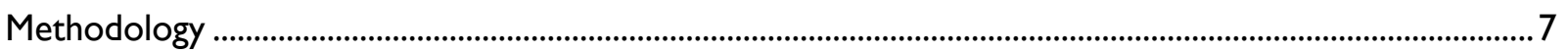

Review of Secondary Data Sources (Desk Review) ........................................................................................... 7

In-Depth Interviews............................................................................................................................................

Focus Group Discussions.........................................................................................................................

Limitations of the Evaluation Methodology …………...................................................................................

Findings, Conclusions, and Recommendations ....................................................................................... I

Findings ......................................................................................................................................................... I

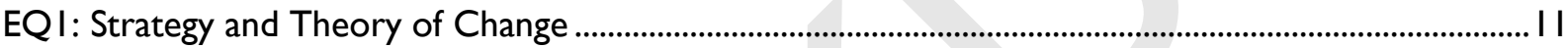

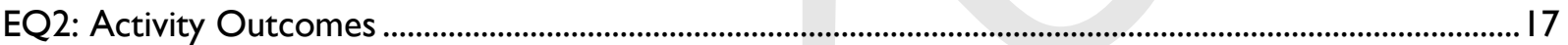

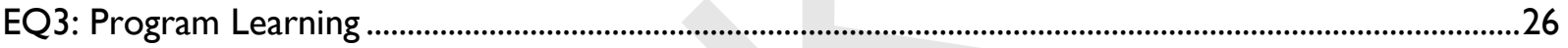

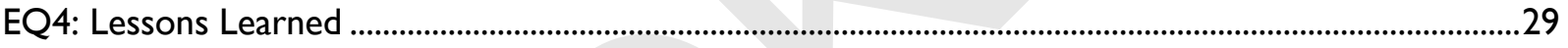

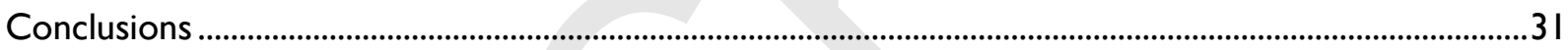

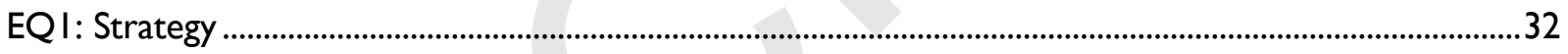

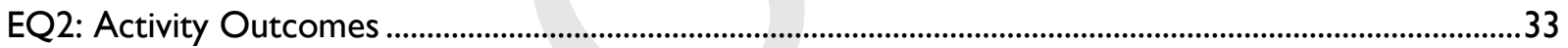

EQ3: Program Learning ....................................................................................................................................34

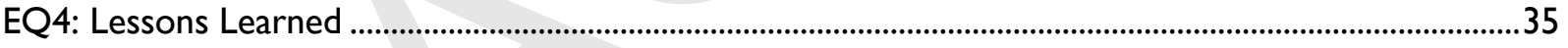

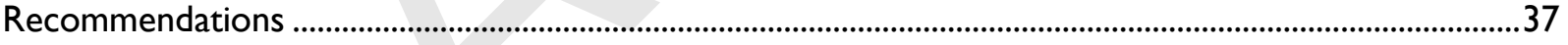

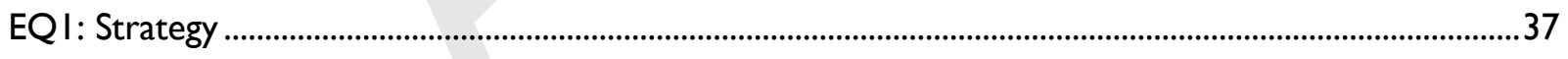

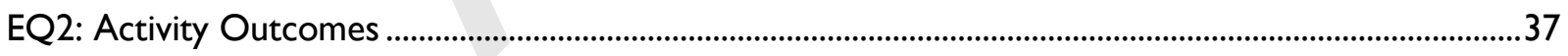

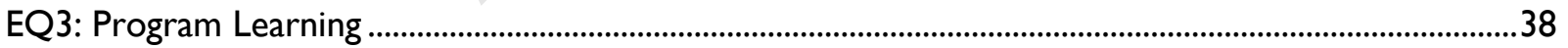

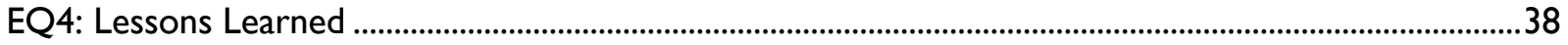

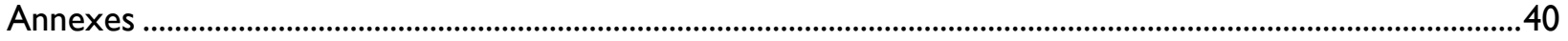

Annex I: Evaluation Statement of Work ...........................................................................................................40

Annex II: Evaluation Methods and Limitations ………….......................................................................56

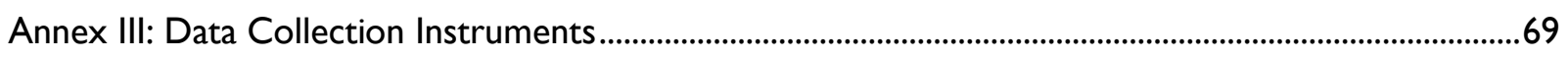

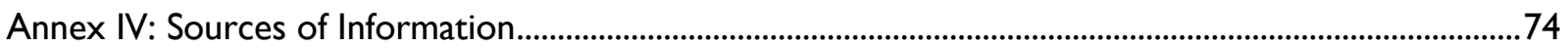




\section{ACRONYMS}

$\begin{array}{ll}\text { AFS } & \text { Afghanis } \\ \text { AOG } & \text { Armed Opposition Group } \\ \text { ASI } & \text { Afghanistan Stabilization Initiative } \\ \text { ATI } & \text { Afghanistan Transition Initiative } \\ \text { CCI } & \text { Community Cohesion Initiative } \\ \text { COIN } & \text { Counterinsurgency } \\ \text { CR } & \text { Country Representative } \\ \text { CSO } & \text { Civil Society Organization } \\ \text { CVE } & \text { Countering Violent Extremism } \\ \text { FGD } & \text { Focus Group Discussion } \\ \text { FPO } & \text { Field Program Officers } \\ \text { GIRoA } & \text { Government of the Islamic Republic of Afghanistan } \\ \text { IDI } & \text { In-Depth Interview } \\ \text { IED } & \text { Improvised Explosive Device } \\ \text { IMU } & \text { Independent Monitoring Unit } \\ \text { IOM } & \text { International Organization for Migration } \\ \text { IP } & \text { Implementing Partner } \\ \text { IQC } & \text { Indefinite Quantity Contract } \\ \text { FPO } & \text { Field Program Officer } \\ \text { M\&E } & \text { Monitoring and Evaluation } \\ \text { MISTI } & \text { Measuring Impact of Stabilization Initiatives } \\ \text { MSC } & \text { Most Significant Change } \\ \text { NATO } & \text { North Atlantic Treaty Organization } \\ \text { OAPA } & \text { Office of Afghanistan and Pakistan Affairs } \\ \text { OTI } & \text { Office of Transition Initiatives } \\ \text { PDU } & \text { Program Development Unit } \\ \text { POC } & \text { Project Oversight Committee } \\ \text { PPR } & \text { Program Performance Review } \\ \text { RQDA } & \text { R-based Qualitative Data Analysis } \\ \text { RSI } & \text { Rahman Safi International Consulting } \\ \text { SI } & \text { Social Impact } \\ \text { SIKA } & \text { Stability in Key Areas } \\ \text { SOP } & \text { Standard Operating Procedure } \\ \text { SOW } & \text { Statement of Work } \\ \text { SPSS } & \text { Statistical Software Package for the Social Sciences } \\ \text { SRS } & \text { Strategy Review Session } \\ \text { TDY } & \text { Temporary Duty } \\ \text { TL } & \text { Team Leader } \\ \text { TO } & \text { Task Order } \\ \text { USAID } & \text { United States Agency for International Development } \\ \text { USIP } & \text { United States Institute of Peace } \\ \text { USG } & \text { United States Government } \\ \text { VE } & \\ & \end{array}$




\section{EXECUTIVE SUMMARY}

This report answers key evaluation questions and presents findings, conclusions, and recommendations from the end-of-project final evaluation of the Community Cohesion Initiative $(\mathrm{CCl})$ of the United States Agency for International Development/Office of Transition Initiatives (USAID/OTI) Afghanistan. USAID/OTI's mission is to support U.S. foreign policy objectives by helping local partners advance peace and democracy in priority countries in crisis. Seizing critical windows of opportunity, USAID/OTI works on the ground to provide fast, flexible, short-term assistance targeted at key political transition and stabilization needs.

The Afghanistan Community Cohesion Initiative was implemented by USAID/OTI from March 2012 to December 2015 in support of the U.S. Government's (USG's) strategy to improve stability in strategically selected areas of Afghanistan, laying the foundation for longer-term development.' The goal of the USAID/OTI Afghanistan $\mathrm{CCl}$ program was to increase community resilience in areas vulnerable to insurgent exploitation. ${ }^{2}$

\section{EVALUATION PURPOSE}

The evaluation findings, conclusions, and recommendations presented in this report come from a comprehensive review of CCl's overall impact and key lessons learned, significant program achievements, challenges encountered, and the strategic design approaches used to facilitate program implementation. Because OTI has determined that no new program of assistance for Afghanistan will follow the closure of $\mathrm{CCl}$ in December 2015, this evaluation is not intended to directly inform the design of follow-on OTI programming in Afghanistan. Rather, the purpose of this evaluation is to offer lessons learned from $\mathrm{CCl}$ related to programming strategy, activity outcomes, and implementation processes that may be applied broadly to other OTI programs in transition contexts beyond Afghanistan's, as well as to inform USAID's ongoing effort to provide longer-term development assistance for Afghanistan.

\section{PROJECT BACKGROUND}

$\mathrm{CCl}$ had three implementing partners (IPs) responsible for managing grants for local communities in Afghanistan: Creative Associates International (Creative), the International Organization for Migration (IOM), and the United States Institute for Peace (USIP). In total, these IPs initiated I,32I sub-activities

\footnotetext{
' While all programming was finished by December 2015, the last contractual end date was March 9, 2016 for IOM, one of OTl's implementing partners.

${ }^{2}$ The scope of work for this evaluation, which appears in Annex I, defines "resilience" as "the capabilities of groups or communities to cope with internal or external stresses and disturbances as a result of social, political and environmental change."
} 
(mainly grants) for a total disbursement of over $\$ 4 \mathrm{I}$ million in program funds.,34 Additionally, OTI awarded a contract to Rahman Safi International (RSI) Consulting for independent monitoring and evaluation of the other IPs. Social Impact (SI) was contracted to provide this independent final evaluation of project performance.

$\mathrm{CCl}$ was a follow-on program to the Afghanistan Stabilization Initiative (ASI), which operated from June 2009 to September 2012 in the southern region of Afghanistan and until June 2012 in the eastern region of the country. ASI sought to improve local perceptions of the legitimacy of the Government of the Islamic Republic of Afghanistan (GIRoA); to establish and/or strengthen ties between the GIRoA, informal governance structures, and the local population; and to strengthen community-based resiliencies to mitigate sources of instability. As a follow-on program to ASI, OTI designed CCl to increase stability in strategically selected areas and thereby contribute to a successful transition of security responsibility from U.S. and international military forces to GIRoA. This USG transition strategy culminated with the exit of most foreign military personnel from Afghanistan in 2014. The closure of $\mathrm{CCl}$ is congruent with the end of the security transition in Afghanistan and the concomitant shift in USG strategy from achieving counterinsurgency (COIN) objectives to achieving longer-term development objectives.

The pursuit of CCl's goal of increasing community resilience did not entail a break with ASl's focus on connecting local communities to GIRoA following the COIN strategy, particularly in the program's early stages. This evaluation found that CCl's focus on cohesion was crucial for enabling the program to adapt to the changing context in Afghanistan, including the end of the U.S. counterinsurgency strategy, the drawdown of international troops, and the transition of security responsibility to Afghan government forces.

\section{EVALUATION METHODS AND LIMITATIONS}

This performance evaluation was designed to provide answers to four questions that were formulated by OTI on program strategy, activity outcomes, program learning, and lessons learned. To answer the evaluation questions, data was collected using the qualitative methods of in-depth interviews (IDIs), focus group discussions (FGDs), and a desk review of key documents. Time and cost limitations necessitated a sampling approach to data collection. The sample included 263 in-depth interviews with local stakeholders, implementing partners, and current and former USAID officials. These 263 interviews are disaggregated by respondent type as follows:

- $\quad$ I35 interviews with local stakeholders in eleven $\mathrm{CCl}$ districts (33 female, 102 male)

- 19 interviews with current and former USAID and USAID/OTI officials

- 23 interviews with IP senior management from Creative, IOM, RSI, and USIP

\footnotetext{
3 The term "sub-activity" refers to a sub-award (e.g., a grant) made from the primary award to an implementing partner. In the remainder of this report, the term "activity" is used in place of "sub-activity" in keeping with common usage for OTI, as reflected in the wording of Evaluation Questions I, 2, and 4.

${ }^{4}$ These figures are taken from the final version of the $\mathrm{CCl}$ database provided by OTI. The I,32I activities include $\mathrm{I}, 27 \mathrm{I}$ that were completed and then closed, for a total disbursement of $\$ 40,749,278$. An additional 50 activities that were not completed but were canceled after a portion of grant funds were disbursed accounted for $\$ 288,028$ of the total disbursement.
} 
- 57 interviews with IP staff from Creative, IOM, and RSI responsible for implementation in the districts

- 29 interviews with USIP grantees responsible for implementation in the districts

In addition to the 263 IDIs, the evaluation team used 33 FGDs to collect data from project stakeholders. Three FGDs - one with male elder participants, one with female elder participants, and one with male youth participants - were conducted in each of the eleven districts where $\mathrm{CCl}$ implemented programming. The districts were selected in consultation with OTI to ensure their representativeness of the breadth of $\mathrm{CCl}$ programming across different regions of Afghanistan and a range of factors that affected project implementation, such as levels of security or insecurity and levels of support or lack thereof from local government officials. Within each district, a representative sample of $\mathrm{CCl}$ activities by sector (infrastructure, training, sociocultural, etc.) was selected for evaluation. The awardees of these activities were the first points of contact in these districts for arranging IDIs and FGDs.

The data from the IDI and FGD transcripts were analyzed using the free and open-source R-based Qualitative Data Analysis (RQDA) software package to conduct coding, summarization, and comparative analysis. The transcripts were coded such that relevant portions of the text were extracted and grouped according to their relevance for answering each of the evaluation questions. Annex IV lists sources of information, including unique identifying codes for each document, FGD, and IDI. The relevant codes for information sources are cited in the body of the report using parenthetical references.

\section{KEY FINDINGS, CONCLUSIONS, AND RECOMMENDATIONS}

Evaluation Question I: Strategy and Theory of Change: Did the program strategy adjust appropriately, given Afghanistan's evolving transition needs, within the context of overarching USG policy? Were the program objectives and sub-objectives framed in a way that facilitated activity identification and design, and how did the implementing partner staffs understanding of the program goal impact activity quality and/or strategic relevance? Did program objective pivots (2013 and 20/4) lead to higher-quality activities and/or more strategically relevant activities, and, if so, did that lead to more contribution to the achievement of the program goal?5,6

\section{Findings}

- $\mathrm{CCl}$ programming made important contributions to the political and security transitions in Afghanistan. During the 20I2-20I4 transition period, there was a significant risk of state collapse and civil war. ${ }^{7} \mathrm{CCl}$ activities that linked rural villages to GIRoA successfully demonstrated the durability of government presence amid the uncertainty around whether GIRoA was capable of taking over security responsibility from international military forces. Amid threats of civil war

\footnotetext{
${ }^{5}$ There are differences between the wording of Evaluation Questions I, 2, 3, and 4 in the executive summary and main body of this report and the wording of these questions in the Evaluation Scope of Work in Annex I. These differences reflect final changes to the evaluation questions that were made by OTI in the planning phase of the evaluation.

'OTI uses the term "pivot" to describe changes to objectives that result from periodic strategy review sessions.

${ }^{7}$ For an example assessment of risk factors during this time period, see the October 2012 report by the International Crisis Group, "Afghanistan: The Long, Hard Road to the 2014 Transition." (DOC 4I). Available online at http://www.crisisgroup.org/en/regions/asia/south-asia/afghanistan/236-afghanistan-the-long-hard-road-to-the-2014transition.aspx
} 
during the crisis after the second round of voting in the 2014 presidential election, CCl's quick mobilization of international observers for the audit of the vote count was important for creating time and space for the two sides in the election dispute to reach a power-sharing agreement and avert state collapse by eventually establishing a new unity government.

- Changes to objectives and sub-objectives in 2013 and 2014 helped clarify the program's intent, but the program goal of increasing community resilience was not well understood by IP local staff and stakeholders. Interviews with IP local staff revealed weak understanding of the concepts of resilience and resiliency, mainly because these terms have no direct translation in local languages, and their English usage had multiple valences that complicated their explanation. $\mathrm{CCl}$ documents used the term resilience variously to describe influential individuals, the abilities of local people to cope with shocks arising from violence and economic exigencies and/or natural phenomena, linkages between communities and GIRoA, and resistance to the insurgency by local communities. ${ }^{8}$

- As a concept, cohesion - within communities, between communities, and between communities and GIRoA-was more effective than resilience for communicating about the implementation processes and intended outcomes of $\mathrm{CCl}$. The term cohesion was easily translated into Afghanistan's local languages. Interviews and focus groups with stakeholders showed that they were receptive to $\mathrm{CCl}$ because they recognized intrinsic value in the objective of increasing cohesion within and between their communities.

- The 2013 change in objectives was part of a successful "reset" of the program under new senior management for $\mathrm{CCl}-\mathrm{Creative}$ more than it was a "pivot" in a new direction. After a weak start to the program in its first year, $\mathrm{CCl}$-Creative gained new leadership that set the program on a more successful trajectory. The revision of the program objectives at the Strategy Review Session (SRS) in summer 2013-still maintaining the focus on cohesion and resilience-was instrumental for implementing the leadership change. Through the SRS process, Creative and OTI forged a new understanding of the program objectives, sub-objectives, and thematic activity areas, including the new focus on peaceful elections and activities for youth.

- The late-20I4 pivot by CCl-IOM oriented activities away from a focus on building ties between communities and GIRoA through "hard" infrastructure and towards more "soft" sociocultural activities, such as sporting and cultural events, designed to build cohesion between groups. This pivot entailed undertaking new types of activities with new partners, such as local civil society organizations (CSOs). The few viable CSO partners working in the districts targeted by CCl-IOM often had weak organizational capacity, which led to weak implementation processes. To compensate, $\mathrm{CCl}-\mathrm{IOM}$ gave extra effort to building CSO capacity. On average, soft activities had an overall quality score equal to the hard activities implemented by $\mathrm{CCl}-\mathrm{IOM}$, according to $\mathrm{CCl}$ 's Independent Monitoring Unit. Most sociocultural activities implemented with CSO partners were popular and novel for the local context and created cohesion between communities. However, no stakeholders considered such events as having created resilience to shocks.

- The late-20I4 pivot by CCI-USIP away from peaceful elections and towards the new objective of countering violent extremism (CVE) resulted in the development of a new theory of change for CVE that the evaluation team drafted using the analysis of the data collected from interviews with the staff and grantees of CCI-USIP. OTI afforded substantial freedom to experiment with different CVE approaches through trial and error. CCI-USIP had the most success with an approach that

${ }^{8}$ See, for example, the document "20I2.12.12 CCI Theory of Change" (DOC-I5). 
focused on training activities through which it built individual capacities to articulate counternarratives instead of extremist narratives that attempt to justify violence. Programming by $\mathrm{CCl}$ USIP towards the CVE objective from late 2014 was the most significant break with the COIN/stabilization theory of change that the program achieved.

- The extent to which $\mathrm{CCl}$ could redefine its strategy for transition was constrained by the orientation of the program towards COIN, which was determined both by USG policy and the mindset of much of the implementation team. Despite changes in CCl's strategy and objectives in 2013 and 2014, CCl-IOM and CCl-Creative remained oriented mainly towards the objective of connecting villages to GIRoA in the same set of contested districts that were prioritized by U.S. military COIN strategists, particularly in the southern and eastern regions.

\section{Conclusions}

- The program goal of community resilience was insufficiently defined to be used effectively by IP local staff to engage with community stakeholders.

- Cohesion worked as a flexible paradigm through which the objectives of the program and changes to the objectives were conveyed to local staff and stakeholders. Compared to resilience, cohesion worked well as a program goal because stakeholders saw increasing cohesion-within communities, between communities, between communities and GIRoA, etc.-as a good in itself and a necessary condition for activities to be successful.

- The 20I3 "reset" of CCl-Creative under new management, and the $20 \mathrm{I} 4$ pivot, were strategically important for the inclusion of the new peaceful elections and CVE objectives as well as new activity areas for youth. Through these changes, $\mathrm{CCl}$ adapted to the transition context in a departure from the village stabilization model of ASI and COIN.

- The 2014 pivot allowed CCI-USIP to generate a theory of change for CVE as follows: If individuals and their communities are provided with messages about peaceful alternatives to extremism and training that builds capacity to peacefully fulfill economic, social, and political aspirations, resolve conflicts, and think critically about extremism, then individuals will be more likely to embrace alternatives to extremism and articulate their own CVE narratives in response to extremist ones that attempt to justify violence. This theory of change for CVE is an important legacy of OTI for the USAID/Afghanistan Mission.

\section{Recommendations}

- Program strategists should not use the term "resilience" in a general sense but should instead be specific about the exigencies against which the program intends to increase resilience. The term should always be used in the context of the (completed) phrase: "Resilience to ." Always discussing resilience to a specific exigency would better enable assessment of how a particular resiliency might be created or enhanced using available resources.

- To gain support from stakeholders, implementers of community-driven programs in conflict environments should convey program objectives in terms of cohesion. Cohesion can be applied to fostering unity and cooperation between all manner of groups and individuals and directed towards a range of goals such as building government legitimacy and peace.

- OTI and its IPs should move faster to change IP senior management and coordinate this change with an SRS process for clarifying objectives when it becomes clear that these factors are creating a drag on program performance, as happened in the first year of $\mathrm{CCl}$. 
- The USAID/Afghanistan Mission should continue to support the expansion of CVE programming following the theory of change developed by CCI-USIP. CCI-USIP's approach to CVE-training and communication activities that build capacity to embrace economic, social, and political alternatives to extremism, think critically about extremism, articulate counter-narratives, and resolve community conflicts without violence-is a viable successor to stabilization activities in the current context in which USAID/Afghanistan is focused on long-term development.

Evaluation Question 2: Activity Outcomes: Based on a sampling of activities and review of existing activity evaluations and analysis, to what extent did activity outcomes contribute to each of the program objectives/goal and sub-objectives? Which types of activities contributed most significantly to the program objectives/program goal and are there identifiable trends across those activities? Were there any unexpected outcomes (positive or negative) observed within these activity categories or within individual activities sampled? To what extent, if any, were immediate activity outcomes sustained upon completion of the activities? If so, which types of activities had the most sustainable outcomes and why?

\section{Findings}

- The quality of processes, especially community-engagement processes, were as important, if not more important, than the quality of outputs for achieving CCl's objectives. High-quality processes built cohesion and created a change in the mentality of local beneficiaries towards increased volunteerism and willingness to work together to achieve common ends. Such changes in mentality were most often reported by respondents as the most lasting effect and the most significant change achieved by $\mathrm{CCl}$ activities. The other major change in mentality surrounded people's understanding of what to expect from the government and how to communicate their needs and expectations to the government.

- Reports of positive outcomes surrounding increased cohesion-within communities, between communities, between communities and GIRoA—far outweighed negative reports from local stakeholders of decreased cohesion and no effect. Cohesion increased where programming processes were implemented with sufficient quality, which led to quality outputs. Perceived corruption related to low quality of inputs and/or outputs was most often mentioned when stakeholders reported decreased cohesion because of activities, such as several cases in Nahr-eSaraj District of Helmand Province.

- The extent to which cohesion could be built between GIRoA and local communities through $\mathrm{CCl}$ activities was limited by local perceptions of GIRoA official corruption.

- Using activities to build cohesion between different groups that were aligned for and against the government, such as the tribes in Terezayi District of Khost Province, was an effective means of improving security and preventing the district from coming under the control of the Taliban. Khas Kunar District of Kunar Province is another example of positive outcome for $\mathrm{CCl}$ on preventing gains by the insurgency through coordination with Afghan Local Police and GIRoA to provide security for activities.

- Acting independently of $\mathrm{CCl}$ implementers, local community elders in the contested districts of Khas Kunar, Terezayi, Adraskan, and Qadis successfully stood together and convinced local Taliban and other anti-government elements not to oppose $\mathrm{CCl}$ projects behind which the community was united, seeking permissions and/or security guarantees from local Taliban for $\mathrm{CCl}$ activities to take place. In such cases the Taliban were convinced to unite with the rest of the 
community behind the project. Insurgent violence at activity sites was thus generally not a cause of unexpected outcomes, with the exception of an incident on a canal project in Terezayi District of Khost Province that contravened an agreement negotiated between local elders and local Taliban. ${ }^{9}$

- As a group, youth stakeholders in $\mathrm{CCl}$ activities were the most consistently positive about activity outcomes. Peace poetry competitions and events for youth proved to be popular sociocultural activities, marked by rates of participation that were often considerably higher than anticipated in activity designs. Respondents in most of the focus districts reported that $\mathrm{CCl}$-supported youth associations sustained activities after $\mathrm{CCl}$.

- A key success of the $\mathrm{CCl}$ program was the fast mobilization of observers by $\mathrm{CCl}$-Creative for the audit of the vote count after the second round of voting in the presidential election. The election observers provided the international oversight that was necessary to retain a minimum atmosphere of civility between the opposing sides. The observers were instrumental in creating the time and space for the opposing sides to reach a power-sharing agreement.

- Both hard and soft projects contributed to achieving CCl's objectives. Water projects helped resolve local disputes and generated increased community resilience to shocks from droughts and floods. Vocational trainings were often cited as having provided lasting benefits in the form of continuing income generation, which increased resilience to economic shocks.

- CCI-USIP credited CVE trainees with stopping an extremist recruitment campaign in Parwan Province. Journalism training for mixed groups of students from public high schools and madrassas [Islamic religious schools] was used by CCI-USIP to achieve CVE outcomes by building cohesion between different groups of youth and training them to articulate counter-narratives.

\section{Conclusions}

- $\mathrm{CCl}$ programming processes for community engagement were generally effective for changing people's mentality and generating cohesion within and between communities.

- Youth are a key group for quick-impact intervention in Afghanistan. Fostering a spirit of volunteerism among youth and support for youth associations that are still active after the closure of the program is one of the most lasting effects of $\mathrm{CCl}$.

- GIRoA official corruption was an external constraint on CCl's performance that could not be systematically addressed through the community-based approach. The outcomes of linking communities and GIRoA were limited by the absence of a GIRoA program of reform to improve governance from the top down. In the absence of systemic reform, particularly anti-corruption reform, the work of building connections between communities and GIRoA could continue indefinitely without achieving an end-state in which GIRoA legitimacy is consolidated and the insurgency is marginalized.

- By acting independently of CCl's implementers to convince local Taliban not to oppose implementation, community elders in contested areas were effective at providing security for activities and connecting their communities more closely with GIRoA. These security

\footnotetext{
${ }^{9}$ Coordination with AGEs and/or violent extremist groups was not an approved $\mathrm{CCl}$ practice or a sanctioned part
} of the $\mathrm{CCl}$ activity development or implementation process. 
arrangements pose a serious dilemma because they enabled $\mathrm{CCl}$ to achieve positive outcomes in contested areas, but they existed outside the framework of the program and of U.S. policy.

\section{Recommendations}

- USAID/Afghanistan should support administrative and anti-corruption reforms to address the constraint that GIRoA official corruption created on the outcomes of activities that linked communities with GIRoA.

- CVE and community-development programming should be implemented through sustained support for youth associations and other CSOs.

- To the extent allowable within the policy constraints set out for engaging with opposing sides in a conflict, project implementers should design activities to create cohesion between the different sides, as in the case of the tribes that were aligned for and against the government in Terezayi District before CCl's intervention.

- In the absence of policies that allow for negotiations with anti-government elements, implementers of stabilization programming should work only in areas where officially sanctioned forces can provide security for activities. Implementers should thereby avoid the need for unsanctioned security guarantees negotiated independently between local community leaders and official enemies.

- USAID/Afghanistan should incorporate CVE curricula into vocational training and other capacitybuilding activities such that trainees learn to think critically about community issues and articulate narratives around the contribution that their skills will make to the peaceful development of their country, in contrast to the violence advocated by extremists.

Evaluation Question 3: Program Learning: To what extent was the program able to learn from ongoing analysis to improve project design over time? Did the impact of the program learning that took place justify the resources invested? What concrete factors or processes could the program have developed or improved to promote program learning, with a particular focus on the role of the Independent Monitoring Unit?

\section{Findings}

- The effective implementation of small community grants is a process of learning-by-doing, which was the mainstay for refining program processes, building relationships with local communities, and building local staff capacity. In this way, the IPs were able to incrementally improve the quality of project implementation over successive cycles of activity implementation. However, in the last stage of $\mathrm{CCl}$ after the late-2014 pivot, short program timelines with few activity cycles and organizationally weak CSOs, worked against program learning-by-doing by $\mathrm{CCl}-\mathrm{IOM}$ because there was not enough time to incorporate lessons learned and capacity building for CSOs into the next activity cycle.

- The establishment of the Independent Monitoring Unit (IMU) in fall 2013 was a crucial addition to the program because it provided OTI with an independent source of information about activities taking place in the field after the drawdown of U.S. troops and the loss of the information they provided to OTI. The IMU became operational too late in the program to contribute substantially to learning by $\mathrm{CCl}$-Creative as it entered its final year of implementation in 20I4. OTI promoted improvement in the performance of $\mathrm{CCl}-\mathrm{IOM}$ by using the IMU to enforce accountability for poor 
inputs and outputs. The IMU was used less for monitoring the relatively small portfolio of activities implemented by CCI-USIP.

- Managing the two-way flow of information between the IMU and the other IPs was challenging and required substantial time and effort from OTI. Effectively monitoring activities independently of the implementer required the IMU to develop a detailed scope of work and report for each and every activity monitored, which involved sharing a large amount of information between the IMU and the other IPs through OTI. Resolving disagreements between the IPs and the IMU over matters such as the correct construction materials for infrastructure projects took substantial time and effort from OTI.

- Information generated by the IMU on activity outcomes was not socialized widely within $\mathrm{CCl}$ IOM and $\mathrm{CCl}$-Creative; rather, the focus was on verifying outputs. $\mathrm{CCl}-\mathrm{IOM}$ 's first priority was to address the substandard inputs and outputs identified by the IMU, and most of the effort available was expended on raising the quality of outputs. $\mathrm{CCl}$-Creative reported that lessonslearned reports from the IMU were relevant but shared too late in the program to be utilized effectively. Both IOM and Creative lacked the staff capacity to utilize detailed analysis in a systematic way for program learning beyond incremental improvement of activity processes and outputs.

- The analytical products generated internally by all of the IPs were important sources of learning to improve program implementation. Analytical products meant for consumption by the larger Mission, such as geospatial analysis of where election violence was likely to occur, were, however, utilized to a lesser extent due to the lack of effective targeting of a large enough audience at the Mission with the capacity to use the data for decision making.

- The experimentation with CVE programming by $\mathrm{CCl}$-USIP generated a theory of change and set of lessons learned that has allowed USIP to identify specific initiatives that are now being scaled up with additional support from USAID/Afghanistan.

\section{Conclusions}

- Learning-by-doing requires several iterations of the activity cycle. The late-20I4 strategic pivot to soft activities implemented with CSO partners allowed for too few iterations for CCI-IOM to learn which activities were most effective for achieving CCl's objectives.

- The investment in the IMU was fully justified by the improvement in the quality of CCI-IOM activity outputs and processes that took place over time. Procurement delays caused the IMU to come online later than planned. Even greater gains would undoubtedly have been made if the IMU had been established earlier in the program.

- Where it made strategic sense, increased standardization of operating procedures and activity designs - for example, specifying acceptable road construction materials - would have promoted more efficiency for information sharing between the IMU and the other IPs and allowed the IMU and other IPs to focus more on outcome assessment and learning.

\section{Recommendations}

- OTI should promote program learning by ensuring that there is adequate time after a strategic pivot for the completion of several programming cycles to incorporate the learning from the last cycle into the next cycle. 
- If the cost is bearable, OTI and other program implementers should make an IMU part of the initial award of all programs that seek to operate across a wide geography of project sites in an insecure environment, using local monitors to access outcomes and results in activity sites where mobility is restricted.

- USAID should consider the IMU as a best practice model of independent monitoring and verification worldwide, if the implementation of an IMU is synchronized effectively with the work of the IPs that it is responsible for monitoring. Effective implementation of the IMU model in Afghanistan and other countries should lead to improvement of project outputs across the missions, much like the positive change in the quality of $\mathrm{CCl}-\mathrm{IOM}$ activities over time.

- The future implementation of the IMU model by USAID and OTI should promote program learning using technology for knowledge management, such as online project management software, to streamline and standardize the process of two-way information sharing between and IMU, OTI, and other IP(s). Such a system should be used to allow a larger volume of information, particularly information necessary for scoping monitoring visits and evaluation feedback to be shared more efficiently. Initial investments in automation should reduce the amount human effort necessary to manage communication and relationships between the IMU and other IPs.

Evaluation Question 4: Lessons Learned: What were the key lessons learned from $\mathrm{CCl}$ and how could they be applied to future programming in non-permissive environments? This should include lessons that can be applied to future programming intended to increase community cohesion and resiliency more broadly and may include lessons about activity development and implementation approaches, strategy development and communication, and operational approaches that are best suited for complex programming in restrictive environments.

\section{Findings}

- Problematic interpersonal relationships and unproductive communication were reported from various aspects of $\mathrm{CCl}$, from the relationships between the leadership of OTI and Creative in Kabul to the relationship between OTI Kabul and OTI Washington.

- $\mathrm{CCl}-\mathrm{IOM}$ learned from its own implementation processes and the findings of the IMU that community oversight using project oversight committees (POCs) was an important factor for assuring the quality of activities. Requirements for POC meetings and signatures were therefore incorporated into grant agreements as a standard operating procedure (SOP) for community engagement.

- Operational lessons learned from the IMU have deeply and directly informed the design of the Mission-wide Monitoring Support Programs that have recently been awarded to provide independent monitoring for all USAID/Afghanistan activities.

- Implementing a program in one of the most corrupt countries in the world naturally entailed substantial risk that corruption could compromise the various aspects of the program. Recognizing the high risk of waste, fraud, and abuse, $\mathrm{CCl}$ was mostly successful at implementing systems of checks and balances for mitigating the risk of corruption internally in IP operations and externally in the IP's relationships with GIRoA officials and community members. Local stakeholders most often perceived that corruption had taken place when projects were not completed according to plan and/or used poor materials. The IMU was crucially important for objective monitoring of the 
quality of activity inputs and whether implementation was done according to plans and specifications.

- While recruiting staff with strong ties to local communities was crucial for the success of the program at community engagement, the IPs relied too heavily on such staff for activity management and verification. Staff "embeddedness" in local communities raised the risk profile of the program because of real or perceived conflicts of interests in the distribution of resources to those groups to which local staff had stronger ties.

- Pushing programming into highly insecure areas, such as remote areas of Sangin and Kajaki Districts in Helmand Province, was risky and met with mixed results because there were inadequate opportunities for quality assurance. Local staff and stakeholders told the evaluation team that only 60 percent of activities were completed in Kajaki because the Taliban did not allow the remainder to proceed. While the IMU was able to visit activities in Kajaki, these visits came too late to provide warning that certain activities were not proceeding as planned.

\section{Conclusions}

- Unity within the team is doubly important for OTl's one-team programming model to be successful in restricted and conflict-affected environments, where there are limited opportunities for working together in the same physical space and forming relationships outside of the workplace. It is crucial to ensure that the members of the team have management and communication skills, styles, and practices, as well as compatible interpersonal relationships, that are strong enough to succeed at remote management.

- Necessary changes at the senior management level of $\mathrm{CCl}-\mathrm{Creative}$ should have been made earlier to move the program forward more quickly during its first year. Interpersonal problems and communication deficits should have been addressed earlier. A systematic approach and set of tools from organizational psychology are required to identify incompatibilities and communication problems within the team and address them early in a program, especially in remote management contexts.

- Where it made strategic sense, greater standardization of programming processes and grant designs, such as the inclusion of POC processes for community oversight in grant agreements, would likely have contributed to greater improvement in the quality of project designs, outputs, and outcomes. With effective management, this standardization would have allowed for increased innovation on a solid foundation of efficient and predictable procedures. Earlier use of the IMU for quality control would have promoted higher-quality inputs, outputs, and outcomes.

- Strict adherence to established SOPs for M\&E and activity verification would clarify decision making around the level of risk that is acceptable for grant awards. An important indicator that a project may be overextending itself is implementation where internal and/or external monitoring cannot take place systematically and with the necessary frequency to verify activity progress.

\section{Recommendations}

- OTI should take a systematic approach to identifying compatibility or lack thereof between members of the team working in restricted environments. There are abundant methods and experts from the field of organizational psychology that offer approaches and techniques for 
teambuilding, improving workplace communication, and identifying and mitigating incompatibilities between coworkers.

- OTI should organize corporate-style retreats and trainings for program senior management from both OTI and IPs to build and deepen the cohesion of the team. Retreats may be linked with Strategy Review Session (SRS) events as needed. The frequency of team-building retreats should be increased as necessary to overcome the challenges of communication in the context of remote management.

- OTI should increase the frequency of management reviews for programs operating in Afghanistan and similarly restricted contexts. OTI and the IPs should move faster to replace senior management when it becomes clear that their tenure is creating a drag on program performance. OTI management should seriously consider whether it would be better to leave the position unfilled or promote someone to act in the role until the right replacement can be found.

- OTI and the IPs should create a regular schedule for bringing the team together to spend time working collaboratively in the same place-not just OTI and the IP senior management, but also the field team if it is distributed geographically across different provincial offices, as in the case of $\mathrm{CCl}$.

- To help avoid miscommunication and excessive formality, OTI and its IPs should communicate in real time to the extent possible via telephone or instant messaging instead of email. Consider appropriate technological solutions such as online collaboration software (where Internet bandwidth is sufficient) for increasing the ease and frequency of real-time communication between members of the team. Software services such as Slack run in a web browser and provide easily accessible and reproducible histories of instant messages exchanged between multiple collaborators on a project.

- To enjoy the advantages offered by employing staff from local communities but mitigate the risk of real or perceived conflicts of interest, solicitations from OTI should specify more key staff positions for expats or highly qualified local nationals, particularly in M\&E, engineering supervision, and regional and provincial management roles for programs in difficult contexts similar to Afghanistan's. Solicitations should include a set-aside for an M\&E specialist firm to provide IMU capacity.

- OTI and USAID should establish systematic procedures for assessing risk to ensure that risks and rewards are clearly calculated and weighed by a program that is extending activities into highly insecure areas. 


\section{EVALUATION PURPOSE AND EVALUATION QUESTIONS}

The purpose of this evaluation is to provide an independent and thorough analysis of the United States Agency for International Development/Office of Transition Initiatives (USAID/OTI) Afghanistan Community Cohesion Initiative's $(\mathrm{CCl})$ performance, including a comprehensive assessment of the program's overall impact and key lessons learned, significant program achievements, challenges encountered, strategic design approaches used to facilitate program implementation, and approach to program-level monitoring and evaluation. This report provides answers to the following evaluation questions, the wording of which was slightly modified by Social Impact (SI) and OTI during the planning phase of the evaluation from the versions that appear in the Statement of Work (SOW) in Annex I.

Evaluation Question I: Strategy and Theory of Change: Did the program strategy adjust appropriately, given Afghanistan's evolving transition needs, within the context of overarching United States Government (USG) policy? Were the program objectives and sub-objectives framed in a way that facilitated activity identification and design, and how did the implementing partner staffs understanding of the program goal impact activity quality and/or strategic relevance? Did program objective pivots (2013 and 2014) lead to higher-quality activities and/or more strategically relevant activities, and, if so, did that lead to more contribution to the achievement of the program goal?

Evaluation Question 2: Activity Outcomes: Based on a sampling of activities and review of existing activity evaluations and analysis, to what extent did activity outcomes contribute to each of the program objectives/goal and sub-objectives? Which types of activities contributed most significantly to the program objectives/program goal and are there identifiable trends across those activities? Were there any unexpected outcomes (positive or negative) observed within these activity categories or within individual activities sampled? To what extent, if any, were immediate activity outcomes sustained upon completion of the activities? If so, which types of activities had the most sustainable outcomes and why?

Evaluation Question 3: Program Learning: To what extent was the program able to learn from ongoing analysis to improve project design over time? Did the impact of the program learning that took place justify the resources invested? What concrete factors or processes could the program have developed or improved to promote program learning, with a particular focus on the role of the Independent Monitoring Unit (IMU)?

Evaluation Question 4: Lessons Learned: What were the key lessons learned from $\mathrm{CCl}$ and how could they be applied to future programming in non-permissive environments? This should include lessons that can be applied to future programming intended to increase community cohesion and resiliency more broadly and may include lessons about activity development and implementation approaches, strategy development and communication, and operational approaches that are best suited for complex programming in restrictive environments.

The primary audiences of this evaluation are USAID/OTI, the USAID Mission in Afghanistan, the U.S. Embassy in Kabul, USAID's Office of Afghanistan and Pakistan Affairs (OAPA), OTI implementing partners, and other local and international stakeholders involved in post-conflict assistance to Afghanistan. The 
evaluation design is utilization-focused such that it will generate useful knowledge for advancing programming innovation in Afghanistan and other transition contexts. 


\section{Project Background}

The Community Cohesion Initiative was USAID/OTI's third program in Afghanistan. First, from 2002 to 2005, the Afghanistan Transition Initiative (ATI) worked to increase the Afghan government's responsiveness to citizens' needs, to raise citizen awareness of and participation in democratic processes, and to bolster the capacity of the Afghan media. Next, from June 2009 to June 2012, OTI re-engaged in the country with Afghanistan Stabilization Initiative (ASI). ASI sought to improve local perceptions of the legitimacy of the Government of the Islamic Republic of Afghanistan (GIRoA); to establish and/or strengthen ties between the GIRoA, informal governance structures, and the local population; and to strengthen community-based resiliencies to mitigate sources of instability. During the final months of ASI, a Program Performance Review (PPR) recommended the creation of a follow-on program that would continue to bulwark the USG's strategy in Afghanistan as it shifted from the counterinsurgency (COIN) strategy to a transition strategy in which Afghan security forces would take over responsibility for providing security. In response to that recommendation, USAID/OTI designed $\mathrm{CCl}$, which was approved for implementation in February 2012.

In February 2012, Creative Associates International (Creative) was awarded a Task Order (TO), under the SWIFT III indefinite quantity contract (IQC), to implement a three-year CCl activity in the eastern and southern regions of Afghanistan. In September 2013, three additional implementing partners (IPs)the U.S. Institute of Peace (USIP), the International Organization for Migration (IOM), and Rahman Safi International Consulting (RSI) - were incorporated into the $\mathrm{CCl}$ project. IOM was awarded a two-year agreement to implement $\mathrm{CCl}$ programming in the northern and western regions of Afghanistan. USIP was awarded a two-year agreement to promote a peaceful outcome for the 2014 Afghan presidential election and to implement initiatives for countering violent extremism. RSI was awarded a two-year contract to provide independent monitoring services for $\mathrm{CCl}$ activities. $\mathrm{CCl}$-Creative closed operations in February 20I5, while CCI-IOM, CCI-RSI, and CCI-USIP closed all activities in December $20 \mathrm{I} 5$.

As the $\mathrm{CCl}$ program entered its final month of closedown in December 20I5, I,32I activities had been initiated (including 50 activities that were eventually canceled), totaling $\$ 41,037,307$ in disbursements. ${ }^{10}$ Activities primarily took the form of in-kind grants. Grantees were predominantly local government entities and line ministries, as well as local community groups, associations, and civil society organizations. CCl's approach to programming focused on community and citizen engagement by developing grant activities at the community level through consultations with a wide range of community voices and interests. Illustrative examples of grant activities included small-scale infrastructure designed to strengthen ties with GIRoA, capacity building activities that support enhanced livelihood opportunities and social cohesion, and strategic communication activities designed to promote peaceful democratic process and provide narratives of peace and Islam that serve as alternative to extremist narratives that promote violence.

${ }^{10}$ These figures are from the final version of the $\mathrm{CCl}$ activity database. 


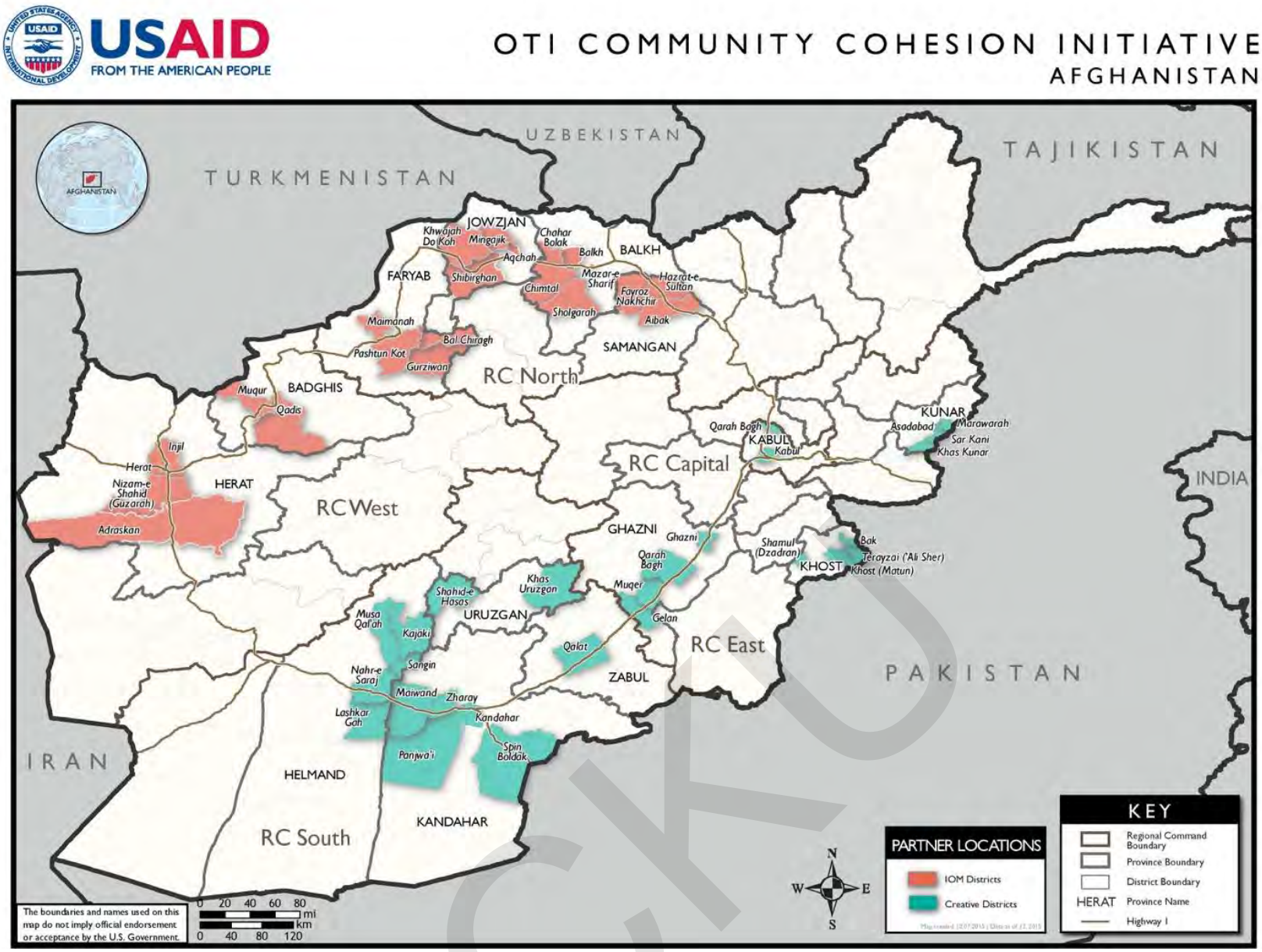

Figure I. Map of the Community Cohesion Initiative programming in rural communities

CCl's goal was to increase community resilience in areas vulnerable to insurgent exploitation. Resilience was defined by $\mathrm{CCl}$ as "the capabilities of groups or communities to cope with internal or external stresses and disturbances as a result of social, political and environmental change." I CCl worked with a theory of change that "durable resilience and cohesion is a result of local will, empowerment, initiative, and leadership and, to this end, $\mathrm{CCl}$ designed and implemented small grants through a process-oriented, community-driven approach to strengthen linkages between communities vulnerable to insurgent exploitation and positive influencers, both GIRoA and other actors." 12

The local support that $\mathrm{CCl}$ gained through its community-driven approach was the critical factor that allowed for the implementation of activities in some of the most insecure areas of Afghanistan. Community support was crucial for bolstering resistance to the insurgency and extending the reach of GIRoA into contested areas. The map displayed below shows the districts of Afghanistan in which $\mathrm{CCl}-\mathrm{IOM}$ and $\mathrm{CCl}-$

\footnotetext{
" Quoted from PDQ III: SOW CCI Final Evaluation Project (see Annex I).

12 This formulation of CCl's theory of change is quoted from "Lessons Learned from the Afghanistan Community Cohesion Initiative" (DOC-I). This articulation of CCl's theory of change is consistent with other CCl documents for the lack of a clear statement of how interventions (inputs) are expected to affect final outcomes. Each grant design was expected to contain a clear articulation of the connection between inputs and one or more outcomes aligned with a program objective and sub-objective.
} 
Creative implemented programming in rural communities. USIP is not shown on the map because of the geographically broader but more diffuse nature of its grant activities.

From its launch in 2012 to mid-20/3, CCl was one of the three principal programs in the USAID/Afghanistan stabilization portfolio, which was managed by the Stabilization Unit independently from the other technical offices at the USAID/Afghanistan Mission. Stabilization programs were designed to support the COIN operations of North Atlantic Treaty Organization (NATO) forces, the regional USG platforms, and GIRoA.

The COIN strategy was first an effort to "clear" an area of insurgents by military force or the threat of force. Next, the government (with international support) would establish its presence and maintain security to "hold" the area. Then the government would "build" its legitimacy by providing services to the people in the area. Local grievances against the government would be addressed by the provision of services, which would win the hearts and minds of the people. The area would become inhospitable to insurgents when the people joined the side of the government because they believed in its legitimacy. The insurgency would ultimately be defeated by destroying its basis of support among the population. $\mathrm{CCl}$ was designed to support COIN operations using its community-based approach to programming in cleared areas where counterinsurgents were beginning to implement the hold phase; that support would continue through the build phase of the COIN strategy. Communities in contested areas could receive grants from $\mathrm{CCl}$ if they chose to build ties with GIRoA.

However, the U.S. military COIN strategy was already nearing the end of its lifespan when $\mathrm{CCl}$ started programming. The drawdown of U.S. troops and the closure of military bases rapidly changed the operating environment for $\mathrm{CCl}$ from 2012 to 2013 . From a height of 99,800 troops in $201 \mathrm{I}$, over 88,200 troops remained in Afghanistan in March 2012. Over the next two years, bases closed rapidly, and troop levels decreased steadily, falling to 65,700 by March 2013 , then to 33,200 by March 2014 , and to 9,100 by March 2015. ${ }^{3}$ The closure of bases meant a rapid decrease in the number of OTI Field Program Officers (FPOs) supervising $\mathrm{CCl}$ in the provinces. OTI eliminated its final field position in June 2014. Thereafter, all remaining OTI staff worked from Kabul, where the USAID Mission was simultaneously drawing down its staff. Starting in February 20I4, OTI had only one full-time resident position at the Mission-the Country Representative (CR). Additional OTI staff assisted the CR in Kabul on a Temporary Duty (TDY) basis.

The decrease in military presence not only resulted in a much smaller OTI program management team, which was relegated to the U.S. Embassy in Kabul, but it also meant that the program was subject to fewer demands from the military leaders of the COIN strategy. The 20I3-20I4 drawdown and transition of security responsibility to Afghan forces meant that fewer U.S. troops were executing COIN operations. Moreover, the security transition and the Bilateral Security Agreement signed in late 2014 by the USG and GIRoA did not mandate the U.S. military to support COIN operations conducted by Afghan forces. The end of COIN led to the dissolution of the Stabilization Unit by the leadership of the USAID/Afghanistan Mission in mid-2013. This administrative change removed a layer of management through which $\mathrm{CCl}$ had been compelled to coordinate with the other stabilization programs on the targeting of activities at different areas on the clear-hold-build continuum of COIN. These changes in USG

\footnotetext{
${ }^{13}$ Congressional Research Service, "Department of Defense Contractor and Troop Levels in Iraq and Afghanistan:
} 2007-20I5," p. 4, accessed 6 DEC 2015 online: https://www.fas.org/sgp/crs/natsec/R44II6.pdf 
strategy opened space for OTI to change the objectives of $\mathrm{CCl}$ and adapt programming to the changing conditions on the ground.

The evolution of $\mathrm{CCl}$ programming came in response to the changes in USG strategy and the political context of Afghanistan. The 2014 transition involved not only a shift in security responsibility from international to Afghan forces, but also a presidential election that would see a new individual occupy the office of the presidency for the first time since 2002. In this context, $\mathrm{CCl}$ adopted a new objective of promoting peaceful elections and played an important role in ensuring that the outcome of the presidential election in 2014 was indeed peaceful.

A second important strategic shift came after the transition was completed in late 2014 , when a new objective of countering violent extremism (CVE) was adopted and the peaceful elections objective was replaced with the broader objective of support to legitimate and peaceful governance processes in the CCl's strategic framework. Like the programming for the peaceful elections objective, which mainly focused on strategic communications to wide radio and television audiences, programming for the CVE objective was a departure from the stabilization/COIN programming modality of village-level small grants. CVE programming focused on marginalized groups, such as urban youth, that are vulnerable to recruitment by violent extremists. However, despite the end of the USG's COIN strategy and the dissolution of USAID's Stabilization Unit, the CCl program never broke with its legacy as a $\mathrm{COIN/stabilization} \mathrm{program.} \mathrm{CCl}$ continued to work in the same contested districts in south and east Afghanistan that were prioritized by the COIN strategy, and $\mathrm{CCl}$-Creative and $\mathrm{CCl}-\mathrm{IOM}$ programming still focused on implementing grants designed to link GIRoA officials and institutions with underserved communities. 


\section{EVALUATION METHODOLOGY AND LIMITATIONS}

\section{METHODOLOGY}

The evaluation methodology integrated different methods and tools for data collection and analysis into an overall strategy for answering the evaluation questions and achieving programmatic learning objectives. A rigorous base of evidence was generated using data from secondary sources already generated by the program in combination with primary data collected using interviews and focus groups. The evaluation team collected data from August 31 to November 9, 20 I5. Primary data collection with CCl stakeholders was completed in eleven focus districts by male and female data collectors employed by a sub-contractor, IDS Hamkaar. The evaluation Team Leader $(T L)$ from Social Impact led all aspects of the evaluation design and implementation over two trips to Afghanistan, including training the data collectors, controlling the quality of the data, analysis, and reporting. (See Annex II for more details on the evaluation methodology and approach.)

As described below, the evaluation questions provided by OTI are grouped into four areas of knowledge utilization - strategy and theory of change, activity outcomes, program learning, and lessons learned. The evaluation questions were answered by analyzing data from secondary sources such as programmatic documents and the OTI database. Moreover, the evaluation team used in-depth interviews and focus groups to collect primary data from OTI and other USAID officials, GIRoA officials, current and former $\mathrm{CCl}$ implementing partner staff members, grantees of $\mathrm{CCl}$-USIP, and $\mathrm{CCl}$ beneficiaries and stakeholders from activity sites in eleven focus districts.

The key methods for data collection and analysis are described below and in further detail in Annex II. The research instruments used to collect data collection from primary sources appear in Annex III. The information sources for the evaluation are listed in Annex IV.

\section{Review of Secondary Data Sources (Desk Review)}

OTI, the IPs, and the Measuring Impacts of Stabilization Initiatives (MISTI) program generated a large volume of documents, datasets, and database records pertaining to $\mathrm{CCl}$ that contain essential information for evaluating the performance of the program. The desk review was a crucial first step in the evaluation methodology that informed the design of the instruments used for collecting data from primary sources using interviews and focus groups. Key sources from the desk review are listed in Annex III. The code for each document is cited in parentheses where it is used as a data source for evaluation findings.

\section{In-Depth Interviews}

Interviews yielded the largest amount of primary-source data generated by the evaluation team. In-depth interviews (IDIs) were used to gather data from key informants that have a detailed understanding of $\mathrm{CCl}$ programming strategy and/or processes. These in-depth interviews provide key informants with the opportunity to offer their expert knowledge and speak directly to the evaluation questions. The evaluation team conducted a total of 263 in-depth interviews. These interviews are disaggregated by type as follows: 
- $\quad$ I35 interviews with local stakeholders in eleven $\mathrm{CCl}$ districts (33 female, 102 male)

- 19 interviews with current and former USAID and USAID/OTI officials

- 23 interviews with IP senior management from Creative, IOM, RSI, and USIP

- 57 interviews with IP staff from Creative, IOM, and RSI responsible for implementation in the districts

- 29 interviews with USIP grantees responsible for implementation in the districts

The TL conducted interviews directly with OTI and USAID officials and IP Staff, while the Afghan field teams conducted interviews with $\mathrm{CCl}$ stakeholders in the focus districts. (See Annex IV for a list of interviews.) The code for each interview transcript is referenced in parentheses where it was used as the data source for a reported finding.

The data from these interviews were analyzed using the free and open-source R-based Qualitative Data Analysis (RQDA) software package to conduct coding, summarization, and comparative analysis across interviews. ${ }^{14}$ The transcripts were coded such that relevant portions of the interview transcripts were extracted and grouped according to their relevance for answering each of the evaluation questions. See Annex II for more details on the evaluation methodology and approach.

\section{Focus Group Discussions}

The evaluation team conducted a total of 33 focus group discussions (FGDs) with local CCl stakeholders. In each district, one FGD was conducted with men, one with women, and one with male youth beneficiaries. ${ }^{15}$ FGDs are a reliable method for collecting qualitative data from groups of program beneficiaries. A key advantage of FGDs is flexibility for in-depth exploration of the group's collective understanding of $\mathrm{CCl}$ processes and outcomes. Compared to the I35 stakeholder IDIs, which focused collecting data from $\mathrm{CCl}$ grantees, local leaders, and other key informants in the eleven districts, the FGDs captured a broader cross-section of beneficiaries who tended to be less educated and literate than the interviewees. (See Annex IV for a list of FGDs and participant characteristics.) The FGD data can therefore be considered more representative of the broad beneficiary population, while the interview data is more representative of the community leaders, who were the key local interlocutors through whom $\mathrm{CCl}$ programming was implemented.

Interviews and FGDs used the most significant change (MSC) method for gathering data. The MSC technique was developed to gather information from a variety of stakeholders-e.g., project staff and beneficiaries - to identify the changes created by a project that should be counted as most significant. MSC was used to inform the design of questions included in interviews and FGDs. The evaluation team used MSC in the wording of the questions asked in interviews and FGDs to collect change stories from the field. The analysis of this qualitative data will determine which changes are most significant for answering the evaluation questions and generating useful knowledge for programming.

\footnotetext{
14 The RQDA software package and documentation are available online at http://rqda.r-forge.r-project.org/

15 Helmand Province was the exception: No female FGD was conducted in Kajaki District for lack of female beneficiaries. To compensate, two FGDs with female beneficiaries were conducted in Nahr-e-Saraj District.
} 
The geographic focus of the evaluation includes the following eleven districts in the north, south, east and west regions of Afghanistan: I) Hazrat-e Sultan in Samangan Province, 2) Adraskan and 3) Injil in Herat Province, 4) Qadis in Badghis Province, 5) Lashkar Gah, 6) Kajaki, and 7) Nahr-e-Saraj in Helmand Province, 8) Kandahar City and 9) Panjwa'i in Kandahar Province, 10) Terezayi in Khost Province, and II) Khas Kunar in Kunar Province. The districts were chosen in consultation with OTI to ensure broad representation of the different geographic and political contexts in which the program implemented activities. Programming in the focus districts included a broad cross-section of $\mathrm{CCl}$ activities completed in the context of a wide range of local problems, and political dynamics at the provincial and district levels of government, that affected the implementation of the program. Within each district, a representative sample of $\mathrm{CCl}$ activities, stratified by sector (infrastructure, training, sociocultural, etc.), was systematically selected for evaluation. The awardees of these activities were the first points of contact in these districts for arranging IDIs and FGDs. Annex II describes the eleven focus districts in further detail and includes the full list of activities selected in each district.

The grantees for each sampled activity were included in the set of key informants for the IDIs. In addition, the field teams used purposeful "snowball sampling" with pre-screening of respondents to identify additional interviewees and FGD participants from the stakeholders of the selected activities in each district. The field teams first contacted $\mathrm{CCl}$ grantees using the contact information in the $\mathrm{CCl}$ activity database. Interviews were conducted with the grantees where possible, and the grantees referred the field teams to key informants from the community who were involved in the activity supported by the relevant grant.

The evaluation methodology was also designed to address the following six areas of thematic focus to which $\mathrm{CCl}$ devoted substantial programming resources across its geography: CVE which became an explicit program objective in 20I4. Youth engagement activities were an increasingly important focus of $\mathrm{CCl}$ from 2014. The use of strategic communications and media to promote peaceful elections also became a focus in 2014. A focus on outlying activities used approaches that were different from the majority of $\mathrm{CCl}$ activities. Programming sought to create community-government linkages through small-scale infrastructure and service provision. And finally, Project Shuras, Cohesion Jirgas, and Project Oversight Committees (POCs) in community-engagement processes were meant to ensure that activity outputs and outcomes would be cohesion-positive.

\section{LIMITATIONS OF THE EVALUATION METHODOLOGY}

The limitations of the evaluation were determined mainly by time and cost considerations. Because of the prohibitive cost and time required to evaluate each and every activity implemented by $\mathrm{CCl}$, a sampling approach was taken. Systematic sampling according to the set of fixed criteria outlined in Annex II was used to eliminate potential sources of bias in the selection of activities. The use of "snowball" methods for selecting interview and focus group respondents entailed a heightened risk that bias would be introduced in the evaluation data, if referrals systematically favored research subjects with a particular bias towards the $\mathrm{CCl}$ program. Alternative methods, such as randomized population sampling were, however, not viable for respondent selection because of inefficiency for identifying respondents with in-depth information about the sample of $\mathrm{CCl}$ activities. The field team was trained to mitigate potential biases from snowball sampling by pre-screening respondents to ensure that a broad pool of stakeholders in $\mathrm{CCl}$ activities were included in IDIs and FGDs. 
A crucial aspect of successful evaluation research is a concerted and systematic effort to identify and control the set of biases that inevitably color the information collected from any single source. The desire to attract follow-on programming is a source of bias that evaluations must often contend with. This source of bias may lead stakeholders and IPs to give evaluators information that they believe will positively influence their chances of benefiting from a follow-on activity. This source of bias was controlled by communicating the fact that USAID/OTI does not intend to undertake any follow-on programming to $\mathrm{CCl}$ in Afghanistan at any time in the near future.

Emotional attachment and professional reputation may enter as a different source of bias in the data collected from OTI officials and the IP Management and staff. Reputational considerations and strong attachments to the program and the areas where it worked may create a tendency to answer questions in ways that cast a positive light on some of the more challenging aspects of $\mathrm{CCl}$. Triangulation of data from different sources is the key analytical technique for identifying and controlling this bias. That is, bias was controlled by cross-referencing information from interviews with OTI officials with information from IPs, with data collected from beneficiaries in the focus districts, and with data from secondary sources, including program documents, and independent monitoring and evaluation (M\&E) reports from the IMU. The triangulation of data from these different sources ensured that the answers to the evaluation questions reflect a distillation of the full range of dynamics surrounding $\mathrm{CCl}$ programming and the various interests of its stakeholders.

Insecurity is a persistent limitation that affects all types of work in Afghanistan, including evaluations. Insecurity may affect the mobility of evaluators and access to research subjects and activity sites. Insecurity may bias evaluation findings if it results in the systematic exclusion of certain types of activity sites and/or groups of respondents. Two districts-Kajaki in Helmand Province and Qadis in Badghis Provincepresented significant security challenges for data collection because of Taliban presence or fighting. In the case of Kajaki, only six out of twelve IDls were completed within the district. The other six interviews and all three focus group discussions were completed in the Helmand Provincial Center of Lashkar Gah with residents of Kajaki that had been stakeholders of $\mathrm{CCl}$ projects in the district, but were then internally displaced to Lashkar Gah because of fighting with the Taliban. In the case of Qadis district, security concerns prevented the female data collector from traveling to the district. She instead conducted three interviews and an FGD with female stakeholders from Qadis in the nearby provincial center of Pul-e-Alam. Six interviews with male beneficiaries from Qadis were also conducted in Pul-e-Alam.

Evaluator conflicts of interests are another potential source of bias. Social Impact certifies that no member of its evaluation team, including subcontractor staff employed to collect data, have a material or perceived conflict of interest that might influence the evaluation process, the quality of the data collected, or the findings of the evaluation. (See Annex V.) 


\title{
FINDINGS, CONCLUSIONS, AND RECOMMENDATIONS
}

\section{FINDINGS}

\author{
EQ I: Strategy and Theory of Change
}

Did the program strategy adjust appropriately, given Afghanistan's evolving transition needs, within the context of overarching USG policy?

$\mathrm{CCl}$ programming made important contributions to the political and security transitions in Afghanistan. During the 20I2-20/4 transition period there was significant risk of state collapse and civil war (DOC-4I). CCl activities that linked GIRoA to rural villages were key to demonstrating the durability of government presence amid the uncertainty around whether GIRoA was capable of taking over security responsibility from international military forces. Amid threats of civil war during the crisis after the second round of voting in the 2014 presidential election, CCl's quick mobilization of international observers to audit the vote count was important for creating time and space for the two sides in the election dispute to reach a power-sharing agreement and avert state collapse by eventually establishing a new unity government.

Interviews with OTI officials, USAID officials, and IP senior management indicated that the effort to improve programming processes was a key driver of changes in the program objectives in both 2013 and 20I4. The initial iteration of CCl's strategic objectives was grounded in the principle that durable stability is the result of local will, community empowerment, local initiative, and local leadership. The USAID/OTI Afghanistan CCl's overarching theory of change purported that community cohesion is strengthened by implementing clusters of small grant activities aimed at bringing community members together with each other and their government. The intent was to improve communities' ability to resolve issues, determine and pursue common goals, and communicate effectively within the community and with various government entities. The evaluation found that in the first year of the program there was a general lack of mutual understanding between OTI and Creative on how to implement this approach in practice.

This lack of mutual understanding, combined with weak management and incapacity, were the main factors that contributed to a lack of implementation by $\mathrm{CCl}$-Creative during the program's first year. At the end of the first year of programming in March 20I3, OTI had cleared 174 activities for implementation, with a total value of $\$ 3,836,664.16$ Yet, $\mathrm{CCl}$-Creative had managed to disburse only USD $\$ 244,428$ on activities, and over USD $\$ 13$ million on operations-an operations-toprogramming ratio of $\mathrm{I} .8 \%$ (DOC-I). With this indicator of weak performance came substantial tension between Creative and OTI. A management review of the CCl program by OTI Washington in June 2013 recommended canceling the task order unless a turnaround plan was quickly enacted (DOC-2). By July 2013 , sufficient funding had been obligated and disbursements were increasing at an appreciable rate to

\footnotetext{
${ }^{16}$ These figures are from the OTI database for Creative.
} 
clear a backlog of $\$ 7$ million in approved grants (DOC-38). CCl-Creative then continued to increase its rate of activity implementation for a variety of reasons, both operational and strategic.

The strategic realignment of $\mathrm{CCl}$ objectives in $20 \mathrm{I} 3$ was a key factor in the successful "reset" of CCl-Creative under new senior management. The 2013 Strategy Review Session (SRS)undertaken with the facilitation of one of OTI's Senior Transition Advisors-was crucial for forging consensus between OTI and Creative on the program's objectives and the "activity areas" outlining the types of activities that would receive approval from OTI (DOC-38) (WAS-CR-0I). Thirteen subobjectives were subsequently defined for use in the design of activities. On this foundation, the new Chief of Party for $\mathrm{CCl}-\mathrm{Creative} \mathrm{made} \mathrm{key} \mathrm{changes} \mathrm{at} \mathrm{the} \mathrm{senior} \mathrm{management} \mathrm{level} \mathrm{and} \mathrm{eliminated} \mathrm{inefficiencies}$ and bottlenecks in program processes, thereby setting the program on a more successful trajectory.

Table I below presents the $\mathrm{CCl}$ program objectives as they were formulated in various phases of the program, drawn from the Evaluation SOW in Annex I and the desk review of program documents (DOC15, DOC-38). With the exception of Objective 2 (Support peaceful election processes and outcomes), the 2013 objectives were equally broad in their formulation as the 2012 objectives. The key difference for $\mathrm{CCl}-\mathrm{Creative's} \mathrm{process} \mathrm{of} \mathrm{activity} \mathrm{development} \mathrm{was} \mathrm{agreement} \mathrm{with} \mathrm{OTI} \mathrm{during} \mathrm{the} \mathrm{July} 20 \mathrm{I} 3$ strategy discussion on which specific types of activities should be the focus of programming. The inclusion of new activity areas in 2013 , such as engaging youths in urban areas and countering electionrelated violence, were important departures from ASI's village stabilization model and were positive examples of how $\mathrm{CCl}$ responded to the changing context of the operational environment.

Table I. CCI Program Objectives by Year

\begin{tabular}{|c|c|c|c|c|c|c|}
\hline 2012 & Objectives & \multicolumn{5}{|c|}{$\begin{array}{l}\text { I. To strengthen ties between local actors, customary governance structures, and } \\
\text { GIRoA } \\
\text { 2. To increase cohesion among and between communities }\end{array}$} \\
\hline \multirow{3}{*}{2013} & $\begin{array}{l}\text { Program } \\
\text { Vision }\end{array}$ & \multicolumn{5}{|c|}{ "Strengthen the resilience of Afghan communities" } \\
\hline & Objectives & \multicolumn{5}{|c|}{$\begin{array}{l}\text { I. Strengthen community capacities to promote peaceful transition } \\
\text { 2. Support peaceful election processes and outcomes } \\
\text { 3. Counter violent threats to peaceful transition }\end{array}$} \\
\hline & $\begin{array}{l}\text { Activity } \\
\text { Areas }\end{array}$ & $\begin{array}{l}\text { Community- } \\
\text { identified } \\
\text { small-scale } \\
\text { infrastructure }\end{array}$ & $\begin{array}{l}\text { Analytics } \\
\text { and data } \\
\text { interpretation }\end{array}$ & $\begin{array}{l}\text { Counter } \\
\text { election-related } \\
\text { violence }\end{array}$ & $\begin{array}{l}\text { Countering } \\
\text { violent threats } \\
\text { to peace and } \\
\text { stability }\end{array}$ & $\begin{array}{l}\text { Engaging } \\
\text { youth in } \\
\text { urban areas }\end{array}$ \\
\hline \multirow[b]{2}{*}{2014} & Objectives & \multicolumn{5}{|c|}{$\begin{array}{l}\text { I. To increase cohesion within and between communities } \\
\text { 2. To support peaceful and legitimate governance processes and outcomes } \\
\text { 3. To counter violent extremism }\end{array}$} \\
\hline & $\begin{array}{l}\text { Sub- } \\
\text { Objectives }\end{array}$ & $\begin{array}{l}\text { To strengthen } \\
\text { community } \\
\text { capacities to } \\
\text { mitigate conflict }\end{array}$ & $\begin{array}{l}\text { To increase } \\
\text { citizens' trust } \\
\text { and confidence } \\
\text { in their } \\
\text { government }\end{array}$ & $\begin{array}{l}\text { To strengthen } \\
\text { the capacity of } \\
\text { legitimate } \\
\text { community } \\
\text { groups and } \\
\text { organizations }\end{array}$ & $\begin{array}{l}\text { To increase } \\
\text { positive } \\
\text { engagement of } \\
\text { youth in their } \\
\text { communities }\end{array}$ & $\begin{array}{l}\text { To support } \\
\text { voices that } \\
\text { promote } \\
\text { moderation, } \\
\text { tolerance, } \\
\text { and peace }\end{array}$ \\
\hline
\end{tabular}


The program retained a strong emphasis on connecting communities to GIRoA, despite the shift in USG strategy from COIN to transition with the drawdown of U.S. troops. After 2012 the phrasing of "strengthen ties" with GIRoA was removed from the $\mathrm{CCl}$ objectives and reformulated in 2013 as "support the legitimacy of local government" (Sub-Objective I.2), and in 20I4 as "increase trust and confidence in government" (Sub-Objective 2). The focus on community-GIRoA linkages was also operationally determined by a series of USAID/Afghanistan Mission Orders, starting on January I, 20I3, that set strict requirements for anti-terrorism vetting of awards greater than USD \$25,000 (DOC-40).

The process of anti-terrorism vetting by USAID was slow and resulted in significant delays for the implementation of activities, which substantially constrained program flexibility and responsiveness to changes in local conditions for achieving quick impacts. If a grantee failed vetting, then the activity could not be implemented. GIRoA officials were more likely to pass vetting than other Afghans because of their clear status on the opposing side to the Taliban and other violent extremist groups. The vetting policy thus promoted a community grants model where a local government official was the grantee, and the benefits of the grant were delivered in kind to local communities, either directly by the IP or through an external service provider. The large majority of grants awarded by $\mathrm{CCl}$-Creative and $\mathrm{CCl}-\mathrm{IOM}$ went to government officials. Host government entities were awarded 346 activities (88.5 percent of the 39I total) implemented in the eleven districts in focus for this evaluation. In 2014 the OTI Country Representative mandated that GIRoA should be included in all $\mathrm{CCl}-\mathrm{Creative}$ and $\mathrm{CCl}-\mathrm{IOM}$ activities, if not as the grantee, then as part of the project oversight committee (POC) that supervised activities along with other stakeholders (WAS-USAID/OTI-13). Programming by CCI-USIP departed from this model by utilizing mainly grants to civil society organizations (CSOs) without GIRoA involvement.

CCl's orientation towards the COIN/stabilization objective of linking communities with GIRoA was determined both by USG policy and the mindset of much of the implementation team. When $\mathrm{CCl}$-Creative and $\mathrm{CCl}-\mathrm{IOM}$ field staff and local stakeholders were asked about the purpose and objectives of $\mathrm{CCl}$, the most common answer was bringing the government closer to the people, connecting the government to the people, and variations on this theme of COIN. The many staff members who had worked for ASI before joining $\mathrm{CCl}$-Creative thought of the new program as an unbroken extension of ASI rather than as a separate program with its own unique objectives. ${ }^{17}$ The emphasis on linking communities with GIRoA was also visible in the documentation on the start-up of CCI-IOM (DOC04) but driven by experience with stabilization programs implemented by IOM in other countries. Moreover, infrastructure activities were commonly perceived by GIRoA counterparts and IP staff as the best way to create community-government linkages by demonstrating the ability of the government to provide for the basic needs of the community. It is therefore unsurprising that infrastructure was the largest category of activities for $\mathrm{CCl}-$ Creative (42 percent of the total), given the large number of staff that $\mathrm{CCl}-\mathrm{Creative}$ inherited from $\mathrm{ASI}$ and the preponderance of grant awards to GIRoA officials. ${ }^{8}$ The

\footnotetext{
${ }^{17}$ According to interviews with IP management and staff, as well as review of secondary data from a survey of $\mathrm{CCl}$ Creative staff conducted prior to the After Exit Review in March 2015 (DOC-42).

${ }^{18}$ The proportional breakdown of the 699 total activities implemented by $\mathrm{CCl}$-Creative, as recorded in the OTI database, is as follows: $42 \%$ Infrastructure, $9 \%$ Technical Assistance, 19\% Sociocultural, $23 \%$ Training, $6 \%$ Media.
} 
balance of IOM activities initially favored infrastructure but shifted to soft activities in 2014 , as discussed below.

The addition of the peaceful election objective in 2013 proved to be an effective response to changes in Afghanistan's political context and USG policy. New leadership of the Program Development Unit (PDU) within $\mathrm{CCl}-$ Creative was instrumental for activity design and implementation towards the newly adopted peaceful election objective. The establishment of the PDU as a Kabul-based programming office separated from the regional programming teams allowed it to focus on new types of "national" activities, such as strategic communications and analytics in support of the new peaceful elections objective, and activities focused on urban youth. As such, the PDU was an effective means of injecting innovation into the program and upsetting some of the inertia surrounding the focus on community infrastructure activities.

Amid a variety of programming by other USAID technical offices and USG agencies on voting, promoting a peaceful election was an important niche occupied by $\mathrm{CCl}$. Strategic communication activities by the PDU and USIP to promote the peaceful conduct and outcome for the election added to the national and international voices that created momentum behind the election process, led to high enthusiasm and participation, and effectively overwhelmed antidemocratic voices (until the situation descended into crisis due to allegations of fraud).

Scenario planning in advance of the election considered the possibility that international observers might be necessary to avert violence if the result of the election was contested. CCl-Creative's fast mobilization of $\mathbf{4 0}$ international observers for the audit of the vote in summer 2014 was a crucial short-term intervention in the presidential election crisis that helped achieve the peaceful transition to a new Afghan president and government.

The addition of the CVE objective in 2014 was an effective response to the expiration of the USG counterinsurgency strategy, and the turning away from stabilization programming by the USAID/Afghanistan Mission. Senior non-OTI officials at the Mission noted that, after the close of the Stability in Key Areas (SIKA) activities, USAID was no longer doing village-level programming because of the reduction in staff and budget that came with the withdrawal of U.S. troops. The withdrawal of U.S. troops had brought stabilization programming to an end: "Stabilization ends when military combat ends" (KBL-USAID-0I).19 The expansion of CVE programming with vulnerable groups, such as youth, was an important means of creating a legacy for OTI in Afghanistan after stabilization. CCI-USIP's experimentation with different CVE approaches in 2014-20I5 has generated a new foundation for future CVE programming by the USAID/Afghanistan Mission.

\footnotetext{
${ }^{19}$ Because stabilization programs were designed to work together with military forces, there is an undeniable logic to the notion that USG stabilization programs should end when USG combat operations also end. This logic holds to the extent that USAID's Afghanistan stabilization programs lacked a strategy separate from COIN. Alternative stabilization strategies that might be envisioned, such as local efforts to promote reconciliation between the government and insurgents, were ruled out by USG policy.
} 
Were the program objectives and sub-objectives framed in a way that facilitated activity identification and design, and how did the implementing partner staff's understanding of the program goal impact activity quality andlor strategic relevance?

The program goal of strengthening community resilience was not well understood by IP Local Staff and $\mathbf{C C l}$ stakeholders. Resilience has no easy translation into Dari or Pashto, and the English usage of this term had multiple valences that complicated its explanation. $\mathrm{CCl}$ documents used the term resilience variously to describe influential individuals, abilities to cope with shocks arising from violence and economic exigencies and/or natural phenomena, links with GIRoA, and resistance to the insurgency (DOC-I5). The term sometimes received direct translation by IP local staff as "resistance," which raised concerns about security (WAS-CR-03). When the evaluation team asked about resilience by translating the term into a local-language phrase about ability to recover from shocks or adverse events, $\mathrm{CCl}$ stakeholders most often discussed the importance of culverts and floodwalls or similar infrastructure to help them withstand natural disasters, and/or the importance of vocational training and other forms of livelihood assistance for increasing incomes to absorb economic shocks. The evaluation found that local stakeholders understood resilience mainly in terms of their ability to meet basic needs and cope with external shocks that were unrelated to the insurgency.

In contrast to "resilience," cohesion was a better term for communicating the intent of the program because it is easily translated into Afghanistan's local languages and was well understood by local stakeholders and IP staff. Indeed, a Creative senior Afghan national staff member named the $\mathrm{CCl}$ program during one of the program's start-up meetings (WAS-USAID/OTI-I4). The cohesion terminology worked as a flexible paradigm through which the objectives of the program, and changes to the objectives, were conveyed to local staff and stakeholders. Interviewees variously described cohesion in terms of coordination, cooperation, communication, unity, and mutual understanding between different communities and people from different areas, between members of the same community, between communities and the government, between youth and elders, between women, and also between local communities, the government, and former and current sympathizers or members of Armed Opposition Groups (AOGs), such as the Taliban. Cohesion, rather than resilience, was understood by IP local staff and community stakeholders as the key factor that empowered communities to resist the insurgency by presenting a united front in the face of Taliban opposition to the project activities in their communities.

Cohesion further emerged as a key determinant of the success of USIP's experiments with CVE activities. USIP management and grantees reported that the capacity of beneficiaries for CVE was critically dependent on the degree to which activities were successful at building cohesion among beneficiaries. For example, building cohesion between students of religious madrassas and public high schools (makhtabs) through journalism and theater training in joint workshops was important for generating mutual understanding between the different groups. By forming relationships in the workshops, the students from different groups not only became more receptive to positive messages about the other and about peace, but they also gained each other's support for completing their CVE journalism projects.

The revision of program objectives in late 2014 clarified the strategy for the final year of programming by $\mathrm{CCI}-\mathrm{IOM}$. Leading up to the 2014 change in strategy, CCl-IOM staff reported that the objectives and sub-objectives with which they started programming in 2013 (over one year after the start of $\mathrm{CCl}$-Creative) were not well understood by the local staff responsible for developing activity 
concepts (KBL-IOM-02). The CCl-IOM team had problems matching the 2013 sub-objectives to the national objectives, and senior management reported that they had difficulty using the 2013 objectives to write grant concepts in a way that could be understood by OTI: "We knew what we were doing, but it didn't look that way on paper." The contortions that the CCl-IOM team found necessary to use the 20I3 objective framework to write grant concepts was like "trying to fit a square peg in a round hole" (KBLIOM-02). It is evident from the provincial "entry memos" prepared during the start-up of CCl-IOM programming in northern and western Afghanistan that IOM expected to implement a traditional type of stabilization programming focused on building community-government linkages through small infrastructure grants (DOC-04). There was no initial effort from $\mathrm{CCl}-\mathrm{IOM}$ to revise the program objectives, most likely because such as an effort was seen by the start-up team as a lower priority than establishing implementation processes for stabilization activities that would follow an assumed formula.

Did program objective pivots (20/3 and 20/4) lead to higher-quality activities andlor more strategically relevant activities, and, if so, did that lead to more contribution to the achievement of the program goal?

Whereas the general lack of grant activity implementation by $\mathrm{CCl}$-Creative before the $20 \mathrm{I} 3$ change in objectives made this more of a "reset" of the program under new management than a "pivot" in a new direction, the 2014 change in objectives represented a more substantial pivot. The 2013 revision of the objectives had opened $\mathrm{CCl}$ to new thematic areas, including support to the 2014 presidential elections and greater engagement with youth. However, the value of $\mathrm{CCl}$-Creative's continuing focus, and CCl-IOM's initial focus on infrastructure under the 2013 objectives, was a source of significant concern from OTI. This was expressed in terms of a lack of confidence that the IPs were designing grants to achieve the program objectives or instead were retrofitting requests for assistance to meet community needs onto the objectives (WAS-USAID/OTI-06). As a result, the sense within OTI Kabul that there was too much emphasis from $\mathrm{CCl}$-Creative on infrastructure became an "existential question" of what the program was achieving by "continuing to pave more of Kunar" in the context of the transition (WAS-USAID/OTI-I0). The focus of CCI-IOM on using infrastructure activities to strengthen community-GIRoA linkages was seen as an obstacle to broader programming for the achievement of cohesion and resilience objectives (WAS-USAID/OTI-06).

The 2014 pivot by IOM to implement more sociocultural activities, such as sporting and cultural events, meant that the program undertook new types of activities with new partners, such as local CSOs. The results of the 2014 pivot for IOM can be seen in the relatively few infrastructure grants in the mix of activities implemented by $\mathrm{CCl}-\mathrm{IOM}$ using the new objectives. Only 30 percent of the post-pivot activities implemented by CCl-IOM were infrastructure grants, compared to 53 percent of activities categorized as sociocultural in the OTI database. For IOM, sociocultural activities were quicker to implement than infrastructure activities, which was an important consideration in the last year of the program. The few viable CSO partners working in the districts targeted by CCl-IOM often had weak organizational capacity, leading to poor implementation, and an expanded effort within $\mathrm{CCl}$ IOM for building the capacity of its CSO partners (KBL-IOM-09, KBL-IOM-03).

According to the CCI-RSI IMU's scoring system, the overall quality of soft activities implemented by CCI-IOM in 2015 was no better or worse than that of the infrastructure activities-both hard and soft activities had an average quality score of $\mathbf{3 . 2}$ on the IMU's 5point scale. The short time remaining for $\mathrm{CCl}-\mathrm{IOM}$ programming constrained opportunities for capacity 
building for the CSOs to improve the quality of activities across iterative programming cycles. Most sociocultural activities implemented with CSO partners were nevertheless popular and novel for the local context and created cohesion between communities. However, no stakeholders considered such events as having created resilience to shocks.

For CCI-USIP, the 20 I 4 change in objectives was a "pivot" in the full sense of the term, from programming exclusively for the peaceful elections objective to programming exclusively for the CVE objective. USIP defines violent extremism as "violence inspired, justified, explained and/or related to any political, religious or social ideology" (DOC-36). While USIP's past and ongoing peacebuilding work falls within a broad definition of CVE, the focus of CCI-USIP was on at-risk individuals and groups that are vulnerable to being recruited or joining violent extremist movements. One senior official at the USAID/Afghanistan Mission noted that CVE is becoming a priority, but it is unclear how to implement CVE programming effectively, given the many social, political, and economic factors that could contribute to the radicalization of an individual. Given this lack of definitional clarity, CCI-USIP described its CVE programming as "emerging" and "experimental" (DOC-36). The substantial freedom to experiment with CVE that was afforded to CCI-USIP by OTI took the form of a trial-anderror process through which CVE was defined in terms of providing opportunities to develop alternatives to extremism and articulate counter-narratives in response to extremist narratives that attempt to justify violence. The evaluation of CVE programming by CCI-USIP found that the theory of change related to this operational definition of CVE can be stated as follows:

If individuals and their communities are provided with messages about peaceful alternatives to extremism and training that builds capacity to peacefully fulfill economic, social, and political aspirations, resolve conflicts, and think critically about extremism, then individuals will be more likely to embrace alternatives to extremism and articulate their own CVE narratives in response to extremist ones that attempt to justify violence.

This theory of change for CVE, founded on building capacity to generate counter-narratives, is an important legacy of USAID/OTI Afghanistan. The theory draws on the insight that behavior change surrounding violent extremism (VE) requires people to internalize alternative messages and freely choose to use these alternative messages to create a counter-narrative, about, for example, peace, development, and the future of Afghanistan. The persuasive power of VE narratives relies on interpreting current events through analogy with historical narratives from the Islamic tradition (e.g., the crusades). This power of analogy often works to the detriment of anti-VE messages when the audience perceives an anti-VE message as anti-Islamic. It follows from this insight that people will be less likely to internalize negative messages that simply condemn VE than they are positive messages of peace that resonate separately from VE messages. As such, individuals will be more likely to create CVE narratives that interpret current events through analogy with alternative Islamic narratives of peace. To build the capacity of individuals to become CVE practitioners, an individual must not only be exposed to alternative messages, but also be trained to recognize a need to counter a VE narrative and gain the capacity to articulate alternative messages into an appropriate counter-narrative.

\section{EQ2: Activity Outcomes}

Based on a sampling of activities and review of existing activity evaluations and analysis, to what extent did activity outcomes contribute to each of the program objectives/goal and sub-objectives? 
Interviews with local stakeholders revealed common perceptions that project activities increased "cohesion" or "cooperation" in their locality. Reports of positive outcomes surrounding increased cohesion far outweighed negative reports from local stakeholders of decreased cohesion. Any of CCl's activities had the potential to contribute to cohesion by uniting communities in support of the implementation process, if programming processes were implemented with a sufficient level of quality and thereby generated high-quality outputs.

Effective community-engagement processes were crucial for the achievement of program objectives. The interview and focus group data with beneficiaries and stakeholders shows clear differences in reported outcomes according to the quality of the engagement process. Beneficiaries that said that they had a say in the project were more likely to report positive outcomes. The following quotation from Kajaki District illustrates the value of consultative processes for achieving positive outcomes:

"Whenever we faced a problem regarding reinforcement and cement, we informed their engineers or other labors. They were accepting our ideas greatly and were hearing them. In fact, the work ended with a great quality and we are happy for that." (KJK-IDI-07)

A municipality official in Kandahar City neatly summarized the community-engagement process that he participated in through $\mathrm{CCl}$, which helped gain the trust and support of the community for the government:

"The local people were present. Whenever we took new projects, we would organize an opening for them. In the opening ceremony, we would make it clear that in these programs, we will build such culverts, we have this amount of money for building culverts, this much people will work on building culverts, it needs this much time and it will take this much days. The local people can also monitor the progress of our activities. The Municipality department can also monitor it. Everything will be mentioned to them so that they know the project is being implemented for them." (KND-IDI-OI)

Weak implementation processes, corruption, and perceptions of corruption were barriers to achieving the program objectives. Afghanistan is one of the most corrupt countries in the world, according to its own population. It ranks 172 nd of 175 countries in the 2014 Corruption Perceptions Index published by Transparency International. ${ }^{20}$ Herat Province, where $\mathrm{CCl}-\mathrm{IOM}$ implemented in Adraskan and Injil districts, was a particular trouble spot: GIRoA officials sometimes directly and unabashedly asked for bribes in exchange for supporting the program.

The extent to which cohesion could be built between GIRoA and local communities was limited by local perceptions of GIRoA official corruption. An important aspect of the $\mathrm{CCl}$ was its IPs' ability to pick and choose the government partners with which grants were implemented in the attempt to avoid corruption and obstructionism from particularly venal local officials. According to senior management from $\mathrm{CCl}-\mathrm{IOM}$, all requests for bribes were resisted and none were paid by the program. Whether or not service providers for in-kind grants made such payments was, however, out of the program's control. In general, the environment of official corruption complicated community-engagement processes. As one female stakeholder of youth activities in Adraskan District of Herat province noted:

${ }^{20}$ Accessed December 6, 2015 online: http://www.transparency.org/cpi20I4 
"There was good development in some activities. But some other projects caused disunity among people. It was due to lack of transparency. People were not aware of the total budget, whether budget was used properly or misused. That is why some people were critics of the district governor." (ADR-IDI-I 2)

Activities were relatively less effective at generating cohesion where pervasive suspicions of corruption were not allayed through effective community engagement and communication surrounding project goals and implementation processes. The use of POCs to monitor activity implementation was an important community-engagement process that drove the success of activities. POCs were institutionalized by $\mathrm{CCl}-\mathrm{IOM}$ as part of the grant approval process-signatures from all POC members were required for the approval of grant milestones. POCs consisted of community members (including women and youth), a government official, and IP staff. The systematic use of POCs had a positive effect on improving $\mathrm{CCl}$ outcomes overall, according to the interview data and outcome analysis completed by the CCI-RSI Independent Monitoring Unit. The use of POCs was mandated by CCl-IOM. Despite the general finding on the value of POCs for quality control, even POCs were not entirely free of rumors of corruption.

For CCl-Creative, accusations of corruption were particularly pervasive in Nahr-e-Saraj District of Helmand Province. While female focus group participants in Nahr-e-Saraj reported a range of lasting benefits from trainings in tailoring, male elders interviewed in the district were highly critical of CCl's other activities. According to one member of the district shura, "Colonel Sarbuand, Naikzad, and the engineer from $\mathrm{CCl}$ got all the money and wasted and used it for their own benefits. I want to take them to the court and I want the government to bring these people to answer our questions (NRS-IDI-02)." Another tribal elder from Nahr-e-Saraj noted the following:

"When the people saw the [Public Solar Light Installation in Grishk (NRS-0026)] project after its completion, they expressed their dissatisfaction... That is why a great distance has been created between the people and government, it is just because of the wide range of corruption within the current governmental authorities. Virtually, the Taliban completely had no meaning in our beloved Afghanistan, but emerged due to the increasingly corrupt activities. People are displeased from the current government and are not interested to cooperate with the government." (NRS-IDI-05)

The negative findings from the above examples from Nahr-e-Saraj are reinforced by other data collected in Helmand Province, where the Taliban has effective control of Kajaki, Musa Qala, and Sangin districts. At the time of writing it was threatening to take control of Nahr-e-Saraj and encircle the provincial center of Lashkar Gah. (CCl implemented programming in all of these districts.) When asked about the most significant change that $\mathrm{CCl}$ created, a former employee of $\mathrm{CCl}$-Creative who worked in Helmand noted the following:

"Instead of creating cohesion between people, it added to the distance between communities... There was a project in Sarwan Qala area of Sangin district. There was no security. The people of the area were not cooperative with the project. The authorities in $\mathrm{CCl}$, district and province selected a person as head of the project. The person was corrupt. This project created a big problem between Ishaqzai and Alokozay tribes. They fought with each other because of the project." (HLM-CR-02)

Such negative results were mixed with positive results in Helmand. As noted above, relatively high-quality implementation processes on some projects in Kajaki District had some positive effects. CCl-Creative 
activities in Kajaki district that provided training in tailoring, carpentry, and electrical repairs had the lasting effects of providing employment and increasing the incomes of beneficiaries in the district center. Beneficiaries also reported positive outcomes from training activities in Nahr-e-Saraj and Lashkar Gah. A male beneficiary from Kajaki District in Helmand Province noted the following:

"So far the relationships between local people and government are strengthened and have become very close. Currently Kajaki is occupied by Taliban, but people do not agree with them and are cursing them for destruction. The government has raised their quality of life and trained the people. These people cannot fight with the Taliban but hate them in their hearts. Long ago they were happy with Taliban but are not satisfied from them now... Now people believe in the implementation of projects and have confidence in government too." (KJK-FGD-0 I, Participant I)

Worsening security conditions in Helmand after the withdrawal of the U.S. Marines had a negative influence on $\mathrm{CCl}$ outcomes. In contrast to Helmand, security in neighboring Kandahar province improved significantly during and after the implementation of $\mathrm{CCl}$ activities. In this environment of improving security, local beneficiaries reported that $\mathrm{CCl}$-Creative made a substantial contribution to improving linkages between local communities and the government. One member of the district shura in Panjwai noted the following:

"Before, there was too much distance between people and government... But now they are so close to the government, even if a police does something wrong, they are going to the district office or to commander office to complain. Now people know that there is someone who can hear them. All people have Tazkira [national ID] now, they got voting cards and know about voting and everyone has voted for their favorite candidate, these all were the result of the projects and people are now well understood about everything... The good thing about $\mathrm{CCl}$ is that they make people work together. Their work was infrastructure work, it was not only for a month or for a year, they have worked for the future." (PNJ-IDI-06)

Activities both hard and soft that were implemented in conditions of sufficient security, and which achieved high-quality outputs using strong community-engagement and oversight processes, were cited by beneficiaries as positive for increasing linkages between communities and government.

Which types of activities contributed most significantly to the program objectives/program goal, and are there identifiable trends across those activities?

Water projects, especially flood walls and irrigation canals, were the most commonly cited sources of increased resilience. Outcome analysis by the IMU also confirmed that water projects were particularly effective for helping to resolve community conflicts over water. The head of a local village shura in Adraskan District of Herat Province reported the following:

"The retention wall project will be one of the long lasting projects that people have seen, and they really appreciated it. By completion and implementation of that project, people are extremely pleased and happy since this project prevents the flood and does not let it destroy their lands. This is what people really wanted and needed from long time ago." (ADR-IDI-05)

Beneficiaries across the focus districts praised the benefits of improved infrastructure when projects were implemented successfully and according to plan. Similarly, training and 
sociocultural activities that were implemented with government involvement, and according to plan, were seen as positive for increasing confidence in the government. The following quote from a female beneficiary from Adraskan District of Herat Province speaks to the cohesion built by the mix of hard and soft activities implemented in the district:

"People's relation has improved with the government; the government was involved in every project, the district was involved, the district chief of police was involved. Previously nobody recognized the district center not even the chief of the police department. Before I didn't know who to refer to in case of issues but during these projects we recognized the chief of police, the district governor, the legal section, as well as the criminal affairs section as now we know who to refer to in case of issues." (ADR-FGD-0 I, Participant I)

The stakeholder quoted above from Adraskan provided good examples of how clusters of $\mathrm{CCl}$ activities achieved synergistic effects in certain districts. Similar to Adraskan is the example of Panjwai District in Kandahar Province, as discussed above, as well as Terezayi District in Khost Province and Khas Kunar District in Kunar Province. The durable gains that we see currently in stability and security in Terezayia border district with Pakistan that was highly insecure in previous years - was seen by the management of $\mathrm{CCl}-\mathrm{Creative}$ as a particularly strong achievement of the program. One local stakeholder in Terezayi noted the following:

"They won the confidence of the tribal leaders in the villages and they were able to achieve their objectives with their help... They had coordination with people and they would hear people's opinions about the projects... It was really difficult for the $\mathrm{CCI}$ program to launch projects in areas such as Ali Sher because people of those the areas were not interested in organizations. They were able to implement their projects in such areas with the support of the tribal leaders." (TRZ-IDI-I2)

As the respondent noted above, the effective targeting of various activities to build cohesion between different tribes in Terezayi was the key to the success of $\mathrm{CCl}$-Creative in the district. The tribes in Terezayi retained relatively strong social organization, in contrast to weaker tribal structures in other provinces. In this context, building cohesion between tribes using $\mathrm{CCl}$ activities was an effective means of improving security, linking communities to GIRoA, and preventing the Taliban from controlling the district.

Acting independently of $\mathrm{CCl}$ implementers, local community elders in areas contested by the insurgency often sought permissions and/or security guarantees from local Taliban for CCI activities to take place. One tribal elder in Terezayi explained that "the Taliban or armed insurgents are from our people and communities; here we have tribal structures, customs and traditions. We have religious scholars/mullahs and they solve any problems we have faced with including giving permissions for projects (TRZ-IDI-02)." This respondent went on to explain that for every CCl project the tribal elders, acting independently of $\mathrm{CCl}$, petitioned the Taliban's Peshawar Shura across the border and asked for the projects to be cleared for implementation. The Peshawar Shura acquiesced as long as the projects were not funded by GIRoA. Respondents reported that linkages between GIRoA and local communities nevertheless improved as a result of $\mathrm{CCl}$-Creative's activities. Respondents in other districts also cited examples of elders approaching local Taliban and convincing them not to oppose projects behind which the community was united. In such cases the Taliban were convinced to unite with the rest of the community behind the project. 
The example of the tribes in Terezayi standing together against the Taliban, or convincing the Taliban not to oppose project activities, is one example of how $\mathrm{CCl}$-Creative programming had CVE effects. As discussed above, the focus of CCl-USIP's CVE programming was similarly predicated on generating cohesion between different groups. This CVE programming, however, did not target rural communities but rather groups within the population, such as youth, that are considered to be particularly vulnerable to recruitment by violent extremists.

Such CVE programming was mainly implemented by $\mathrm{CCl}$-USIP, though $\mathrm{CCl}$-Creative and $\mathrm{CCl}-\mathrm{IOM}$ also implemented youth-focused activities that had CVE effects. By providing employment opportunities for youth in areas where the insurgency is strong, vocational trainings made a valuable contribution to preventing recruitment of youth by insurgents. One beneficiary of electrician training in Kajaki ${ }^{21}$ noted the following:

"The armed opponents of the Afghan government were trying to encourage the jobless youth in Kajaki against the government, they were trying to give them weapons so they could fight against the Afghan government... But when the $\mathrm{CCl}$ programs, trainings and projects were implemented, it brought many positive changes in our youth... Now most of them are tailors, electricians and carpenters and they can feed their families and are serving their nation with the help of the professions they learned from $\mathrm{CCl}$ trainings... They were prevented from joining the armed opponents." (KJK-IDI-09)

As the quote above demonstrates, CVE outcomes were achieved by capacity-building activities that gave youth marketable skills. The CVE effects of such activities could be expanded with the addition of a strategic communications component to the training, following the theory of change for CVE developed by CCI-USIP described in the previous section. Journalism and theater training given to mixed groups of teenage students from madrassas and state high schools was a successful CCI-USIP activity that built cohesion among the students while building their capacity to articulate counter-narratives in various media. CCI-USIP credited CVE trainees with stopping an extremist recruitment campaign in Parwan Province by reporting the recruiters to the police (DOC-36).

The objectives of CVE and countering violent threats to a peaceful transition were also pursued through poetry competitions held by $\mathrm{CCl}-\mathrm{IOM}$ and $\mathrm{CCl}$-Creative across their implementation districts. Peace poetry competitions and events for youth proved to be popular sociocultural activities, marked by unexpectedly high rates of participation. These activities were important for generating cohesion among youth, and between youth and elders, and for popularizing narratives of peace as alternatives to VE narratives. One youth interviewee in Kandahar said the following:

"Armed opposition groups and the illegal powerful groups, do exist here... At first some of them thought poems were not effective, but later, they found out that the poems were being recited by people and could point out some problems of the society. This was one of the ways we could call authorities to work for their people and country." (KND-IDI-04)

As a group, youth stakeholders in $\mathrm{CCl}$ activities were the most consistently positive about activity outcomes. Activities that supported new or existing youth associations had some of the most

${ }^{21}$ This beneficiary was a participant in a 12-week vocational training in basic electrical skills for 15 youth, ages 16 to 29, from the Zamindawar village clusters in Kajaki District (activity number KJK0006). 
consistently positive outcomes reported by local stakeholders, youth and elders alike, across the eleven focus districts. Stakeholders reported that the youth councils established by $\mathrm{CCl}-\mathrm{Creative}$ and $\mathrm{CCl}-\mathrm{IOM}$ across the implementation districts remained active after the completion of activities. A stakeholder engaged with youth in Adraskan District of Herat Province noted that the "project related to youths was very effective. The youth council has ten members, including chief, deputy chief, and secretary. Now youths have become very active. The youth council also received materials. It is possible with the support of people and government; they can do something for youths in the future (ADR-IDI-02)."

Trainings for youth on professional development, such as writing CVs and passing the "Kankor" university entrance examination, were well received by youth stakeholders but are unlikely to have positive outcomes for CVE if they raise unrealistic expectations about what the government can provide for education. Both rural youth and relatively well educated urban youth are vulnerable to recruitment by VEs. One elder female interviewee in Kandahar City said the following:

"I think the main objective of $\mathrm{CCl}$ was to establish relations between people and government and they did it. But these relations aren't established in a good way because the government couldn't do anything useful for the youth who failed in the university entrance exam. The public universities don't have the capacity to take all the students, so it can increase the distance between government and people." (KND-FGD-0 I, Participant 4)

The concern expressed in the quote above about providing the right type of training, and avoiding the setting of unrealistic expectations among youth, is an important consideration for designing capacitybuilding activities to have CVE effects.

Moreover, while sociocultural events were generally appreciated by most youth stakeholders and credited with generating cohesion, many female stakeholders saw one-day events as superfluous, for the likely reason that women had fewer opportunities to maintain new social ties after the completion of events relative to male beneficiaries (KBL-RSI-03). One elder female FGD participant in Adraskan noted the following:

"I am not against all the projects but I am against some projects such as racing project and boat riding competition. ${ }^{22}$ This organization should have invested their money to a long lasting activity through which people could earn something and feed their families. In the running race, everyone with long beard was running from Bargini to Omarkhail and at the end was paid 800 AFS [Afghanis]." (ADR-FGD-0I, Participant I)

While sociocultural events were novel for the local context and generally popular, no stakeholders considered such events as having contributed to resilience. Stakeholders, as well as IP local staff, criticized one-day events for lacking sustainable outcomes. IP management suggested that these events were effective to the extent that they built cohesion to reinforce the outcomes of other activities (KBL-IOM-02, KBL-IOM-I2).

${ }^{22} \mathrm{CCl}$ did not support any boating activities. The description of the race, however, matches one of the activities sampled. 


\section{Were there any unexpected outcomes (positive or negative) observed within these activity categories or within individual activities sampled?}

Positive unexpected outcomes included the popularity of certain sociocultural activities, such as essay and poetry competitions, and turnout for sporting events and celebration on women's day and farmer's day that was much higher than anticipated in activity designs. Also, certain media activities implemented by the PDU of $\mathrm{CCl}$-Creative were unexpectedly popular, gathering a television audience large enough to spark demand for re-broadcasting to sell advertising. $\mathrm{CCl}$-Creative produced a television series called "Dream and Achieve" in which Afghan entrepreneurs presented business ideas to a panel of judges. This activity provided Afghan youth with positive role models working to develop their communities and the country.

Peaceful elections messaging by the PDU and CCI-USIP was effective for drowning out negative antidemocratic messages. High female turnout was observed in areas where PDU messages were targeted and women had not voted in large numbers previously. The high turnout and generally peaceful atmosphere in which the 2014 election was conducted were unexpectedly positive outcomes to which $\mathrm{CCl}$ made a meaningful contribution through its media campaigns. One representative of a $\mathrm{CCl}$ USIP grantee organization, the Awoshtoon Cultural Society, noted the following about the voter turnout:

"We asked them to take part in elections. The objective was achieved very well via events, poetry and tournaments. As an example I can say that there were four or five elections in Paktia but people had not participated in them as they did in the last election. Similarly in Khost, Ghazni and Paktika around I.5 million people voted. If you see the electoral data you find out that this time the number of voters are much higher than last elections and it is a great achievement for us." (KHT-USIP-OI)

One female beneficiary in Kunar linked security from new roads built by $\mathrm{CCl}$ and ASI to elections, describing the benefits of the roads that were asphalted by $\mathrm{CCl}$ in terms of reduced risk from improvised explosive device (IED) explosions, thereby promoting greater security for voting and a higher turnout among women in Kunar for the 2014 election (KUR-FGD-0I, Participant I).

Further, a key success of the $\mathrm{CCl}$ program was the fast mobilization of observers by $\mathrm{CCl}$-Creative for the audit of the vote count after the second round of voting in the presidential election. The election observers provided the international oversight that was necessary to retain a minimum atmosphere of civility between the opposing sides. The observers were instrumental in creating the time and space for the opposing sides to reach a power-sharing agreement.

Negative unexpected outcomes included security incidents at project sites that delayed or stopped work. Stakeholders reported one IED explosion on a road project in Nahr-e-Saraj and one in Sangin District of Helmand Province (NRS-IDI-0I, HLM-CR-0I, WAS-CR-0I). Despite tribal elders in Terezayi District of Khost Province seeking assurances from the Taliban that project sites would not be attacked, the following incident occurred in Terezayi:

" $[T]$ he activities were being done and the workers were busy, but when our team got to the site next morning, they found mines everywhere, while the government and the people of the society had already told us that there wouldn't be such problems. When our team started working, the mines exploded and a few of our workers got injured, which had a very bad effect on the morale of our team and on the program." (KHT-CR03) 
In this case, the work on the project did eventually resume and Terezayi is a district where security improved while $\mathrm{CCl}$ was operating, and where security has been maintained since $\mathrm{CCl}$-Creative completed activities in the district. Such incidents as the one reported in the quote above show the volatility of implementing programming in areas that had not been fully cleared of insurgents. This incident, however, was an exception-unsanctioned negotiations between local community elders and local Taliban, conducted independently of $\mathrm{CCl}$ implementers, generally succeeded at preventing attacks on activity sites in contested districts, according to stakeholders interviewed in Terezayi, Adraskan, Badghis, and Samangan Districts (TRZ-IDI-02, TRZ-IDI-03, TRZ-IDI-06, TRZ-IDI08, ADR-IDI-0I, ADR-IDI-05, ADR-IDI-I0, ADR-FGD-02, BDG-FGD-02, SMG-IDI-08).

Analysis of the data from the MISTI program further shows that $\mathrm{CCl}$ activity sites were more secure than SIKA sites. Villages where SIKA project activities took place saw an increase in the rate of insurgent attacks after projects started, compared to a counterfactual control group of villages that did not receive activities. The MISTI data, however, showed no statistical relationship between $\mathrm{CCl}$ activities and insurgent violence. This finding could be interpreted to show that CCl's community-driven process was less risky for villages in insurgent areas than the SIKA model, which engaged with communities via the Ministry of Rural Rehabilitation and Development and the village Community Development Councils that it sponsored.

In the absence of coordination with security forces (or security forces to coordinate with) to keep an area clear of insurgents and protect project villages, there is nevertheless a risk that stabilization activities will do more harm than good if they attract insurgent violence. This risk was mitigated effectively in Khas Kunar District in Kunar Province, where security was seen to improve steadily after the start of $\mathrm{CCl}$ programming because of a mix of factors including negotiation with the Taliban, improved government security, and improved security by Afghan Local Police (KUR-IDI-I3, KUR-IDI-09, KUR-FGD-03). In Panjwai District in Kandahar Province, respondents reported that GIRoA security forces effectively protected $\mathrm{CCl}$ activity sites from insurgent threats. There were no reports of any Taliban activity around $\mathrm{CCl}$ activities in Injil District of Herat Province, close to Herat City.

Local stakeholders in Kajaki also reported that elders had received permission from the local Taliban for certain activities to move forward (KJK-IDI-03, KJK-IDI-07, KJK-IDI-08, KJK-IDI-09, KJK-IDI-I0). Certain karez [underground canal] cleaning projects meant to take place in Taliban-controlled areas of Kajaki apparently did not receive permission from the Taliban and were therefore never implemented. This finding corroborated the findings of the IMU, which were submitted to OTI after the implementing partner had closed its offices in Helmand. Unable to visit the project sites or send local IP staff back to project sites, OTI noted the discrepancies but could not verify activity outputs. The OTI database, however, indicates that these projects ( $\mathrm{KJKOOIO}$ and $\mathrm{KJKOOI2}$ ) have been closed and all grant funds disbursed. One local stakeholder who was employed as a manager of the activities for cleaning the Loy Neche and Kochne Neche karezes reported the following when asked by the focus group moderator whether the projects were completed:

"No, this was not possible, there were Taliban. To do anything there, you had to tell the Taliban. But we could not tell them this... we did not complete our work... Only one or two days for formalities and pictures. In the picture they showed that the project was started. Nothing has been done in the area, and the money has gone to the pockets of some local people in the area." (KJK-FGD-02, Participant 7) 
The finding illustrated by the quotation above demonstrates the risks that surrounded implementing activities in areas where the Taliban have significant influence. There is nevertheless evidence from the MISTI program that shows strong impacts on stability from SIKA and $\mathrm{CCl}$ projects in villages located in areas where Taliban presence was relatively strong. The overall findings from Kajaki are mixed: while $\mathrm{CCl}$ Creative's Community Engagement Manager for Kajaki admitted that only 60 percent of activities were completed (HLM-CR-03), CCl's objectives were substantially achieved according to the beneficiaries of those projects that were completed. This finding suggests that short-term activities have the biggest impacts in areas such as Kajaki that have had the least prior experience with development and service provision from the government.

To what extent, if any, were immediate activity outcomes sustained upon completion of the activities? If so, which types of activities had the most sustainable outcomes and why?

Training activities were a particular source of satisfaction for both men and women and were often cited as having provided lasting benefits in the form of continuing income generation. Water projects and road projects also generated lasting benefits for the local people in the form of increased community resilience.

Most respondents reported that links between GIRoA and their community had increased as a result of $\mathrm{CCl}$ programming. Concerns were expressed that ties with $\mathrm{GIRoA}$ will weaken in the absence of future projects. One local staff member from CCl-IOM criticized the short-term nature of the program from the perspective that the 18 months over which the program operated in his province of Samangan was not enough time to make real changes in the lives of the people. Such critiques were common from local stakeholders and IP staff who understood the purpose of the project in terms of development and were therefore frustrated by the short duration of the program and lack of a follow-on activity.

However, development or sustainable service delivery was never CCl's objective. Rather than development, a change in mentality was the most lasting effect and the most significant change achieved by the project that was most often cited across all of the research subjects. This change in mentality concerned increased cohesion between the people and willingness to work together to achieve common ends. The other major change in mentality surrounded people's understanding of what to expect from the government and how to communicate their needs and expectations to the government.

\section{EQ3: Program Learning}

To what extent was the program able to learn from ongoing analysis to improve project design over time?

The program was able to achieve substantial learning from ongoing analysis that improved the quality of project implementation over time. The establishment of the Independent Monitoring Unit (IMU) in Fall 2013 was a crucial addition to the program because it provided OTI with an independent source of information about activities taking place in the field after the drawdown of U.S. troops and the loss of the information they provided to OTI. The IMU became operational too late in the program to contribute substantially to program learning by $\mathrm{CCl}$ Creative. OTI promoted improvement in the performance of $\mathrm{CCl}-\mathrm{IOM}$ by using the IMU to enforce accountability for poor inputs and outputs. The independent check on program activities from the IMU 
not only gave OTI new capacity to supervise the quality of activities, but also promoted improvement in the M\&E work of CCI-IOM.

The IMU completed M\&E on over 60 percent of activities and provided a report on each activity for which independent monitoring was completed. The IMU's findings were summarized in a spreadsheet tracker, and each activity was scored on a $\mathrm{I}-5$ scale for both the physical quality of the work and the quality of the process used to implement the activity. The IMU's tracker showed a steady increase in the quality of the activities monitored from one year to the next. Activities with end dates in 2013 had an average overall score of 2.95, which increased to 3.15 for activities that ended in 2014 and to 3.72 for activities that ended in 2015 .

When the IMU was first established in 2013, it was used mainly as an independent check for OTI on the other IPs. OTI maintained a strong "firewall" between the IMU and the other IPs to protect the independence of the IMU as it established its operations. Over time OTI changed the way it managed the relationship between the IMU and the IPs. Intensive management was required to foster a productive working relationship between the IMU and the IPs. OTI chaired monthly, then biweekly, then weekly meetings between the IMU and the other IPs to identify differences between M\&E findings on the different sides and to set out next steps for remedying problems that the IMU identified. The practice of undertaking joint site visits emerged through this process as a key method for reconciling conflicting M\&E findings between the IMU and the IPs.

The information shared with $\mathrm{CCl}-\mathrm{Creative}$ and $\mathrm{CCl}-\mathrm{IOM}$ was initially limited to flagging deficiencies in activity outputs and process. The information in the spreadsheet tracker was typically the full extent of the information that $\mathrm{CCl}$-Creative and $\mathrm{CCl}-\mathrm{IOM}$ used from the IMU. CCl-Creative and $\mathrm{CCl}-\mathrm{IOM}$ perceived the IMU as mainly providing an extra layer of monitoring and verification rather than providing evaluation data and analysis that they could use to improve the design of activities at the strategic rather than operational level.

Information generated by the IMU on activity outcomes was not socialized widely within CCI-IOM. CCl-Creative reported that lessons-learned reports from the IMU were relevant but shared too late in the program to be utilized effectively. Both IOM and Creative lacked the staff capacity to utilize detailed analysis in a systematic way for program learning. Understaffing of provincial and district M\&E officers was an internal problem for the IPs, particularly for CCl-IOM, which lacked fulltime local-national M\&E officers dedicated to each district where activities were taking place (KBL-IOM09). Intensive management by OTI was necessary to promote teamwork between the IMU and the other IPs.

Did the impact of the program learning that took place justify the resources invested?

The investment in the IMU was fully justified by the improvement in the quality of activity outputs and processes that took place over time. Even greater gains would undoubtedly have been made if the IMU had been established earlier in the program. Operational lessons learned from the IMU have deeply and directly informed the design of the Mission-wide Monitoring Support Programs that have recently been awarded to provide independent monitoring for all USAID/Afghanistan activities. 
The program also invested significant resources in generating analytical products through the PDU of CCl-Creative that met with less uptake at the Mission beyond OTI. For example, three activities on geospatial analysis of areas where electoral violence was likely to take place were implemented by the U.S. contractor, Digital Globe. These analyses were valuable for the design of $\mathrm{CCl}$ programming to target strategic communications around peaceful elections at specific areas deemed to be at risk of violence. The Mission, however, lacked the capacity to make broader use of the data and analysis that OTI made available. This was an apparent overestimation of the audience for these analytical products at the Mission (WAS-CR-02).

The analytical products generated internally by the IPs were important sources of program learning. These products included the districts' problem sets generated by $\mathrm{CCl}-\mathrm{IOM}$ to identify priorities for activity design and implementation. CCI-USIP's analytical products, and its focus on evaluation over monitoring, were important sources of program learning for its CVE activities. This learning process resulted in the generation of a theory of change for CVE focused on capacity building and community cohesion, and the identification of successful activities and activity processes to be scaled up with additional support from USAID/Afghanistan.

The investment in experimentation with CVE programming by $\mathrm{CCI}$-USIP was justified by the generation of an innovative theory of change and set of lessons learned for effective programming. This process allowed USIP to identify specific initiatives that are now being scaled up with additional support from USAID/Afghanistan.

What concrete factors or processes could the program have developed or improved to promote program learning, with a particular focus on the role of the Independent Monitoring Unit?

The effective implementation of small community grants is a process of learning-by-doing, which was the mainstay for refining program processes, building relationships with local communities, and building local staff capacity. In this way, the IPs were able to incrementally improve the quality of project implementation over time over successive cycles of activity implementation. In the last stage of $\mathrm{CCl}$ after the late-2014 pivot, short program timelines with few activity cycles and organizationally weak CSOs worked against program learning-by-doing by $\mathrm{CCl}-\mathrm{IOM}$ because there was not enough time to incorporate lessons learned and capacity building for CSOs into the next activity cycle. Implementing soft activities with CSOs over a larger number of activity cycles would have promoted more program learning.

Managing the two-way flow of information between the IMU and the other IPs was challenging and required substantial time and effort from OTI. The ability to monitor and verify an activity effectively, and independently of the implementer, requires a detailed understanding of each activity. The IMU was successful because it developed a clear and detailed scope for the monitoring of each and every activity that it visited. Developing a customized monitoring plan for each activity is a highly labor-intensive process because no two activities are the same. Monitors required detailed understanding of activity work plans in all cases, as well as engineering designs and site specifications in the case of construction projects, and curricula, expected attendance, meeting times, etc. in the case of training activities. 
Greater standardization of operating procedures and activity designs-for example, proper construction materials-would have promoted more efficiency for program learning, allowing the IMU to focus more on evaluation than verifying that it was monitoring the correct specifications for each activity. Resolving disagreements between the IPs and the IMU over matters such as the correct construction materials for infrastructure projects took substantial time and effort from OTI.

Program learning would be promoted by using online project management technology to streamline and standardize the process of two-way information sharing between the IMU and the other IPs, and allow a larger volume of information, particularly activity scoping and evaluation information, to be shared more efficiently.

\section{EQ4: Lessons Learned}

What were the key lessons learned from $\mathrm{CCl}$ and how could they be applied to future programming in non-permissive environments? This should include lessons that can be applied to future programming intended to increase community cohesion and resiliency more broadly and may include lessons about activity development and implementation approaches, strategy development and communication, and operational approaches that are best suited for complex programming in restrictive environments.

OTI's one-team approach is intrinsic to its institutional identity and its mode of operation. Non-permissive environments that restrict personal mobility, such as Afghanistan, present particular challenges to teambuilding because opportunities for interpersonal interaction are limited.

Discussion of lessons learned with OTI officials and IP management frequently touched on the importance of cohesion within the team. As such, it is essential for the success of the program to ensure that the members of the team have compatible interpersonal relationships, and management and communication styles and practices, as well as communication skills that are strong enough to succeed at remote management. Problematic interpersonal relationships and unproductive communication were reported from various aspects of $\mathrm{CCl}$, from the relationships between the leadership of OTI and Creative in Kabul to the relationship between OTI Kabul and OTI Washington. Cohesion within the team is doubly important in the context of remote management when there are limited opportunities for working together in the same physical space and forming relationships outside of the workplace. Several key lessons follow from this finding:

- Take a systematic approach to identifying compatibility or lack thereof between members of the team. There are abundant methods and experts from the field of organizational psychology that offer approaches and techniques for teambuilding and for identifying and mitigating incompatibilities between coworkers.

- Organize corporate-style retreats and trainings for program senior management from both the OTI and IP sides to build and deepen the cohesion of the team. Retreats may be linked with SRS events as needed. Increase the frequency of team-building retreats as necessary to overcome the challenges of communication in the context of remote management.

- Increase the frequency of management reviews and move fast to replace people in key positions when it becomes clear that their tenure is creating a drag on program performance. Seriously 
consider whether it would be better to leave the position unfilled or promote someone to act in the role until the right replacement can be found.

- Create a regular schedule for bringing the team together to spend time working together in the same place, not just OTI and the IP senior management, but also the field team if it is distributed geographically across different provincial offices, as in the case of $\mathrm{CCl}$.

- To help avoid miscommunication and excessive formality, communicate via telephone or instant messaging instead of email. Consider appropriate technological solutions for increasing the ease and frequency of real-time communication between members of the team.

Beyond key lessons learned about managing interpersonal relationships, remote management, and teambuilding, this performance evaluation of $\mathrm{CCl}$ generated lessons learned for assuring the quality of programming processes and outputs. $\mathrm{CCl}$ demonstrated the crucial importance of adherence to the OTI mantra that processes are just as important as outputs for achieving program objectives. In order to maintain consistency in the quality of both processes and outputs, OTI should establish standard operating procedures (SOPs) for common types of activity processes where it makes strategic sense. For example, the evaluation found that the quality of outputs was improved by the consistent use of POCs in the implementation of grants. CCl-IOM's incorporation of required meetings and signatures from Project Oversight Committees into grant agreements was an important SOP for community engagement that was effectively built onto IOM's existing SOPs for grant awards and disbursements. The creation of new SOPs for local CSO partners to follow in the implementation of sociocultural events, trainings, and other activities would likely have effected increases in local CSO capacities and improved the quality of outputs.

In a remote management situation such as $\mathrm{CCl}$, marked by a strong reliance on local staff for effective engagement with stakeholders across large areas, greater standardization would promote transparency, quality control, and anti-corruption. Programming should not become mechanical because of the use of SOPs. It is a management challenge to maintain flexibility and promote innovation on top of standardized programming processes. Continuous assessment of activities is necessary to promote program learning through which certain standards may be abandoned or reformed and new ones established. Effective management of programming using SOPs would promote efficiency and free up staff time for innovation on top of standardized models.

Closely related to the challenges of standardization are lessons learned from dealing with the challenges of corruption. Implementing a program in one of the most corrupt countries in the world naturally entailed substantial risk that corruption could compromise the various aspects of the program. Strong measures to mitigate the risk of corruption were important for achieving the successes of the program. Flexibility in the choice of government counterparts is important for avoiding particularly venal officials. Further, the establishment of the IMU was a crucial enhancement of OTI's capabilities for monitoring and verification of activities. An IMU should be part of the initial award of all programs that seek to operate across a wide geography of sites in an insecure environment. The effectiveness of the IMU for providing anti-corruption capabilities is enhanced by strong M\&E and finance capacity on the IP side, generating layers of redundancy that produce resilience to corruption within the program.

Local staff from the provinces and districts in which they worked were crucial for the effectiveness of CCl's programming processes because they enjoyed the advantages of relatively greater freedom of 
movement in insecure areas compared to people from outside the area. Locals also had a deeper understanding of how best to engage with communities and which activities would be most effective for building cohesion and resilience. CCl's IPs, however, relied too heavily on local staff for activity management and verification. The embeddedness of staff in local communities raised the risk profile of the program because of real or perceived conflicts of interests in the distribution of resources to those groups to which local staff had stronger ties. More supervision by expats or highly-qualified local staff with origins outside of the locality is needed to mitigate this risk.

$\mathrm{CCl}-\mathrm{Creative} \mathrm{in} \mathrm{particular} \mathrm{proposed} \mathrm{an} \mathrm{unrealistic} \mathrm{"Afghan} \mathrm{first"} \mathrm{staffing} \mathrm{model} \mathrm{that} \mathrm{lacked} \mathrm{adequate}$ capacity to achieve a quick startup of programming in a way that was congruent with OTl's design. OTl's expectations for the quality of programming, and the research and analysis that should inform the design of activities, were based on experience with the relatively expat-heavy model of ASI-East. The expectations of OTI Kabul were thus not aligned with the capacities of CCl-Creative's staffing model.

Pushing programming into highly insecure areas, such as remote areas of Sangin and Kajaki Districts in Helmand Province, was risky and met with mixed results. Activity sites in such highly insecure areas meant a greater risk of corruption because access was restricted to a small number of staff with strong local ties that offered some security. While external monitors from the IMU were able find ways to access these areas at great risk, the security environment generally precluded systematic monitoring of activity progress by non-members of the local community. Activity outcomes in these areas were indeed weaker than in other areas. SOPs surrounding regular activity verification should be established and adhered to in all activities. If a decision is taken to accept a greater level of risk by, for example, implementing an activity in an area where access is restricted to local community members only, then the risks should be explicitly weighed versus the potential rewards. Close attention should be paid to finding alternative ways of assessing activity outcomes in cases where OTI calculates that the potential rewards of implementation outweigh the risks.

\section{CONCLUSIONS}

The community-based programming that $\mathrm{CCl}$ implemented was generally effective as a bottom-up means of linking rural communities in unstable areas to local government, though GIRoA official corruption limited the extent to which positive outcomes were achieved. Maintaining and expanding linkages between the government and local communities in areas contested by the insurgency reduced the uncertainty that surrounded the transition of security responsibility from international to Afghan forces during the 20I22014 period. $\mathrm{CCl}$ activities were important for allaying fears among local communities that they would be abandoned by GIRoA and left to the mercy of a resurgent Taliban. While there is no counterfactual comparison possible for the events of this period, it is reasonable to suggest that the Taliban and other violent extremist groups would have had more opportunities to gain local support amid the uncertainty of the transition period if not for $\mathrm{CCl}$ programming. The potential for a bottom-up approach to result in durable legitimacy for Afghan government institutions is, however, limited in the absence of top-down reforms from the national government to eliminate corruption and increase the accountability of local officials to the populations they serve.

CCl's key intervention at the national level took place when the second run-off round of voting in the 2014 presidential election descended into allegations of fraud and threats of civil war. CCl's fast 
mobilization of 40 international election audit observers created space for the opposing sides to reach a compromise that averted violence by including both sides in the new government. While the election thus had a peaceful outcome, the power-sharing arrangement between the opposing sides is unconstitutional, and the government that emerged after a long period of negotiation is politically weak and internally divided. The political weakness of the divided government means that there is little likelihood that topdown systemic reform will be undertaken or that it would succeed if attempted. Until systemic top-down reform becomes viable, additional community-driven programming like CCl's will be unlikely to effect a political transition to an end state in which GIRoA legitimacy is consolidated and the insurgency is marginalized.

\section{EQI: Strategy}

The program goal of community resilience was insufficiently defined to be used effectively by IP local staff to engage with community stakeholders. Local staff and stakeholders found it difficult to differentiate between the $\mathrm{CCl}$ resilience objective and the $\mathrm{CCl}$ objective of helping meet basic needs, because increased ability to meet basic needs makes people more resilient to shocks. Resilience was thus not effective as a goal for a program that was designed to support political transition, not meeting basic development needs.

Cohesion worked as a flexible paradigm through which the objectives of the program, and changes to the objectives, were conveyed to local staff and stakeholders. The value of increased community cohesion was universally appreciated and the combination of various types of activities was effective for enhancing cohesion. $\mathrm{CCl}$ was successful where its activities met the objective of generating cohesion within communities, between communities, and between communities and GIRoA, and where community leaders acted independently of the program to convince local Taliban and other armed opposition groups not to oppose the implementation of activities.

The 2013 "reset" of $\mathrm{CCl}$-Creative under new management, and the 2014 pivot, were strategically important for the inclusion of the new peaceful elections and CVE objectives, as well as new activity areas for youth. Programming remained largely oriented towards the objective of connecting communities to GIRoA, mainly through small infrastructure activities-the hallmark of COIN/stabilization. Nevertheless, the inclusion of new activity areas in 2013, such as engaging youth in urban areas and countering election-related violence, was an important departure from the village stabilization model of ASI; these activities served as important examples of how $\mathrm{CCl}$ responded to the changing context of the operational environment in Afghanistan. The 2013 strategy revision prepared $\mathrm{CCl}$ to make a valuable contribution to the 2014 political transition via a peaceful presidential election and, ultimately, a power-sharing agreement between the two presidential frontrunners, Abdullah Abdullah and Ashraf Ghani.

New leadership of the PDU within $\mathrm{CCl}-\mathrm{Creative}$ was instrumental for activity design and implementation towards the peaceful election objective. The PDU injected innovation into the program and upset some of the inertia surrounding the focus on community infrastructure activities. Past experience with elections in Afghanistan showed that there was a real risk of violence surrounding the voting process. $\mathrm{CCl}$-Creative and $\mathrm{CCl}$-USIP occupied an important niche in advocating vigorously for peaceful elections through strategic communications in the Afghan media, which contributed to the high 
level of enthusiasm and large turnout in areas such as Khost, Paktia, and Paktika Provinces, where insecurity kept people away from the polls in past elections.

CCl's support for peaceful elections was an important part of the united front of Afghans and the international community that pulled together to ensure that the elections would result in a new person occupying the office of the presidency in 2014 for the first time since the fall of the Taliban in 200I. Antidemocratic voices were drowned out by pro-democracy communications that generated enthusiasm for a peaceful popular vote. The Taliban had no consistent antidemocratic message against the election that resonated with the population. The insurgency effectively acquiesced to the popularity of the election and mounted no widespread campaign of violence to disrupt voting.

$\mathrm{CCl}$ had recognized in scenario planning that the risk of violence was not limited to voting day. Afghanistan's experience with widespread fraud in the last presidential election, and the lack of adequate reform of Afghanistan's Independent Electoral Commission and the rules governing the election, meant that there was a real risk of fraud that might lead to violence. When the second run-off round of the election descended into accusations of fraud and threats of civil war, $\mathrm{CCl}$-Creative was ready to quickly mobilize international observers of the audit of the vote to support Secretary of State Kerry's call for a power-sharing agreement between the two sides. The mobilization of international observers by $\mathrm{CCl}$ undoubtedly made a crucial contribution to the political transition by creating time and space for the opposing sides to reach an agreement, leading to the formation of the new government.

The 2014 strategic pivot was most valuable for affording CCI-USIP the opportunity to experiment with different approaches to CVE programming. The validity of CCI-USIP's theory of change for CVE, founded on building capacity to generate counter-narratives, was supported by observing which CVE approach yielded the strongest outcomes. The approach to CVE developed by CCI-USIP is an important legacy of OTI in Afghanistan that is being expanded through additional support from USAID.

\section{EQ2: Activity Outcomes}

Strong community-engagement processes were the key to the success of $\mathrm{CCl}$. The use of POCs to monitor activity implementation was an important community-engagement process that drove the success of grant activities. An important aspect of CCl's success was its IPs' ability to pick and choose the government partners with which grants were implemented in the attempt to avoid corruption and obstructionism from particularly venal local officials. In general, the environment of official corruption limited the effectiveness of activities intended to build cohesion between communities and GIRoA.

The most significant change from building linkages between communities and GIRoA was a change in mentality and knowledge towards the proper role of the government. $\mathbf{C C l}$ programming changed the mentality of the people but could not by itself address the corruption that delegitimizes the government and fuels the insurgency. GIRoA official corruption was an external constraint on CCl's performance that could not be systematically addressed through the community-based approach. The extent to which community-based programming contributed to the transition was limited by the absence of a GIRoA program of reform to improve governance from the top down. 
Youth are a key group for quick-impact intervention in Afghanistan. Fostering a spirit of volunteerism within youth and support for youth associations that are still active after the closure of the program is one of the most lasting effects of $\mathrm{CCl}$. Peace poetry competitions and events for youth proved to be popular sociocultural activities, marked by unexpectedly high rates of participation.

All activities that were implemented in conditions of sufficient security and achieved high-quality outputs using strong community-engagement and oversight processes showed positive outcomes for cohesion. Efforts to build cohesion between different groups (or tribes in the case of Terezayi district of Khost province) were the key to CCl's contribution to preventing Taliban control of the district. By acting independently of CCl's implementers to convince local Taliban not to oppose implementation, community elders in contested areas were effective at providing security for activities and connecting their communities more closely with GIRoA.

\section{EQ3: Program Learning}

OTl's exit from Afghanistan left two important legacies at the Mission in the form of lessons learned from the IMU and from CVE programming (KBL-USAID-0I, KBL-USAID-03). The investment in the IMU was justified by the improvement in the quality of $\mathrm{CCl}-\mathrm{IOM}$ activity outputs and processes that took place over time. Procurement delays caused the IMU to come online later than planned. Even greater gains would undoubtedly have been made if the IMU had been established earlier in the program such that it could have contributed more to learning by $\mathrm{CCl}$-Creative.

With no more military bases or USAID field personnel in Afghanistan's provinces to monitor activities, the IMU has provided the Mission with a best practice model of monitoring and verification, which it has used to design and launch the regional Monitoring Support Programs that will provide independent M\&E for all of the activities of USAID/Afghanistan. The IMU model is based on highly detailed scopes of work, strong management of relationships between the M\&E provider and the other IPs, and standardized information-sharing procedures. Effective Mission-wide implementation of the IMU model should lead to improvement of project outputs across the Mission, much like the positive change in the quality of $\mathrm{CCl}$ activities over time.

The successful experimentation with CVE programming conducted by $\mathrm{CCI}-$ USIP is a second important legacy that $\mathrm{CCI}$ left at the USAID/Afghanistan Mission, now that all village-level stabilization projects have closed. Programming according to the theory of change that CCI-USIP developed for CVE and CCI-USIP's most successful CVE initiatives are being scaled up through expanded support from the Mission over five years (KBL-USAID-0I). Beyond the CVE activities implemented by $\mathrm{CCl}$, other kinds of capacity building, and vocational training in particular, had some of the most sustainable effects observed from the data collected for this evaluation. All types of training activities could potentially be vehicles for the development of individual and community capacities to articulate counter-narratives in response to extremist narratives that seek to justify violence. Activities that build capacity for CVE are viable alternatives to stabilization activities and could build on the success of vocational training activities in Helmand Province in Kajaki (despite insecurity) and in Nahr-e-Saraj (despite corruption). Adding a CVE dimension to capacity-building activities implemented with CSO partners is a viable strategy for community cohesion programming in Afghanistan. 
Learning-by-doing requires several iterations of the activity cycle. The late-20I4 strategic pivot to soft activities implemented with CSO partners allowed for too few iterations for CCI-IOM to learn which activities were most effective for achieving CCl's objectives. Additional iterations of soft activities implemented via CSOs would improve activity design and allow for the incorporation of CVE. The best approach in this context is relatively long-term programming from USAID, not short-term programming from USAID/OTI.

Where it made strategic sense, increased standardization of operating procedures and activity designsfor example, specifying acceptable road construction materials-would have promoted more efficiency for information sharing between the IMU and the other IPs and allowed the IMU and other IPs to focus more on outcome assessment and learning.

\section{EQ4: Lessons Learned}

The one-team model with the IPs is intrinsic to OTI's institutional identity and operational culture. The type of remote management necessary in the restricted and conflict-affected environment of Afghanistan presented significant challenges to the one-team model. Lessons learned for remote management of programs in other restricted contexts include the need to take a systematic approach to identify incompatibilities and communication problems within the team. Unity within the team is doubly important for OTl's one-team programming model to be successful in restricted and conflictaffected environments, where there are limited opportunities for working together in the same physical space and for forming relationships outside of the workplace. It is crucial to ensure that the members of the team have management and communication skills, styles, and practices, as well as compatible interpersonal relationships, that are strong enough to succeed at remote management.

Necessary changes at the senior management level of CCl-Creative should have been made earlier to move the program forward more quickly during its first year. Interpersonal problems and communication deficits should have been addressed earlier. A systematic approach and set of tools from organizational psychology are required to identify incompatibilities and communication problems within the team and address them early in a program, especially in remote management contexts. OTI Kabul started the program with expectations for research, analysis, and grant concepts that were effectively beyond the capacity of $\mathrm{CCl}$-Creative to deliver using its Afghan-first staffing model. Adjusting expectations earlier towards realism would have promoted team building.

Where it made strategic sense, greater standardization of programming processes and grant designs would likely have contributed to greater improvement in the quality of project designs, outputs, and outcomes. The best example was CCl-IOM's incorporation of POCs into its grant cycle, which led to increased quality of activity outputs. It is not surprising that activity outcomes were weaker where monitoring and verification of activities were not possible because of insecurity, such as in Taliban-controlled areas of Kajaki District in Helmand Province.

Strict adherence to established SOPs for M\&E and activity verification would clarify decision making around the level of risk that is acceptable for grant awards, because implementation in areas where systematic monitoring is not possible because of insecurity is a clear indicator that the program may be overextending itself. Systematic procedures for assessing risk were necessary to ensure that 
risks and rewards were clearly calculated by the program as it extended programming into areas where insurgent influence was strong. 


\section{RECOMMENDATIONS}

Various recommendations follow from the evaluation of the successes and challenges of implementing a large, complex program with multiple implementing partners spread across a wide geography in an insecure and dynamic environment where the mobility of USG officials is highly restricted. Flexibility in responding to changes in the strategic and operational environment is crucial for promoting the achievement of positive outcomes and impacts. Innovative ways of promoting the effectiveness of OTl's one-team model are necessary to cope with restrictions on mobility and opportunities for co-location of the team. Innovative methods to promote program learning through the use of independent monitoring and intensive analysis are necessary to promote continuous improvement of programming for making a decisive contribution to the success of a transition.

\section{EQI: Strategy}

Program strategists should not use the term resilience in a general sense but should instead be specific about the exigencies against which the program intends to increase resilience. The term should always be used in the context of the (completed) phrase: "Resilience to ." Reference to a specific exigency would better enable assessment of how a specific resiliency might be created or enhanced using available resources.

To gain support from stakeholders, implementers of community-driven programs in conflict environments should convey program objectives in terms of cohesion. Cohesion can be applied to fostering unity and cooperation between all manner of groups and individuals and directed towards a range of goals such as building government legitimacy and peace.

OTI and its IPs should move faster to change IP senior management, and coordinate this change with a strategic review process for clarifying objectives, when it becomes clear that these factors are creating a drag on program performance, as in the first year of $\mathrm{CCl}$.

The USAID/Afghanistan Mission should continue to support the expansion of CVE programming following the theory of change developed by CCI-USIP. CCI-USIP's approach to CVE-building capacity to articulate counter-narratives-is a viable successor to stabilization activities in the current context in which USAID/Afghanistan is focused on long-term development.

\section{EQ2: Activity Outcomes}

To circumvent the constraints on program outcomes created by GIRoA official corruption, USAID/Afghanistan should implement community cohesion programming via support for youth associations and other CSOs. In the current context, the appropriate type of programming to achieve objectives like CCl's is assistance for GIRoA reform, and relatively long-term programming for vocational training and capacity building, especially for youth, implemented through CSO partners, and including a CVE component.

To the extent allowable within the policy constraints set out for engaging with opposing sides in a conflict, project implementers should design activities to create cohesion between the different sides. Cohesion programming should be considered by implementers in conflict-affected contexts as a potentially viable means of local peacebuilding. Project implementers in conflict-affected contexts should design activities to 
generate cohesion between conflicting groups as part of the process of awarding and implementing grants. Rather than a one-sided COIN model of winning hearts and minds through the delivery of government services, the theory of change for such programs should focus on using community-driven processes to generate the cohesion necessary for local conflict resolution. Activities following this design would require the participation of parties to a conflict in consultative and capacity-building processes, leading to gains in cohesion as a precondition for a grant award. Grants would then pay peace dividends to the community during and after implementation.

To provide necessary security for activities while avoiding the need for unsanctioned security guarantees negotiated independently between local community leaders and official enemies, implementers of stabilization programming should not work in contested districts without coordination with security forces.

USAID/Afghanistan should incorporate CVE curricula into vocational training and other capacity-building activities such that trainees learn to articulate narratives around the contribution that their skills will make to the peaceful development of their country, in contrast to the violence advocated by extremists.

\section{EQ3: Program Learning}

OTI should promote program learning by ensuring that there is adequate time after a strategic pivot for the completion of several programming cycles to incorporate the learning from the last cycle into the next cycle.

If the cost is bearable, OTI and other program implementers should make an IMU part of the initial award of all programs that seek to operate across a wide geography of project sites in an insecure environment, using local monitors to access outcomes and results in activity sites where mobility is restricted.

USAID should consider the IMU as a best practice model of independent monitoring and verification worldwide, if the implementation of an IMU is synchronized effectively with the work of the IPs that it is responsible for monitoring. Effective implementation of the IMU model in Afghanistan and other countries should lead to improvement of project outputs across a program portfolio, much like the positive change in the quality of $\mathrm{CCl}-\mathrm{IOM}$ activities over time.

The future implementation of the IMU model by USAID and OTI should promote program learning using technology for knowledge management, such as online project management software, to streamline and standardize the process of two-way information sharing between and IMU, OTI, and other IP(s). Such a system should be used to allow a larger volume of information-particularly information necessary for scoping monitoring visits, and evaluation feedback - to be shared more efficiently. Initial investments in automation should reduce the amount of human effort necessary to manage communication and relationships between the IMU and other IPs.

\section{EQ4: Lessons Learned}

OTI should take a systematic approach to identifying compatibility or lack thereof between members of the team working in restricted environments. There are abundant methods and experts from the field of organizational psychology that offer approaches and techniques for teambuilding and for identifying and mitigating incompatibilities between coworkers. 
OTI should organize corporate-style retreats and trainings for program senior management from both OTI and IPs to build and deepen the cohesion of the team. Retreats may be linked with SRS events as needed. Increase the frequency of team-building retreats as necessary to overcome the challenges of communication in the context of remote management.

OTI and the IPs should create a regular schedule for bringing the team together to spend time working collaboratively in the same place, not just OTI and the IP senior management, but also the field team if it is distributed geographically across different provincial offices, as in the case of $\mathrm{CCl}$.

OTI should increase the frequency of management reviews for programs operating in Afghanistan and similarly restricted contexts. OTI and the IPs should move faster to make changes in senior management when it becomes clear that their tenure is creating a drag on program performance. OTI management should seriously consider whether it would be better to leave the position unfilled or promote someone to act in the role until the right replacement can be found.

To help avoid miscommunication and excessive formality, OTI and its IPs should communicate in real time to the maximum extent possible via telephone or instant messaging instead of email. Consider appropriate technological solutions such as online collaboration software (where Internet bandwidth is sufficient) for increasing the ease and frequency of real-time communication between members of the team. Software services such as Slack run in a web browser and provide easily accessible and reproducible histories of instant messages exchanged between multiple collaborators on a project.

To enjoy the advantages offered by employing staff from local communities but mitigate the risk of real or perceived conflicts of interest, solicitations from OTI should specify more key staff positions for expats or highly qualified local nationals, particularly in M\&E, engineering supervision, and regional and provincial management roles for programs in difficult contexts similar to Afghanistan's. Solicitations should include a set-aside for an M\&E specialist firm to provide IMU capacity.

OTI and USAID should establish systematic procedures for assessing risk to ensure that risks and rewards are clearly calculated and weighed by a program that is extending activities into highly insecure areas. 


\section{ANNEXES}

\section{ANNEX I: EVALUATION STATEMENT OF WORK SECTION C - DESCRIPTION/SPECIFICATIONS/STATEMENT OF WORK}

\section{C.I Purpose and Background}

The objective of this Task Order is to conduct an independent performance evaluation of the USAID/OTI Afghanistan $\mathrm{CCl}$, which began in February 2012 and will end in late 20I5. The primary audiences are USAID/OTI, the USAID Mission in Afghanistan, the U.S. Embassy in Kabul, USAID's Office of Afghanistan and Pakistan Affairs (OAPA), and other local and international stakeholders involved in post_conflict assistance to Afghanistan. Under this Task Order, the contractor shall deploy evaluators to Afghanistan, on two (2) separate occasions, to ascertain additional information about the USAID/OTI

Afghanistan CCl's programmatic and operational approaches in the implementation of the program. Evaluation efforts should include a thorough analysis of USAID/OTI Afghanistan CCl's approach to program_level monitoring and evaluation including a comprehensive review of the program's overall impact and key lessons learned, significant program achievements, challenges encountered, and strategic design approaches used to facilitate program implementation. From this work, and from interviews and research conducted prior to travel to Afghanistan, a final evaluation report and other defined deliverables will be produced and delivered to USAID/OTI. All deliverables for this Task Order shall be provided to USAID/OTI following the deliverable schedule outlined in this document. Deliverable due dates may be adjusted with advanced written approval by the USAID/OTI TOCOR to take into account any changing conditions and circumstances.

USAID's Office of Transition Initiatives (OTI) is implementing the Afghanistan Community Cohesion Initiative $(\mathrm{CCl})$ in support of the U.S. Government's (USG's) strategy to improve stability in strategically selected areas of Afghanistan, laying the foundation for longer_term development. The goal of the USAID/OTI Afghanistan CCl program is to increase community resilience in areas vulnerable to insurgent exploitation. Although the particular objectives of the program have changed over time, the goal of the program has remained relatively constant. Programming towards this goal has been implemented by three partners: Creative Associates, the International Organization for Migration (IOM), and the U.S. Institute of Peace (USIP). An additional partner, Rahman Safi International (RSI) Consulting, provides USAID/OTI with an independent (or third_party) monitoring mechanism that can reach parts of the country that are inaccessible to USG personnel due to insecurity. The USAID/OTI Afghanistan CCl focuses on activities at the community level developed through consultations with a wide range of community voices and interests. Illustrative examples of small grant activities include small_scale infrastructure designed to strengthen community capacities to promote a peaceful transition; strategic communication activities that both draw from and inform socio_political life at the community level; and locally supported livelihood activities that bolster the community consultative process.

\section{C.2 Statement of Work}


The Afghanistan CCl is USAID/OTl's third program in Afghanistan. From 2002 to 2005, the USAID/Afghanistan Transition Initiative (ATI) worked to increase the Afghan government's responsiveness to citizens' needs, to raise citizen awareness of and participation in democratic processes, and to bolster the capacity of the Afghan media. From June of 2009 to June of 2012, USAID/OTI reengaged in Afghanistan with the USAID/Afghanistan Stabilization Initiative (ASI). ASI sought to improve local perceptions of the legitimacy of the Government of the Islamic Republic of Afghanistan (GIRoA); to establish and/or strengthen ties between the GIRoA, informal governance structures, and the local population; and to strengthen community-based resiliencies to mitigate sources of instability. During the final months of the ASI program, a Program Performance Review (PPR) was conducted. As part of that PPR assessment process, an analysis of current and potential USAID/OTI opportunities and programming approaches was undertaken using USAID/OTI's Four Criteria for Engagement. The final analysis recommended and advocated for a follow-on program that could continue to bulwark the USG's strategy in Afghanistan. In response to that recommendation, USAID/OTI designed the Community Cohesion Initiative, which was approved for implementation in February 2012.

Below, USAID/OTI's four criteria for engagement as well as a snapshot of the analysis from the PPR are presented:

I. Is the country important to U.S. national interests? Yes, Afghanistan remained a critical priority country for the United States;

2. Is there a "window of opportunity"? Security gains in the country were slowly transitioning from international to Afghan security forces. As international military forces made a final push in the remaining three years before the 2014 drawdown, the team saw a critical role for ongoing stabilization programming to strengthen opportunities for formal governance processes to operate;

3. Can USAID/OTI's involvement significantly increase the chances of a successful transition? Although the USAID Afghanistan Mission had other stabilization programs, USAID/OTI's "emphasis on locallytargeted, process-oriented grants and an ability to work in post-cleared areas" would remain an important part of the strategy. In cooperation with the Mission's Stability in Key Areas (SIKA) program, USAID/OTI's "stabilization efforts should set the stage for longer-term development programs as areas transition to full GIRoA control."

4. Is the operating environment sufficiently stable? Despite the instability, the operating environment in Afghanistan was sufficiently stable to continue programming even in insecure districts.

As noted above, the objective of this Task Order is to conduct an independent program performance evaluation of the USAIDIOTI Afghanistan CCI which was implemented from February 2012 to late 2015.

Initially, Creative Associates International was the sole implementing partner for the USAID/OTI CCI program. In February 2012, they were awarded a Task Order, under the SWIFT III indefinite quantity contract (IQC), to implement a three-year program in the eastern and southern regions of Afghanistan. In September 2013, the U.S. Institute of Peace (USIP), the International Organization for Migration (IOM), and Rahman Safi International Consulting (RSI) were incorporated into USAID/OTI's CCl programming platform. USIP was awarded a two-year agreement to support the 2014 Presidential elections and initiatives that counter violent extremism. IOM was awarded a two-year award to implement program activities in the northern and western regions of Afghanistan. And, RSI was awarded a two-year contract 
to provide independent monitoring services for USAID/OTI activities until the end of the program. To date, over I,000 activities, totaling approximately $\$ 40,000,000$, have been initiated. Grantees have predominantly consisted of local government entities and line ministries as well as local community groups, associations, and civil society organizations. The Creative Associates International component of USAID/OTI CCI ended in February 2015 while USIP, IOM, and RSI are scheduled to close out program implementation activities in late 2015.

\begin{tabular}{|c|c|c|c|c|}
\hline $\begin{array}{l}\text { Implementing } \\
\text { Partner }\end{array}$ & $\begin{array}{l}\text { Type of } \\
\text { Award }\end{array}$ & $\begin{array}{l}\text { Award } \\
\text { Ceiling } \\
\text { Amount }\end{array}$ & $\begin{array}{l}\text { Current Period } \\
\text { of Performance }\end{array}$ & CCl Program Focus \\
\hline $\begin{array}{l}\text { Creative } \\
\text { Associates } \\
\text { International }\end{array}$ & $\begin{array}{l}\text { SWIFT III } \\
\text { IQC Task } \\
\text { Order }\end{array}$ & $\begin{array}{l}\$ 161.5 \\
\text { Million }\end{array}$ & $\begin{array}{c}\text { February 2012- } \\
\text { February } 2015\end{array}$ & $\begin{array}{l}\text { To strengthen resilience of } \\
\text { Afghan communities in the Eastern } \\
\text { and Southern Region of Afghanistan }\end{array}$ \\
\hline IOM & PIO award & $\$ 36$ Million & $\begin{array}{l}\text { September 2013- } \\
\text { September } 2015\end{array}$ & $\begin{array}{l}\text { To strengthen resilience of } \\
\text { Afghan communities in the } \\
\text { Northern and Western } \\
\text { Regions of Afghanistan }\end{array}$ \\
\hline RSI & Contract & $\$ 4.8$ Million & $\begin{array}{l}\text { August 2013- } \\
\text { October } 2015\end{array}$ & Independent Monitoring Unit \\
\hline USIP & $\begin{array}{l}\text { Interagency } \\
\text { Agreement }\end{array}$ & $\$ 7.5$ Million & $\begin{array}{l}\text { September 2013- } \\
\text { September 2015 }\end{array}$ & Elections and CVE \\
\hline
\end{tabular}

\section{A. Program Description and Theory}

When USAID/OTI initially launched the Afghanistan $\mathrm{CCl}$, the programmatic focus was on the following two objectives:

I. To strengthen ties between local actors, customary governance structures, and GIRoA; and

2. To increase cohesion among and between communities.

As the follow-on to ASI, USAID/OTI's Afghanistan CCI was one of three principal stabilization programs in the USAID/Afghanistan Stabilization Unit portfolio. During the first year and a half, the program was designed to respond to the demands of various stakeholders including the North Atlantic Treaty Organization (NATO) forces, the regional US Government platforms, and the GIRoA. The USAID/OTI Afghanistan $\mathrm{CCl}$ strategically supported international efforts to target key phases along the stability continuum of clear, build, hold and transition.

This initial iteration of the USAID/OTI Afghanistan $\mathrm{CCl}$ was grounded in the principle that durable stability is the result of local will, community empowerment, local initiative, and local leadership. The USAID/OTI Afghanistan CCl's overarching theory of change purported that community cohesion is strengthened by implementing clusters of small grant activities aimed at bringing community members together with each other and their government. These activities were designed to improve communities' ability to resolve issues, determine and pursue common goals, and communicate effectively within the community and with various government entities. Furthermore, the USAID/OTI Afghanistan CCI maintained that the project 
processes were as important as the project outputs in contributing to the program's overall strategic goal of stabilization.

In August 2013, the Creative Associates International component of the USAID/OTI Afghanistan CCI refined its program objectives due to significant changes in the operating environment and a recognized need to shift the program's strategy. As part of this strategic shift, USAID/OTI incorporated the three new implementing partners into the USAID/OTI Afghanistan $\mathrm{CCl}$ programming platform. This enabled USAID/OTI to expand its geographic reach beyond the eastern and southern regions of Afghanistan and to incorporate strategically targeted regions in the northern and western regions of Afghanistan. It also enabled the USAID/OTI Afghanistan CCl programming platform to embrace new thematic areas including support to the 2014 presidential elections and support to initiatives that counter violent extremism (CVE).

For the Creative Associates International team, this meant a strategic realignment of the program's goal, objectives, and sub-objectives. This learning opportunity allowed the program team to further redefine and articulate a revised analysis of the political context and to integrate lessons learned through programming initiatives implemented up to that point in time. The USAID/OTI Afghanistan CCI Creative team adjusted the goal, objectives, and sub-objectives to better reflect the program's overall strategic intent. The newly articulated goal, objectives, and sub-objectives were defined as follows:

USAID/OTI Afghanistan CCI Program Goal23 (February 2012-December 2014): To strengthen the resilience of Afghan communities

Objective I: To strengthen community capacities to promote peaceful transition:

I.I: To demonstrate the value of inclusion, peaceful co-existence and/or collaboration between different communities or groups;

I.2: To support the legitimacy of the local government and/or community leaders;

I.3: To strengthen communities' desire and ability to resolve disputes peacefully;

I.4: To build community capacity to engage in civic advocacy in pursuit of greater transparency and accountability; and

I.5: To establish local relationships and/or situational awareness to enable further program engagement.

Objective 2: To support peaceful electoral processes and outcomes:

2.I: To support community-driven efforts to prevent or mitigate electoral conflict or violence;

2.2: To enable community-level stakeholders to identify, report, and manage electoral conflict or violence; and

\footnotetext{
${ }^{23}$ The USAID/OTI Afghanistan CCI's working definition of "resilience" is "the capabilities of groups or communities to cope with internal or external stresses and disturbances as a result of social, political and environmental change." Thus, the USAID/OTI Afghanistan CCI's objectives are meant to address the "capabilities" to promote resilience.
} 
2.3: To enable community-level stakeholders to identify, report, and manage electoral conflict or violence.

Objective 3: To counter violent threats to a peaceful transition:

3.I: To increase educational opportunities;

3.2: $\quad$ To increase opportunities for licit employment and income generation;

3.3: To increase opportunities that build a sense of belonging and self-esteem based on non-violent characteristics;

3.4: To increase the exposure of individuals and institutions which reject violence as an acceptable way of achieving goals;

3.5: To foster tolerance and trust among different identity groups.

In December 20I4, the USAID/OTI Afghanistan CCl program management team recognized the need to further reassess and define the programming goal, objectives and sub-objectives for the IOM and USIP components of the USAID/OTI Afghanistan CCl programming platform in Afghanistan. The revised objectives were determined after a thorough review of the political and security landscape in Afghanistan, an analysis of USG political imperatives in Afghanistan, and a series of consultations with IOM and USIP. This process helped to not only revise the goal, objective and sub-objectives but it helped the USAID/OTI Afghanistan $\mathrm{CCl}$ team to develop a strategic framework and methodology for developing and designing activities. The newly articulated goal, objectives, and sub-objectives were defined as follows:

USAID/OTI Afghanistan CCI Program Goal (December 20I4-Present): Resilient Afghan communities that support legitimate governance processes.

\section{Objectives:}

I: To increase cohesion within and between communities.

2: To support peaceful and legitimate governance processes and outcomes.

3: To counter violent extremism.

Sub-Objective I: To strengthen community capacities to mitigate conflict.

Sub-Objective 2: To increase citizens' trust and confidence in their government.

Sub-Objective 3: $\quad$ To strengthen the capacity of legitimate community groups and organizations.

Sub-Objective 4: To increase positive engagement of youth in their communities.

Sub-Objective 5: $\quad$ To support voices which promote moderation, tolerance, and peace.

\section{Evaluation}

\section{a. Evaluation Questions}


The evaluation lines of inquiry should maximize learning opportunities for the audiences described above through the review of the program's strategy, approaches, and practices, as well as provide an assessment of the program's overall contributions and key lessons learned. The evaluation plan and methodology should be designed to:

I. Document the relevancy and contributions of USAID/OTI's Afghanistan CCI to U.S. foreign policy priorities and shifting dynamics, including but not limited to:

a. Improving local government responsiveness to community priorities;

b. Improving community resiliency and capability to withstand instability and insecurity;

c. Increasing interaction between communities and district government officials;

d. Creating space for community engagement and community advocacy;

e. Strengthening community capacities to manage conflicts and counter violence in their communities; and

f. Supporting peaceful, transparent, and credible elections;

2. Identify the extent to which the program achieved intended and unintended results; and

3. Identify best practices and approaches from the USAID/OTI Afghanistan $\mathrm{CCl}$ relevant to the USAID Mission in Afghanistan, other stakeholders, and other USAID/OTI programs.

More specifically, the evaluation team will answer the four key questions noted below. Please note that the level of effort (LOE) presented here is only to illustrate USAID/OTI's intended focus. The contractor should follow the LOE requirements described in the timeline for purposes of a work plan.

I. Did the program respond appropriately to Afghanistan's evolving transition needs and did the program achieve or meaningfully contribute to the stated objectives? (20\% of LOE)

To answer this question, the contractor should consider whether USAID/OTI's areas of programmatic and geographic focus were appropriate given the political realities in Afghanistan and USAID/OTI's role within the USAID Mission and U.S. Embassy Kabul; whether

USAID/OTI appropriately adapted its strategy to account for shifting political realities and windows of opportunity during the life of the program; and the extent to which appropriate gender considerations were incorporated into the USAID/OTI Afghanistan CCl's strategy and implementation.

Additionally, the contractor should consider the following: the extent to which USAID/OTI's Afghanistan $\mathrm{CCl}$ increased community cohesion and resiliency and how activity outcomes contributed to program impact; the extent to which the program teams understood the program's objectives; and the extent to which program staff genuinely utilized the objectives in the design of activities.

2. To what extent did the process of developing and implementing USAID/OTI Afghanistan CCl's activities strengthen resilience of Afghan communities and bolster capacities to promote a peaceful transition? ( $30 \%$ of LOE) 
To answer this question, the contractor should consider the extent to which project oversight committees (Shuras) and other processes put in place to facilitate the implementation of small grant activities contributed to promoting resilience within the community. Did OTI's emphasis on locally-targeted, process-oriented grants and an ability to work in post-cleared areas strengthen communities' ability to resolve issues?

3. To what extent was the program able to learn from ongoing analysis to improve project design over time including how the USAID/OTI Afghanistan CCl implemented the program? $(20 \%$ of LOE)

To answer this question, the contractor should consider that the program invested significant resources to support the design and creation of analytical products and technical advisors meant to better inform and strategically guide programming. How effective was this investment in integrating ongoing analysis to improve project design over time?

4. What were key lessons learned from the USAID/OTI Afghanistan $\mathrm{CCl}$ and how could they be applied to future programming in Afghanistan (i.e., lessons for the USAID Mission) or elsewhere? (30\% of LOE)

To answer this question, the contractor should consider lessons that can be applied to future programming intended to increase community cohesion and resiliency more broadly, and the extent to which USAID/OTI's approach to monitoring and evaluation was helpful in documenting program impact and feeding into program design.

\section{b. Evaluation Methodology}

Drawing on the contractor's technical, country/regional, and thematic experience, the contractor shall propose and justify an evaluation methodology best suited to the country context, the nature of the program, and the evaluation questions. The contractor should also describe how they plan to overcome any shortcomings inherent in the proposed methods.

The evaluation team, upon award, will develop criteria to systematically test and review lines of inquiry, indicators and/or standards of achievement for all evaluation questions. USAID/OTI shall concur with the final list of evaluation questions as these are the measures of success or benchmarks against which the final evaluation team will compare the data they collect throughout the evaluation.

Given the nature of USAID/OTI programming, it is expected that the evaluation plan will utilize primarily qualitative research methods, including but not limited to a desk review of program literature and reporting, internal evaluations, staff and beneficiary interviews, and focus groups. Additional quantitative methods (such as surveys) can be proposed as part of the evaluation plan to enrich the qualitative findings. The evaluation team will also integrate data and analysis from all USAID/OTI Afghanistan CCI studies and analysis that USAID/OTI has commissioned throughout the life of the program (copies will be given to the team), including all Strategy Review Sessions (SRSs), PPR documents, Rolling Assessment (RA) documents, the USAID/OTI Afghanistan CCl Cluster Evaluations, and other assessments/evaluation tools.

\section{c. Evaluation Plan}

The contractor shall propose a detailed evaluation plan to gauge the relevance, effectiveness, and impact of USAID/OTI's Afghanistan CCl. The evaluation plan must include the following: an evaluation planning 
matrix, a description of methods as described previously, tasks, a timeline, and the responsible team member(s). The evaluation planning matrix will outline the indicators or standards of achievement against which questions are assessed and detail the means of verification and sources of data. In answering the evaluation questions, the contractor shall utilize data that is disaggregated and analyzed by sex, whenever such data is available, and by other factors such as age group, rural/urban, and region, when possible and relevant. A detailed draft timeframe of the process must be included in the evaluation plan and will be finalized, in close coordination with USAID/OTI, upon award.

At a minimum, the Evaluation Plan should include a combination of the following:

\section{Interviews with Key Informants and Stakeholders}

- Pre-Deployment Visit to Washington, DC: The evaluation team will travel to Washington, DC to meet with USAID/OTI Washington, D.C.-based staff. This visit will serve to better orient the evaluation team as well as will help the evaluation team to ascertain additional information about the various components of the USAID/OTI Afghanistan CCI, USAID/OTI contractual mechanisms, and USAID/OTI Afghanistan CCl's operational context in Afghanistan.

- The evaluation team will meet with current and, when possible and at the direction of USAID/OTI, previous USAID/OTI and implementing partner staff. Interviews should also be conducted, when possible and at the direction of USAID/OTI, with relevant USAID and U.S. Embassy leadership, and a select group of awardee leadership from NGOs and CSOs. The evaluation team should seek to interview as many awardees as possible, all USAID/OTI local program staff, at least five (5) people each from the USAID Mission and U.S Embassy, all expatriate USAID/OTI and IOM, USIP and RSI staff, and the former USAID/OTI Country Representative and Deputies (if available).

- The team should also interview select USAID/OTI staff with significant USAID/OTI Afghanistan $\mathrm{CCl}$ and Afghanistan experience. Interviews should be conducted with other analysts and stakeholders as determined between the contractor and USAID/OTI to gain a broader understanding of the contextual environment in which the USAID/OTI program was operating.

\section{Review and Analysis of Existing Documentation}

- USAID/OTI's program performance management system includes periodic SRSs and rolling assessments where the USAID/OTI team analyzes the current operating environment and determines if programmatic focus is properly targeted and changes course if it is not. Annual PPRs are conducted by USAID/OTI staff not connected to the Afghanistan program to offer independent analysis of the status of the program. The Evaluation Team will review SRS and rolling assessment summaries (and detailed notes when necessary), all PPR reports, in addition to quarterly and annual reports, and M\&E products produced by USAID/OTI and by external consultants, such as the USAID/OTI Afghanistan $\mathrm{CCl}$ cluster evaluations.

- USAID/OTI also maintains an activity database that documents the programmatic assumptions, background, justification, and internal evaluations of every activity that USAID/OTI has supported during the life of the USAID/OTI Afghanistan $\mathrm{CCl}$. The activity database also contains information on the program's six clusters. The evaluation team will have access to USAID/OTI's Activity Database, which will allow the team to review data related to individual activities as well as search and run reports. 
- The team should utilize data and information from the Measuring Impacts of Stabilization Initiatives (MISTI), a third-party monitoring and evaluation (M\&E) program that provides independent monitoring and evaluation and impact assessments of USAID stabilization programs, including the USAID/OTI Afghanistan CCl.

- USAID/OTI is supporting a limited number of external research initiatives in connection with the USAID/OTI Afghanistan CCl. The evaluation team shall review the information provided through the research initiatives. Moreover, the evaluation team should be prepared to weave the provided analysis, as well as its own analysis of the data, into its final report.

- In coordination with USAID/OTI, the evaluation team should obtain access to the data and reports generated by RSI.

- Because Creative Associates will have exited country by the time of the award of this Task Order, the evaluation team must pay particular attention to incorporating previous data collection from USAID/OTI reports documenting the Creative Associates' contribution to the USAID/OTI Afghanistan $\mathrm{CCl}$. Where appropriate, and if directed by USAID/OTI, the evaluation team may supplement desk reviews with interviews from former Creative Associates USAID/OTI CCI employees.

\section{Field Work and Data Collection Processes}

As part of the field work and data collection process, the evaluation team must travel to Afghanistan on two (2) separate occasions.

- Trip \#I: The initial data collection trip will acquaint the evaluation team with team members working to implement the USAID/OTI $\mathrm{CCl}$ in Afghanistan, will help to facilitate initial introductions with key stakeholders, grantees, and other key actors who will be interviewed as a part of the evaluation process, and will allow time for the evaluation team to conduct site visits to select USAID/OTI CCI program implementation sites. Site visits should include interviews with beneficiaries, partners, other stakeholders, and/or focus groups as available and where appropriate. Specific visits and availability will depend on the timing of the field work and on security. The initial trip is currently envisioned for July or August 2015, though these dates are subject to change.

- The exact dates, timeline, and schedule of work to be executed must be approved by USAID/OTI prior to purchasing airline tickets for members of the evaluation team. USAID/OTI anticipates that the initial visit will last approximately ten (I0) working days in country.

- Trip \#2: USAID/OTI anticipates that a longer more expansive field work and data collection trip will take place in September or October 2015, though these dates are subject to change. As part of this field work and data collection trip, the evaluation team must visit partner events, trainings, and/or community centers as available during the field visit period, with a fair distribution across types of activities, regions, and objectives. Specific visits and availability will depend on the timing of the field work. USAID/OTI will work with the evaluation team to compile a list of possible site visits that reflects the diversity of its work, from which the evaluation team will select. Site visits should include interviews with beneficiaries, partners, and other stakeholders, and focus groups where appropriate. 
- The exact dates, timeline, and schedule of work to be executed must be approved by USAID/OTI prior to purchasing airline tickets for members of the evaluation team. USAID/OTI anticipates that Trip \#2 will last approximately twenty-four (24) working days in country.

○ Non-Permissive Implementation Regions: The Offeror shall propose how to best utilize the services of local research and analysis firms to execute data collection and analysis in harder to reach and non-permissive regions of program implementation.

- Geographic Component: Where appropriate, the report should incorporate maps. USAID/OTI's Data Analysis team is available to devote a reasonable amount of time, subject to concurrence of the USAID/OTI Task Order Contracting Officer's Representative (TOCOR), to generate a series of maps using data provided by the evaluation team. The evaluation team should share its information, including the raw data, with the USAID/OTI Data Analysis team via the USAID/OTI TOCOR. Where applicable, information gathered by the evaluation team should be coded, using the geographic codes used in the USAID/OTI database, at the village level, to coincide with the language and spelling in USAID/OTI's Activity Database.

\section{d. Evaluation Team Composition}

The contractor is required to field the following positions and/or their own proposed configuration, within the specified timeframe, to ensure the successful implementation of all evaluation activities outlined in the Scope of Work (SOW). The contractor is strongly encouraged to suggest its own evaluation team configuration that meets its preferred technical approach.

At a minimum, the contractor must propose an evaluation team that meets the following criteria:

- Candidates for the senior and mid-level positions shall possess fluent written and spoken English to prepare the written evaluation and to present findings at various briefings. At least one (I) team member must be a Host Country National (HCN).

- The team members' collective experience should be complementary in technical evaluation practices and application, transition programming experience, and country and/or regional experience.

- The contractor must provide a description of how each member contributes to meeting the needs of the evaluation team as a whole.

- USAID/OTI requires that the same team be available for all field trips; although dates can be adjusted per the proposed team's availability, the field visits are currently envisioned for July or August 2015 and September or October 2015. Any adjustments to dates must be approved by USAID/OTI and require advanced written approval by the USAID/OTI TOCOR.

- The HCN team member(s) need not travel to Washington, D.C. for the pre-deployment visit and/or presentation of findings to USAID/OTI.

- A signed commitment letter shall be provided for each of the two (2) proposed key personnel candidates indicating:

- Availability to serve in the stated position; 
- The date or number of days from award of the Task Order the candidate will begin serving in the position;

$\bigcirc$ The intended term of service; and

- Agreement to the compensation levels as set forth in the cost proposal.

- The Project Manager must be available to start work within ten (10) days of the contract start date, and the other key personnel must be available in accordance with the timeline set forth in the proposal.

Below, please find an illustrative team structure that incorporates the required two (2) key personnel and illustrative non-key personnel:

\section{Key Personnel:}

- One (I) Senior-level Evaluation Expert: The Senior-Level Evaluation Expert will play a lead role in the technical design and execution of the evaluation. The proposed candidate must have a minimum of eight (8) years of experience in the management of monitoring and evaluation programs including the input into strategic planning, especially for conflict-sensitive, governance, and transitional programming. The Senior-Level Evaluation Expert should possess extensive experience evaluating stabilization programs in transitional environments including the use of conflict mapping and/or other qualitative, open-ended tools to assess the context of social conflict and relate it to program interventions. The Senior-Level Evaluation Expert should have experience working in areas where access is difficult. Experience in the cooperating country or region is preferred. The successful candidate must be fluent in English.

- One (1) Mid-level Project Manager: The Mid-Level Project Manager is responsible for the overall execution and completion of the Task Order SOW. The proposed Mid-Level Project Manager is responsible for the submission of all deliverables, for maintaining regular communications with USAID/OTI, for identifying potential problems and possible solutions, for creating financial reports, and any other services deemed necessary for the successful implementation of the Task Order SOW. At a minimum this position should be filled by someone with a minimum of five (5) years of professional experience in a related field. The successful candidate must be fluent in English.

\section{Non-Key Personnel:}

The contractor may propose additional and/or alternative positions as appropriate for the execution of the Task Order Statement of Work. The contractor shall identify one (I) illustrative candidate to fulfill each of the non-key personnel positions below:

- Two (2) Field Worker/Evaluation Analysts: The two (2) Field Worker/Evaluation Analysts must have a minimum of five (5) years of related experience in the design, implementation and supervision of field monitoring and evaluation plans, or field-based research in transitional environments. Experience working with small grants programs in the cooperating country is preferred. This evaluation will rely heavily on qualitative data, and the field worker/evaluation analysts must be experienced in analyzing, aggregating, and presenting qualitative data. The 
evaluation team will be expected to analyze and incorporate data from past quantitative analysis. Accordingly, at least one of the field worker/evaluation analysts should demonstrate a capacity to analyze data sets, evaluate survey methodology, and clearly articulate results from quantitative surveys. The successful candidates must be fluent in English, and it is required that at least one (I) of the candidates is proficient in Dari.

- One (1) Data Analyst: Familiarity or experience with data collection and accurate data entry using intermediate computer skills is required. The incumbent will be responsible for compiling data, entering data electronically, assisting the team in generating information products, providing any logistical support in country and other duties as assigned. Fluency in English is required.

Résumés of illustrative candidates for these non-key personnel positions shall be submitted; however commitment letters shall not be signed with the non-key personnel candidates and no promise of employment shall be given.

In addition to the evaluators engaged by the Offeror, a USAID/OTI staff member may participate in the evaluation as a fully vested team member. USAID/OTI will arrange and fund international travel, per diem, secure lodging, in-country air travel, and any visa for the USAID/OTI member of the evaluation team.

\section{e. Evaluation Timeline}

Below, is an illustrative Evaluation Timeline. The Contractor shall describe in a clear, concise manner the management processes, staffing structure, and timeline that will convincingly demonstrate how the Offeror will effectively implement the requirements of the Task Order. The final Evaluation Timeline shall be finalized in consultation with USAID/OTI and the evaluation team.

Clearly state all assumptions. At a minimum, the contractor's approach to and/or understanding of the evaluation time line must consider the following:

Phase I: Planning

- Onboard members of the Evaluation team

- Consultations with USAID/OTI

- Document analysis/background reading of materials provided by USAID/OTI

- Submission of the draft evaluation planning matrix, tasks, timeline, and the responsible team member(s)

- Submission of fully developed methodological framework

- Incorporation of USAID/OTI feedback into the draft evaluation planning matrix, tasks list, timeline, and methodological framework

Phase 2: Research and Field Work

- Design data collection instruments

- In cooperation with USAID/OTI, develop a list of possible site visits that reflects the diversity of its work, from which the evaluation team will select 
- Draft scope of work documents for each of the two site visits

- Conduct field work and data collection processes (two visits to Afghanistan)

- Incorporation of USAID/OTI feedback into the data collection instruments

- Presentation of interim findings to USAID/OTI, select USAID Kabul staff, and the USAID Mission

Phase 3: Analysis and Reporting

- Analysis of fieldwork data

- Submission of draft report to USAID/OTI and IPs

- Incorporation of feedback from USAID/OTI, IPs, and/or other stakeholders and resubmission to USAID/OTI for concurrence

Phase 4: Submission and Presentation of Findings

- Submission of final report and raw data

- Submission of final PowerPoint presentation

- A minimum of three presentations in Washington, DC delivered by the Team Leader and/or Project Manager to USAID/OTI Senior Leadership, the USAID/OTI Afghanistan team, IP staff, and other relevant USG personnel. Presentations to other, non-US government audiences as appropriate (think tanks, Afghanistan audiences, etc.) as identified by USAID/OTI.

- Publishing, online posting, and other report distribution processes must be approved by the USAID/OTI TOCOR in advance.

- The final report must be submitted to the USAID Development Clearinghouse (DEC).

\section{Logistics and Security}

The contractor is responsible for securing all logistics and arrangements for the evaluation team (excluding any USAID/OTI personnel). This includes security. The contractor should take into account the current security context in Afghanistan and shall provide arrangements to support necessary security measures for staff while in Afghanistan. Moreover, the contractor will be responsible for the following:

- The Project Manager is responsible for all scheduling components including arranging meeting locations and confirming times/dates/locations with the team and interviewees.

- The USAID/OTI Afghanistan CCI IOM team will make available a conference room in its Kabul office; however, meetings offsite are sometimes preferable and the evaluation team will be responsible for securing meeting space for such occasions.

- USAID/OTI will facilitate access into the US Embassy as well as will help to facilitate meetings times and locations with select US Embassy and USAID staff members.

- The Contractor shall arrange and purchase airfare for all international and U.S. travel. 
- The contractor shall provide per diem (lodging and M\&IE) for the evaluation team in both the U.S. and in Afghanistan, and shall procure and fund in-country air travel and ground transportation.

- The contractor will submit security and logistics plans, to the USAID/OTI Country Representative, via the USAID/OTI TOCOR in Washington, D.C. as requested. The contractor will be responsible for securing relevant visas and other travel documents.

\section{E. Deliverables}

All deliverables will require USAID/OTI concurrence prior to their finalization. If the contractor believes that the deadlines specified below should be altered, this should be noted in their proposal. Deliverable due dates may be adjusted with advanced written approval by the USAID/OTI TOCOR to take into account any changing conditions and circumstances.

I. An updated evaluation plan including revised information on scheduling, interviewees, and focus is due to USAID/OTI at least two (2) weeks prior to any trips to Washington, D.C. or Afghanistan.

2. An evaluation plan based on the guidelines provided in this document, including the data collection methods. The plan will also include a draft schedule and potential interviewee list for field visits. The first draft will be due to USAID/OTI for review and comment within approximately one (I) month of the contract award.

3. A draft trip report based on the first field visit will be due to USAID/OTI within two (2) weeks of the team's return from Afghanistan.

4. While in Afghanistan, hold weekly meetings to brief USAID/OTI on the evaluation team's progress.

5. A briefing to staff in Afghanistan, including USAID/OTI staff, USAID/OTI CCI staff, and interested personnel from the U.S Embassy. To be scheduled during the second field trip.

6. A draft evaluation report. The draft evaluation report should include findings, conclusions, recommendations, and key lessons learned from the program. USAID/OTI will provide feedback on this report to the evaluation team and coordinate feedback from the IPs and other stakeholders. Due within two (2) weeks of the second (final) field visit.

7. A second draft evaluation report, incorporating (as appropriate) feedback from USAID/OTI on the first draft report. Due within two (2) weeks of receiving USAID/OTI's feedback.

8. A final evaluation report of no more than 30 pages, excluding annexes but including findings, conclusions, and recommendations for USAID/OTI programming more broadly. The report is due within two (2) weeks of receiving USAID/OTI's final feedback.

9. A final Power Point presentation summarizing key findings, conclusions and recommendations, to be presented by the Senior-level Evaluation Expert in Washington, 
DC and a second team member to USAID/OTI Senior Leadership and relevant USAID/OTI Afghanistan staff, as well as key IP staff. Additionally the evaluation team should prepare a more broad presentation for other USAID/OTI staff. To be scheduled as the report is being finalized, but no later than one (I) month after the second field trip.

10. A presentation to USAID/OTI, IOM, USIP and Creative Associates International, and other USG personnel in Washington, D.C. To be scheduled as report is being finalized, but no later than one (I) month after the second field trip.

I I. Branding Implementation Plan and Marking Plan. See Section F below.

\section{a. Report Content}

The draft and final evaluation reports should adhere to USAID guidelines and be structured as follows:

- Cover Page and Photo

- List of Acronyms

- Table of Contents

- Executive Summary: up to five (5) pages. The summary should be a clear and concise standalone document that gives readers the essential contents of the evaluation report, previewing the main points in order to enable readers to build a mental framework for organizing and understanding the detailed information within the report.

- Program context: Briefly discuss the country situation, what the USAID/OTI Afghanistan CCI set out to do, and other essential background information.

- Methodology: Discuss the data collection methods used including strengths and weaknesses, the sampling methods, potential biases and how they were addressed, inclusion of stakeholders and staff, rough schedule of activities, description of any statistical analyses undertaken. The section should also address constraints and weaknesses of the evaluation process. In accordance with ADS 203, the report should also state why a performance evaluation was conducted in lieu of an impact evaluation.

- Limitations: Spell out what can and cannot be concluded from the evaluation. All actual or potential conflicts of interests among members of the evaluation team should be noted in this section.

- Findings: The evaluation team should determine how to best organize the results based on the evaluation questions. The findings should include both data and data analysis, and should be directly based on the data gathered.

- Conclusions/Recommendations/Lessons Learned: Map how findings link to conclusions and then to recommendations. This is also the space for the evaluation team to think about the data and results, and make concrete recommendations for future project improvements/ changes, pulling out organization lessons learned, and commenting on the data and results. Everything presented in this section must be directly linked back to the information presented in the Findings section of the report. There should not be any conclusions that do not link to findings, or any recommendations that don't link to conclusions. 
- Annexes: Annexes should include maps, data collection instruments in English and translation, list of stakeholders interviewed (including number and type of interactions), the SOW, qualitative protocols developed and used, any data sets that can be provided in the electronic format, and any required photos, participant profiles, or special documentation needed.

\section{END OF SECTION C}




\section{ANNEX II: EVALUATION METHODS AND LIMITATIONS}

\section{A. Description of Focus Districts where Evaluation Fieldwork was Implemented}

Adraskan District (Herat Province): This rural district has been largely cut off from government and international support but the local government has been quite cooperative and supportive of $\mathrm{CCl}$. IOM implemented both infrastructure activities as well as social-cultural activities particularly targeting youth. In contrast to several other districts, Adraskan is thus a district in which programming took place in an environment of political support and space for innovative soft activities with youth.

Injil District (Herat Province): This district provides an interesting comparison to Adraskan and has interesting political and social dynamics, with a large Pashtun internally displaced population and a relatively educated urban population. Local government officials were, at best, neutral in their support of the program and at worst predatory. OTI's programming in Injil in the last nine months of the program targeted the more urban, educated yet politically and socially marginalized youth population.

Hazrat-e Sultan District (Samangan Province): Samangan is a northern province that borders eastern and central provinces and Hazrat-e Sultan was the site of some fairly major protests/demonstrations several years ago. The district is an incursion point for extremists coming from the east. A large focus of IOM's programming in Hazrat-e Sultan was in bringing the district government and communities together around basic service delivery (education and water activities in particular), with the goal of creating positive interactions and trust.

Qadis District (Badghis Province): The District Governor of Qadis was supportive of $\mathrm{CCl}$ activities involving youth, and proactively requested assistance reaching youth audiences to gain from them a better understanding of security in the district. This is also one of the last two districts IOM entered. Therefore it would be interesting to see what, if anything, IOM was able to accomplish in a short (approximately I year) time period and if there were any enduring impacts despite the lack of opportunity to implement multiple rounds of programming.

Lashkar Gah (Helmand Province): The Creative team in Helmand had a very good relationship with the Provincial Governor (at least in 20 I4) and he was supportive of $\mathrm{CCl}$ working in unstable areas of Helmand. There were important examples of productive relationships between local $\mathrm{CCl}$ staff with government and communities, particularly in insecure areas. There may have been a missed opportunity to do youthfocused programming or programming focused on addressing a rapidly-growing urban area surrounded by Taliban-controlled areas.

Kandahar City (Kandahar Province): The sheer number of activities implemented in Kandahar by OTI (ASI and $\mathrm{CCl}$ ) make this an important geographic area to explore further.

Panjwa'i District (Kandahar Province): A supportive District Governor and well-connected local staff led to a progression of activities in the district and apparently high levels of local ownership of projects.

Terayzai District (Khost Province): An important district on the border with Pakistan, Creative implemented a wide range of soft and hard activities in Terayzai over 20I2-20I4. 
Khas Kunar District (Kunar Province): A district that forms part of Kunar's border with Pakistan, $\mathrm{CCl}$ programming in Khas Kunar represented a continuation of programming by the Afghanistan Stabilization Initiative (ASI). Creative implemented a wide range of soft and hard activities in Khas Kunar, much like the other border districts of Marawara and Sarkani.

Kajaki District (Helmand Province): Located in northern Helmand Province, Kajaki District is the location of the Kajaki Dam - a major source of electricity for southern Afghanistan. International assistance for Afghanistan has a major objective of supporting the installation of a third turbine to increase power production at the dam, and the rehabilitation and upgrading of transmission lines that bring the electricity to the population centers of Kandahar and Lashkar Gah. Creative implemented a relatively small number of activities in Kajaki that were nevertheless highly important for expanding GIRoA engagement with local communities in this deeply rural district where the Taliban have substantial presence.

Nahr-e Saraj District (Helmand Province): Located north of Lashkar Gah, Nahr-e Saraj District has seen fewer territorial gains by the Taliban in 2014 and 2015 than the neighboring districts of Sangin and Musa Qal'ah. Like Lashkar Gah, both SIKA-South and CCl implemented activities in Nahr-e Saraj. An important consideration is whether the relatively large number of activities implemented in the district has made communities more resistant to Taliban influence.

\section{B. Key Activity Themes for the Evaluation}

Countering Violent Extremism (CVE): CVE became an explicit program objective in 20I4. Prior to the 2014 revision of program objectives, CVE-like work fell under the "Countering threats to a peaceful transition" objective. The bulk of what OTI would be comfortable calling true CVE activities were implemented by USIP in 2014 and 2015.

Youth Engagement: Youth engagement activities were an increasingly important focus of CCl from $20 \mathrm{I} 4$. Select activities implemented by IOM and Creative focused specifically on youth, as well as a large number of USIP's CVE and peace building activities. Some activities under the 20I2/20I3 objectives appear to be youth-focused in the titles (rehabilitating a school, for example), but were in fact focused on communitygovernment linkages and community cohesion, rather than engaging youth.

Elections: Specifically the use of strategic communications and media to promote peaceful elections in 2014 is an area of interest.

Outlying Activities: These activities include those are coded as "National" in the CCl database and the activities implemented by USIP. These activities used approaches that were different from the majority of $\mathrm{CCl}$ activities. They were some of the most intentional and expensive activities implemented by Creative, e.g. mobilization of election monitors.

Community-Government Linkages: Programming typically sought to link local communities with their government through small-scale infrastructure and service provision. A large portion of the activities implemented by Creative and IOM were intended to achieve this objective, which was however interpreted in many ways by local staff, thus activity selection, design and outcomes may vary widely. Nonetheless, this was such a strong theme of both Creative and IOM that it would be impossible to understand the program without diving deeper into how this goal was established (strategy), understood, 
programmed against, and received by communities and government. This broad theme was also utilized in every district where Creative and IOM worked. Therefore, informative comparisons may be drawn between districts with different characteristics or different processes employed by the district or provincial teams. Identifying activity outcomes will require filtering out poor perceptions of government that may have arisen from the 2014 presidential election crisis and subsequent difficulties with establishing a functional government.

Community Engagement Processes: OTI places crucial emphasis on programming processes over and above outputs with the reasoning that the achievement of an output, such as a rehabilitated piece of infrastructure, may not create cohesion if the process through which that output is achieved is divisive. The use of Project Shuras, Cohesion Jirgas and Project Oversight Committees were crucial forms of community engagement in the activity process that were meant to ensure that activity outputs and outcomes would be cohesion-positive.

\section{Limitations of the Evaluation Methodology}

A crucial aspect of successful evaluation research is a concerted and systematic effort to identify and control the set of biases that inevitably color the information collected from any single source. The desire to attract follow-on programming is a source of bias that evaluations must often contend with. This source of bias is often a feature of the village context in Afghanistan where project beneficiaries and stakeholders attempt to provide the information that they think will prompt the delivery of additional benefits from a new project activity. This source of bias may also affect the information that IPs give to evaluators if they calculate that certain evaluation findings would positively influence their chances of winning the award of a follow-on program.

This common source of bias was be controlled by conveying to the $\mathrm{CCl}$ beneficiaries, stakeholders, and IPs the fact that USAID/OTI does not intend to undertake any follow-on programming to $\mathrm{CCl}$ in Afghanistan at any time in the near future. Rather, the research subjects of the evaluation were prompted to share their knowledge of the program for the purpose of understanding its most and least effective aspects.

Emotional attachment and professional reputation may enter as a different source of bias in the data collected from OTI and the IP Management and staff. Reputational considerations and strong attachments to the program and the areas where it worked may create a tendency to answer questions in ways that cast a positive light on some of the more challenging aspects of $\mathrm{CCl}$. Triangulation of data from different sources is the key analytical technique for identifying and controlling this bias. That is, bias will be controlled by cross-referencing information from interviews with OTI officials, with information from IPs, with data collected from beneficiaries in the focus districts, plus data from secondary sources including independent M\&E reports from RSI. The triangulation of data from these different sources will ensure that the answers to the evaluation questions reflect a distillation of the full range of dynamics surrounding $\mathrm{CCl}$ programming and the various interests of its stakeholders.

Evaluator conflicts of interests are another potential source of bias. Social Impact certifies that no member of its evaluation team, including subcontractor staff employed to collect data, have a material or perceived conflict of interest that might influence the evaluation process, the quality of the data collected, or the findings of the evaluation. 
The limitations of the evaluation are determined mainly by time and cost considerations. Because of the prohibitive cost and time required to evaluate each and every activity implemented by $\mathrm{CCl}$, a sampling approach must be taken. Sampling bias is controlled using the systematic selection of the activities in the sample according to a fixed set of criteria outlined in Appendix D, including the formulation of evaluation questions, and the selection of districts and themes of particular interest.

Insecurity is a persistent limitation that affects all types of work in Afghanistan, including evaluations. Insecurity may affect the mobility of evaluators and access to research subjects and activity sites. Insecurity may create bias in evaluation findings if it results in the systematic exclusion of certain types of activity sites and/or groups of respondents. If during the course of fieldwork insecurity compromises the evaluation team's ability to fulfill the evaluation plan, then Social Impact will immediately begin working with OTI to identify the best means of revising the evaluation plan such that inaccessible locations and/or respondents are replaced with comparable ones that are accessible. Thereby the evaluation team will control the potential source of sampling bias that might arise from insecurity.

The IPs were very cooperative and engaged in frank, honest discussion about all aspects of CCl. Reports from the field indicated that the IP provincial staff cooperated closely with the subcontractor's data collection teams, which facilitated access and engagement with key informants and beneficiaries of $\mathrm{CCl}$ activities. The subcontractor has provided frequent updates on the progress of fieldwork and has coped successfully with security problems that have arisen over the past two weeks in Kajaki District of Helmand Province and Qadis District of Badghis Province, with a contingency plan in place to provide transportation to focus group participants such that FGDs may take place in safe locations outside of these districts. The team was able to gather data providing answers to the evaluation questions on schedule and according to plan. 


\section{Evidence Matrix}

\begin{tabular}{|c|c|c|c|}
\hline Evaluation Question & $\begin{array}{l}\text { Data } \\
\text { Collection } \\
\text { Methods }\end{array}$ & Questions in Data Collection Instruments & $\begin{array}{c}\text { Respondent } \\
\text { Group }\end{array}$ \\
\hline $\begin{array}{l}\text { Ia. Did the program } \\
\text { strategy adjust } \\
\text { appropriately, given } \\
\text { Afghanistan's evolving } \\
\text { transition needs, within } \\
\text { the context of } \\
\text { overarching USG policy? }\end{array}$ & $\begin{array}{l}\text { Desk review, } \\
\text { interviews }\end{array}$ & $\begin{array}{l}\text { - How was the strategy of the } \mathrm{CCl} \text { program formulated initially and how was it related to } \\
\text { other OTI programs? (OTI) } \\
\text { Were there changes in programming strategy over the life of the program that were } \\
\text { particularly significant? If so, what changes in strategy were most important and why? } \\
\text { (OTI, USAID-OAPA, IP Management) } \\
\text { Was the program strategy adjusted appropriately given changes in USG policy towards } \\
\text { - } \text { - Waghanistan? (OTI, USAID-OAPA) } \\
\text { Afghanistan over the life of the program? (OTI, USAID-OAPA, IP Management) }\end{array}$ & $\begin{array}{l}\text { OTI, USAID- } \\
\text { OAPA, IP } \\
\text { Management }\end{array}$ \\
\hline $\begin{array}{l}\text { Ib. Were the program } \\
\text { objectives and sub- } \\
\text { objectives framed in a } \\
\text { way that facilitated } \\
\text { activity identification and } \\
\text { design, and how did the } \\
\text { implementing partner } \\
\text { staff's understanding of } \\
\text { the program goal impact } \\
\text { activity quality and/or } \\
\text { strategic relevance? }\end{array}$ & $\begin{array}{l}\text { Desk review, } \\
\text { interviews }\end{array}$ & $\begin{array}{l}\text { - How would you describe the strategy of } \mathrm{CCl} \text { in your own terms? (IP Management, IP } \\
\text { - } \quad \text { In yourf) } \\
\text { Afghanistan that are cohesive and those that are not cohesive? (IP Staff) } \\
\text { - In your view which types of activities implemented by } \mathrm{CCl} \text { were most relevant to the } \\
\text { program strategy? (OTI, IP Management) } \\
\text { - To what extent were the objectives clear enough that they could be achieved with the } \\
\text { available set of programming resources and capabilities? (OTI, IP Management) } \\
\text { - How would you describe the objectives of the CCl program in your own terms? (IP } \\
\text { Staff) } \\
\text { Which activities were the most important for achieving the program objectives, and } \\
\text { why? (IP Staff) } \\
\text { USIP had the objective of countering violent extremism. Please describe in your own } \\
\text { terms the meaning of this objective? (USIP Partners) }\end{array}$ & $\begin{array}{l}\text { OTI, IP } \\
\text { Management, } \\
\text { IP Staff, USIP } \\
\text { Partners }\end{array}$ \\
\hline $\begin{array}{l}\text { Ic. Did program objective } \\
\text { pivots (20I3 and } 2014 \text { ) } \\
\text { lead to higher quality } \\
\text { activities and/or more } \\
\text { strategically relevant } \\
\text { activities, and, if so, did } \\
\text { that lead to more } \\
\text { contribution to the }\end{array}$ & $\begin{array}{l}\text { Desk review, } \\
\text { interviews, } \\
\text { focus groups }\end{array}$ & $\begin{array}{l}\text { - CCl's objectives were revised twice during the life of the program, once in } 2013 \text { and } \\
\text { once in } 2014 \text {. Did these changes in objectives have significant effects on the design of } \\
\text { activities that } \mathrm{CCl} \text { implemented? If so, what were the most significant changes? (OTI, IP } \\
\text { Management) } \\
\text { - Was there a significant change in the quality of } \mathrm{CCl} \text { activities following the revision to } \\
\text { the program objectives in } 20 \mathrm{I} 3 \text { and/or } 20 \mathrm{I} 4 \text { ? If so, how did the quality of activities } \\
\text { change? (OTI, IP Management) } \\
\text { Please tell me in your own words how you understood the purpose of the project? } \\
\text { (Local Stakeholders) }\end{array}$ & $\begin{array}{l}\text { OTI, USAID- } \\
\text { OAPA, IP } \\
\text { Management, } \\
\text { IP Staff, Local } \\
\text { Stakeholders }\end{array}$ \\
\hline
\end{tabular}




\begin{tabular}{|c|c|c|c|}
\hline Evaluation Question & $\begin{array}{l}\text { Data } \\
\text { Collection } \\
\text { Methods }\end{array}$ & Questions in Data Collection Instruments & $\begin{array}{l}\text { Respondent } \\
\text { Group }\end{array}$ \\
\hline $\begin{array}{l}\text { achievement of the } \\
\text { program goal? }\end{array}$ & & $\begin{array}{l}\text { - To what extent did you have a say in what activities took place or how they were } \\
\text { managed? (Local Stakeholders) }\end{array}$ & \\
\hline $\begin{array}{l}\text { 2a. Based on a sampling } \\
\text { of activities and review of } \\
\text { existing activity } \\
\text { evaluations and analysis, } \\
\text { to what extent did } \\
\text { activity outcomes } \\
\text { contribute to each of the } \\
\text { program objectives/goal } \\
\text { and sub-objectives? }\end{array}$ & $\begin{array}{l}\text { Desk review, } \\
\text { interviews, } \\
\text { focus groups }\end{array}$ & $\begin{array}{l}\text { - What did the project do and how were you involved? (Local Stakeholders) } \\
\text { - The project was intended to help people to work together to solve their own problems. } \\
\text { Did the activities of the project lead the people to work together more than before the } \\
\text { project started? If so then what did the project do that had the biggest effect on } \\
\text { cooperation between the people? (Local Stakeholders) } \\
\text { - The project was intended to give people resources to make them more capable of } \\
\text { recovering from shocks or other negative events that could threaten their survival. } \\
\text { Thinking about the situation of the people in this area now compared to before the } \\
\text { project, to what extent was there a change in people's abilities to recover from negative } \\
\text { events because of the activities of the project? Which abilities of the people were } \\
\text { particularly affected by the project? (Local Stakeholders) } \\
\text { Considering all the work of CCI, what do you consider to be the most significant change } \\
\text { that was created by the program? (All respondents) } \\
\text { Were there changes in community cohesion that resulted from project activities? If so, } \\
\text { what was the most significant change in cohesion that you witnessed? (IP Staff) } \\
\text { Were there changes in resilience, or the ability of the local people to recover from } \\
\text { shocks or negative events that could threaten their survival, because of project } \\
\text { activities? If so, what was the most significant change in resilience that you witnessed? (IP } \\
\text { Staff) } \\
\text { Which activities were most effective for countering violent extremism? (IP Management) } \\
\text { Which activities were most effective for connecting the government to local people? (IP } \\
\text { - Tanagement, IP Staff) } \\
\text { To what extent did project oversight committees affect the quality of the activities that } \\
\text { CCl implemented in the districts? (IP Staff) } \\
\text { To what extent was the ink spot tactic used in the development of new activities? (OTI, } \\
\text { area and expanding to neighboring areas, like a spot of ink expanding on a piece of } \\
\text { paper? (IP Staff) }\end{array}$ & $\begin{array}{l}\text { OTI, IP } \\
\text { Management, } \\
\text { IP Staff, USIP } \\
\text { Partners, } \\
\text { Local } \\
\text { Stakeholders }\end{array}$ \\
\hline $\begin{array}{l}2 \mathrm{~b} . \text { Which types of } \\
\text { activities contributed } \\
\text { most significantly to the }\end{array}$ & $\begin{array}{l}\text { Desk review, } \\
\text { interviews, } \\
\text { focus groups }\end{array}$ & $\begin{array}{l}\text { - In your experience, what was the most significant change that the activities of the } \\
\text { project created? (Local Stakeholders) }\end{array}$ & $\begin{array}{l}\text { OTI, IP } \\
\text { Management, } \\
\text { IP Staff, USIP }\end{array}$ \\
\hline
\end{tabular}




\begin{tabular}{|c|c|c|c|}
\hline Evaluation Question & $\begin{array}{l}\text { Data } \\
\text { Collection } \\
\text { Methods }\end{array}$ & Questions in Data Collection Instruments & $\begin{array}{l}\text { Respondent } \\
\text { Group }\end{array}$ \\
\hline $\begin{array}{l}\text { program } \\
\text { objectives/program goal } \\
\text { and are there identifiable } \\
\text { trends across those } \\
\text { activities? }\end{array}$ & & $\begin{array}{l}\text { - Thinking about villages that received activities compared to similar villages that did not } \\
\text { receive activities, which activities had the biggest effects on the lives of the local people? } \\
\text { (IP Staff) } \\
\text { - Considering all the work of CCl, what do you consider to be the most significant change } \\
\text { that was created by the program? (All respondents) } \\
\text { - Were there changes in community cohesion that resulted from project activities? If so, } \\
\text { what was the most significant change in cohesion that you witnessed? (IP Staff) } \\
\text { - Were there changes in resilience, or the ability of the local people to recover from } \\
\text { shocks or negative events that could threaten their survival, because of project } \\
\text { activities? If so, what was the most significant change in resilience that you witnessed? (IP } \\
\text { Staff) } \\
\text { - How did your organization work against violent extremism? (USIP Partners) } \\
\text { - Which activities were most effective for countering violent extremism? (IP Management) } \\
\text { - Which activities were most effective for engaging youth? (IP Management, IP Staff) } \\
\text { - What was the most significant change created by youth engagement activities that you } \\
\text { witnessed? (IP Staff) } \\
\text { - What was the most significant change that you witnessed from activities meant to } \\
\text { connect government to local people? (IP Staff) } \\
\text { some of the activities of the project were intended to establish new relationships, or } \\
\text { strengthen existing relationships between the local people and the government. To what } \\
\text { extent did relationships between the people and the government change as a result of } \\
\text { the project? (Local Stakeholders) } \\
\text { - Did people's confidence in the government change as a result of the project? If so what } \\
\text { did the project do to cause this change in confidence? (Local Stakeholders) } \\
\text { - The project was also intended to reduce the influence of armed opposition groups such } \\
\text { as the Taliban on people in this area. To what extent did the influence of armed } \\
\text { opposition groups change as a result of the project? (Local Stakeholders) } \\
\text { - To what extent did CCI have an effect on the elections in } 20 \text { I4? (OTI, OAPA, IP } \\
\text { Management) } \\
\text { What were the most effective ways of making local people in the districts part of the } \\
\text { activity process? (IP Staff) }\end{array}$ & $\begin{array}{l}\text { Partners, } \\
\text { Local } \\
\text { Stakeholders }\end{array}$ \\
\hline $\begin{array}{l}\text { 2c. Were there any } \\
\text { unexpected outcomes } \\
\text { (positive or negative) }\end{array}$ & $\begin{array}{l}\text { Desk review, } \\
\text { interviews, } \\
\text { focus groups }\end{array}$ & $\begin{array}{l}\text { - Were there any activities that had unexpected results for the local people? If so what } \\
\text { were these results and why were they unexpected? (IP Management, IP Staff, USIP } \\
\text { Partners) }\end{array}$ & $\begin{array}{l}\text { OTI, USAID- } \\
\text { OAPA, IP } \\
\text { Management, }\end{array}$ \\
\hline
\end{tabular}




\begin{tabular}{|c|c|c|c|}
\hline Evaluation Question & $\begin{array}{l}\text { Data } \\
\text { Collection } \\
\text { Methods }\end{array}$ & Questions in Data Collection Instruments & $\begin{array}{l}\text { Respondent } \\
\text { Group }\end{array}$ \\
\hline $\begin{array}{l}\text { observed within these } \\
\text { activity categories or } \\
\text { within individual activities } \\
\text { sampled? }\end{array}$ & & $\begin{array}{l}\text { - To what extent did armed opposition groups or other people in this area oppose the } \\
\text { work of the project? If so, then how was the opposition to the work of the project } \\
\text { overcome so that the work could go forward? (Local Stakeholders) } \\
\text { - Considering all the work of CCl, what do you consider to be the most significant change } \\
\text { that was created by the program? (All respondents) } \\
\text { - Were there changes in community cohesion that resulted from project activities? If so, } \\
\text { - What was the most significant change in cohesion that you witnessed? (IP Staff) } \\
\text { Were there changes in resilience, or the ability of the local people to recover from } \\
\text { shocks or negative events that could threaten their survival, because of project } \\
\text { activities? If so, what was the most significant change in resilience that you witnessed? (IP } \\
\text { Staff) } \\
\text { - How did your organization work against violent extremism? (USIP Partners) } \\
\text { - Which activities were most effective for countering violent extremism? (IP Management) } \\
\text { - What was the most significant change created by youth engagement activities that you } \\
\text { witnessed? (IP Staff) } \\
\text { - What was the most significant change that you witnessed from activities meant to } \\
\text { connect government to local people? (IP Staff) } \\
\text { To what extent did CCI have an effect on the elections in 20I4? (OTI, OAPA, IP } \\
\text { Management) } \\
\text { What were the most effective ways of making local people in the districts part of the } \\
\text { activity process? (IP Staff) }\end{array}$ & $\begin{array}{l}\text { IP Staff, USIP } \\
\text { Partners, } \\
\text { Local } \\
\text { Stakeholders }\end{array}$ \\
\hline $\begin{array}{l}2 \mathrm{~d} \text {. To what extent, if } \\
\text { any, were immediate } \\
\text { activity outcomes } \\
\text { sustained upon } \\
\text { completion of the } \\
\text { activities? If so, which } \\
\text { types of activities had the } \\
\text { most sustainable } \\
\text { outcomes and why? }\end{array}$ & $\begin{array}{l}\text { Desk review, } \\
\text { interviews, } \\
\text { focus groups }\end{array}$ & $\begin{array}{l}\text { - To what extent did the project create lasting changes to the situation of the people here } \\
\text { after the end of the project? (Local Stakeholders) } \\
\text { - What were the most lasting effects of CCl programming after activities were } \\
\text { completed? (IP Staff) }\end{array}$ & $\begin{array}{l}\text { OTI, IP } \\
\text { Management, } \\
\text { IP Staff, USIP } \\
\text { Partners, } \\
\text { Local } \\
\text { Stakeholders }\end{array}$ \\
\hline $\begin{array}{l}\text { 3a. To what extent was } \\
\text { the program able to learn } \\
\text { from ongoing analysis to }\end{array}$ & $\begin{array}{l}\text { Desk review, } \\
\text { interviews }\end{array}$ & $\begin{array}{l}\text { - To what extent was the program able to learn to improve project design over time? } \\
\text { (OTI, IP Management) } \\
\text { - What, if anything, did you learn in the course of your work on CCl that you used to } \\
\text { improve the quality of the activities that you implemented? (IP Staff) }\end{array}$ & $\begin{array}{l}\text { OTI, IP } \\
\text { Management, } \\
\text { IP Staff, USIP } \\
\text { Partners }\end{array}$ \\
\hline
\end{tabular}




\begin{tabular}{|c|c|c|c|}
\hline Evaluation Question & $\begin{array}{l}\text { Data } \\
\text { Collection } \\
\text { Methods }\end{array}$ & Questions in Data Collection Instruments & $\begin{array}{l}\text { Respondent } \\
\text { Group }\end{array}$ \\
\hline \multicolumn{4}{|l|}{$\begin{array}{l}\text { improve project design } \\
\text { over time? }\end{array}$} \\
\hline $\begin{array}{l}\text { 3b. Did the impact of the } \\
\text { program learning that } \\
\text { took place justify the } \\
\text { resources invested? }\end{array}$ & $\begin{array}{l}\text { Desk review, } \\
\text { interviews }\end{array}$ & $\begin{array}{l}\text { - Did the program learning that took place justify the resources invested in data collection } \\
\text { and analysis? (OTI, IP Management) }\end{array}$ & $\begin{array}{l}\text { OTI, IP } \\
\text { Management, } \\
\text { IP Staff }\end{array}$ \\
\hline $\begin{array}{l}\text { 3c. What concrete } \\
\text { factors or processes } \\
\text { could the program have } \\
\text { developed or improved } \\
\text { to promote program } \\
\text { learning, with a particular } \\
\text { focus on the role of the } \\
\text { Independent Monitoring } \\
\text { Unit? }\end{array}$ & $\begin{array}{l}\text { Desk review, } \\
\text { interviews }\end{array}$ & $\begin{array}{l}\text { - Do you believe that the quality of the activities implemented by the program improved } \\
\text { over time? If so, then what were the most important ways that the team learned to } \\
\text { improve programming? (IP Management, IP Staff) } \\
\text { - What, if anything, could have been done to use tools like monitoring and evaluation to } \\
\text { improve the process of learning how to do more effective programming? (OTI, IP } \\
\text { Management, IP Staff) }\end{array}$ & $\begin{array}{l}\text { OTI, IP } \\
\text { Management, } \\
\text { IP Staff, USIP } \\
\text { Partners }\end{array}$ \\
\hline $\begin{array}{l}\text { 4a. What were the key } \\
\text { lessons learned from } \mathrm{CCl} \\
\text { and how could they be } \\
\text { applied to future } \\
\text { programming in non- } \\
\text { permissive environments? }\end{array}$ & $\begin{array}{l}\text { Desk review, } \\
\text { interviews, } \\
\text { focus groups }\end{array}$ & $\begin{array}{l}\text { - What lessons should be learned from } \mathrm{CCl} \text { for creating a new program to work in the } \\
\text { same areas? (IP Staff) } \\
\text { - What lessons were learned from } \mathrm{CCl} \text { and how could they be applied to future } \\
\text { programming in Afghanistan or other countries? (OTI, IP Management) }\end{array}$ & $\begin{array}{l}\text { OTI, IP } \\
\text { Management, } \\
\text { IP Staff, USIP } \\
\text { Partners, } \\
\text { Local } \\
\text { Stakeholders }\end{array}$ \\
\hline $\begin{array}{l}\text { 4b. This should include } \\
\text { lessons that can be } \\
\text { applied to future } \\
\text { programming intended to } \\
\text { increase community } \\
\text { cohesion and resiliency } \\
\text { more broadly, }\end{array}$ & $\begin{array}{l}\text { Desk review, } \\
\text { interviews, } \\
\text { focus groups }\end{array}$ & $\begin{array}{l}\text { - Were there changes in community cohesion that resulted from project activities? If so, } \\
\text { what was the most significant change in cohesion that you witnessed? (IP Staff) } \\
\text { Were there changes in resilience, or the ability of the local people to recover from } \\
\text { shocks or negative events that could threaten their survival, because of project } \\
\text { activities? If so, what was the most significant change in resilience that you witnessed? (IP } \\
\text { Staff) } \\
\text { The project was intended to help people to work together to solve their own problems. } \\
\text { Did the activities of the project lead the people to work together more than before the } \\
\text { project started? If so then what did the project do that had the biggest effect on } \\
\text { cooperation between the people? (Local Stakeholders) } \\
\text { The project was intended to give people resources to make them more capable of } \\
\text { recovering from shocks or other negative events that could threaten their survival. } \\
\text { Thinking about the situation of the people in this area now compared to before the }\end{array}$ & $\begin{array}{l}\text { OTI, IP } \\
\text { Management, } \\
\text { IP Staff, USIP } \\
\text { Partners, } \\
\text { Local } \\
\text { Stakeholders }\end{array}$ \\
\hline
\end{tabular}




\begin{tabular}{|c|c|c|c|}
\hline \multirow[t]{2}{*}{ Evaluation Question } & $\begin{array}{c}\text { Data } \\
\text { Collection } \\
\text { Methods }\end{array}$ & Questions in Data Collection Instruments & $\begin{array}{l}\text { Respondent } \\
\text { Group }\end{array}$ \\
\hline & & $\begin{array}{l}\text { project, to what extent was there a change in people's abilities to recover from negative } \\
\text { events because of the activities of the project? Which abilities of the people were } \\
\text { particularly affected by the project? (Local Stakeholders) } \\
\text { - The project was also intended to reduce the influence of armed opposition groups such } \\
\text { as the Taliban on people in this area. To what extent did the influence of armed } \\
\text { opposition groups change as a result of the project? (Local Stakeholders) } \\
\text { - To what extent did armed opposition groups or other people in this area oppose the } \\
\text { work of the project? If so, then how was the opposition to the work of the project } \\
\text { overcome so that the work could go forward? (Local Stakeholders) }\end{array}$ & \\
\hline $\begin{array}{l}\text { 4c. And may include } \\
\text { lessons about activity } \\
\text { development and } \\
\text { implementation } \\
\text { approaches, strategy } \\
\text { development and } \\
\text { communication, and } \\
\text { operational approaches } \\
\text { that are best suited for } \\
\text { complex programming in } \\
\text { restrictive environments. }\end{array}$ & $\begin{array}{l}\text { Desk review, } \\
\text { interviews, } \\
\text { focus groups }\end{array}$ & $\begin{array}{l}\text { - Did people's confidence in the government change because of the project? If so, what } \\
\text { did the project do to cause this change in confidence? (Local Stakeholders) } \\
\text { - Was the program strategy adjusted appropriately given changes in USG policy towards } \\
\text { Afghanistan? (OTI, USAID-OAPA) } \\
\text { - Was the program strategy adjusted appropriately given the progression of events in } \\
\text { Afghanistan over the life of the program? (OTI, USAID-OAPA, IP Management) } \\
\text { - Which activities were most effective for engaging youth? (IP Management, IP Staff) } \\
\text { - What was the most significant change created by youth engagement activities that you } \\
\text { witnessed? (IP Staff) } \\
\text { - What was the most significant change that you witnessed from activities meant to } \\
\text { connect government to local people? (IP Staff) } \\
\text { - To what extent did CCI have an effect on the elections in } 20 \text { I4? (OTI, OAPA, IP } \\
\text { Management, IP Staff) } \\
\text { - What were the most effective ways of making local people in the districts part of the } \\
\text { activity process? (IP Staff) } \\
\text { What was the most significant change created by CCl's activities with local councils that } \\
\text { you witnessed? (IP Staff) }\end{array}$ & $\begin{array}{l}\text { OTI, IP } \\
\text { Management, } \\
\text { IP Staff, Local } \\
\text { Stakeholders }\end{array}$ \\
\hline
\end{tabular}




\section{E. Evaluation Team Staffing and Training}

Four days of training were held for the staff tasked with data collection in the eleven focus districts for the $\mathrm{CCl}$ Final Evaluation. A total of 22 data collectors traveled from the provinces to the subcontractor's office in Kabul for the training. In addition, training participants included the two Evaluation Analysts responsible for managing data collection from Kabul, the Qualitative Analyst, eight Provincial Coordinators responsible for managing the fieldwork in each province, and six Quality Control Officers. The large pool of 14 Transcribers and 20 Translators ensured that the data was quickly prepared for analysis in the form of English-language transcripts.

\section{Training Summary}

The Team Leader led the first two days of training with translation by the Evaluation Analysts. Photographs were taken on the first day of training. The training was held in a large basement room of the IDS Hamkaar office. The TL gave a series of presentations on the first two days of the training. The Evaluation Analysts led the third and fourth days of training, and focused on reviewing the translation of the questions for interviews and focus group discussions (FGDs), along with hands-on practice sessions. The following points summarize the content covered during the training days:

- Training Day I

- Explanation of the objectives of the evaluation to the field team

- Familiarize the field team with the $\mathrm{CCl}$ program, including its objectives and approach to implementation.

- Techniques and best practices for key informant interviews (KIls)

- Techniques and best practices for FGDs

- Review KII and FGD questions

- Group discussion and question and answer session

- Training Day 2

- Review $\mathrm{CCl}$ activity types

- Review activities sampled in each focus district

- Review IP Staff questionnaire

- Techniques and best practices for selecting key informants for specific activity types

- Techniques and best practices for selecting FGD participants

- Mock interviews and hands-on practice of interview techniques

- Make-up training session for Helmand team

- Training Day 3

- Mock interview and hands-on practice of interview techniques

- Mock FGDs and hands-on practice of group facilitation techniques 
- Group discussion and question and answer session on the translated versions of the interview questionnaires and FGD guide, probing and follow-up techniques

○ Make-up training session for Helmand team

- Break out training for female data collectors

- Training Day 4

- Use of technology: Digital voice recorders, taking coordinate using geographic positioning system (GPS) devices, taking photographs

- Review of sampled activities by district

- Review of community engagement techniques and locating eligible interviewees

The only problem encountered with the training was a delay in the flight from Lashkar Gah to Kabul that caused the data collectors from Helmand Province to arrive in the afternoon on the second training day. Special make-up training sessions were held for the Helmand team to cover the material missed on the first and second days.

Moreover, the female data collectors were less active participants in the training sessions compared to the male data collectors. Therefore, a break-out session only for the female data collectors was organized by the evaluation analysts for additional review of the training materials and questions and answers on collecting data from female beneficiaries and key informants. 


\section{F. Sampling Design}

The selected activities comprise a stratified random sample of 10 activities from each of the eleven focus districts identified in Section II, for a total of IIO activities on which that the evaluation field team will focus its data collection effort. The sample was drawn systematically from the full set of activities that were closed, completed, or cleared for implementation by either IOM or Creative as of August $2015(\mathrm{CCl}$ activities implemented by USIP will be evaluated separately using a snowball sampling method).

The sample is stratified such that the ten activities sampled in each district are representative of the proportion of the total activities implemented in each district to address each program objective. Within the stratification by objective, a second level of stratification by activity sector - infrastructure, media, sociocultural, technical assistance, and training - ensured that the set of activities included in the sample are representative of the activity types that were most often implemented to address each objective in each district. The sampling method followed the following steps:

I. A report was generated in Excel from the OTI Anywhere activity database listing all IOM and Creative activities categorized as closed, completed, or cleared in each of the eleven focus districts

2. The excel file was transferred to the Statistical Software Package for the Social Sciences (SPSS). SPSS was used to generate summary statistics on the distribution of activities across the program objectives and implementation sectors by district.

3. A random number was generated in Excel for each activity. The activities were first sorted by their random number, then by sector, then objective, and finally by district to arrive at the randomized list of activities used for sample selection.

4. Ten activities were selected from each district in proportion to the distribution of all activities implemented in each sector to address each objective.

The sampling method thus ensures that the list of activities selected is maximally representative of $\mathrm{CCl}$ programming in the focus districts. The evaluation field team will visit each activity site and collect data from the beneficiaries of each activity using interviews and focus groups. 


\section{ANNEX III: DATA COLLECTION INSTRUMENTS}

\section{OTI Questionnaire}

I. Please describe for me in brief your role on the $\mathrm{CCl}$ program. How did you engage with the program and did your engagement change over time?

2. How was the strategy of the $\mathrm{CCl}$ program formulated initially and how was it related to other OTI programs?

3. Which changes in programming strategy over the life of the program were particularly significant? What changes in strategy were most important and why? (Cheat sheet - discussion of programming against the changing objectives)

4. Was the program strategy adjusted appropriately given changes in USG policy towards Afghanistan?

5. CCl's objectives were revised twice during the life of the program, once in 2013 and once in 2014 . Did these changes in objectives have significant effects on the design of the activities that $\mathrm{CCl}$ implemented? If so, what were the most significant changes?

6. Was there a significant change in the quality of $\mathrm{CCl}$ activities following the revision to the program objectives in 2013 and/or 20I4? If so, how did the quality of activities change?

7. To what extent were the objectives clear enough that they could be achieved with the available set of programming resources and capabilities?

8. To what extent was the program able to learn to improve project design over time?

9. Do you believe that the quality of the activities implemented by the program improved over time? If so, then what were the most important ways that the team learned to improve programming?

10. What, if anything, could have been done differently with tools like monitoring and evaluation to improve the process of learning how to do more effective programming?

II. Did the program learning that took place justify the resources invested in data collection and analysis?

12. To what extent was the ink spot tactic used in the development of new activities?

13. To what extent did $\mathrm{CCl}$ have an effect on the elections in 2014 ?

14. What are the most important lessons learned from $\mathrm{CCl}$ and how could they be applied to future programming in Afghanistan or other countries?

15. Considering all the work of $\mathrm{CCl}$, what do you consider to be the most significant change that was created by the program?

\section{OAPA Questionnaire}

I. Please describe for me in brief your relationship to the $\mathrm{CCl}$ program. How did you engage with the program and did your engagement change over time? 
2. Were there changes in programming strategy over the life of the program that were particularly significant? If so, what changes in strategy were most important and why? (Cheat sheet - discussion of programming against the changing objectives)

3. Was the program strategy adjusted appropriately given changes in USG policy towards Afghanistan?

4. To what extent did $\mathrm{CCl}$ have an effect on the elections in 2014 ?

5. Considering all the work of $\mathrm{CCl}$, what do you consider to be the most significant change that was created by the program?

\section{IP Management Questionnaire}

I. Please describe for me in brief your role on the $\mathrm{CCl}$ program. How did you engage with the program and did your engagement change over time?

2. How would you describe the strategy of $\mathrm{CCl}$ in your own terms?

3. Was the program strategy adjusted appropriately given the progression of events in Afghanistan over the life of the program?

4. In your view which types of activities implemented by $\mathrm{CCl}$ were most relevant to the program strategy?

5. CCl's objectives were revised twice during the life of the program, once in 2013 and once in 2014 . Did these changes in objectives have significant effects on the design of the activities that $\mathrm{CCl}$ implemented? If so, what were the most significant changes?

6. Was there a significant change in the quality of $\mathrm{CCl}$ activities following the revision to the program objectives in 2013 and/or 20 I4? If so, how did the quality of activities change?

7. To what extent were the objectives clear enough that they could be achieved with the available set of programming resources and capabilities?

8. To what extent was the program able to learn to improve project design over time?

9. $\mathrm{CCl}$ had the objective of countering violent threats to peaceful transition, and also countering violent extremism. Please describe in your own terms the meaning of these objectives and how the program addressed them?

10. Which activities were most effective for countering violent extremism?

II. Were there any unexpected outcomes of activities? If so what were these outcomes and why were they unexpected?

12. Which activities were most effective for engaging youth?

13. To what extent did $\mathrm{CCl}$ have an effect on the elections in $20 \mathrm{I} 4$ ?

14. To what extent was the ink spot tactic used in the development of new activities?

15. Do you believe that the quality of the activities implemented by the program improved over time? If so, then what were the most important ways that the team learned to improve programming? 
16. What, if anything, could have been done to use tools like monitoring and evaluation to improve the process of learning how to do more effective programming?

17. What lessons were learned from $\mathrm{CCl}$ and how could they be applied to future programming in Afghanistan or other countries?

18. Considering all the work of $\mathrm{CCl}$, what do you consider to be the most significant change that was created by the program?

\section{IP Staff Questionnaire}

I. Please describe for me briefly your role on the $\mathrm{CCl}$ program. What work do you do on the program and has your work changed over time?

2. How would you describe the strategy and objectives of the $\mathrm{CCl}$ program in your own terms?

3. Which activities were the most important for achieving the program objectives, and why?

4. In your experience what are some important differences between communities in Afghanistan that are cohesive and those that are not cohesive?

5. Were there changes in community cohesion that resulted from project activities? If so, what was the most significant change in cohesion that you witnessed?

6. Were there changes in resilience, or the ability of the local people to recover from shocks or negative events that could threaten their survival, because of project activities? If so, what was the most significant change in resilience that you witnessed?

7. Thinking about villages that received activities compared to similar villages that did not receive activities, which activities had the biggest effects on the lives of the local people, and why?

8. What were the most lasting effects of $\mathrm{CCl}$ programming after activities were completed?

9. Were there any activities that had unexpected results for the local people? If so what were these results and why were they unexpected?

10. What was the most significant change created by youth engagement activities that you witnessed?

II. What was the most significant change that you witnessed from activities meant to connect government to local people?

12. What were the most effective ways of making local people in the districts part of the activity process?

13. To what extent did project oversight committees affect the quality of the activities that $\mathrm{CCl}$ implemented in the districts?

14. To what extent did you attempt to expand activities in a district by starting from one area and expanding to neighboring areas, like a spot of ink expanding on a piece of paper?

15. Do you believe that the quality of the activities implemented by the program improved over time? If so, then what were the most important ways that the team learned to improve programming?

16. What, if anything, could have been done to use tools like monitoring and evaluation to improve the process of learning how to do more effective programming? 
17. What lessons should be learned from $\mathrm{CCl}$ for creating a new program to work in the same areas?

18. Considering all the work of $\mathrm{CCl}$, what do you consider to be the most significant change that was created by the program?

We are now going to shift topics away from the final evaluation to briefly discuss the systems, processes, and operations of the $\mathrm{CCl}$ program. These questions are part of the OTI After Action Review that will take place in Washington in January. Your feedback will help not only the people who worked on this program but also other OTI programs. Your responses will only be shared with the Review's facilitators.

19. What went well with this program operationally (systems, processes, communication)? What could have been improved with this program's operations?

20. How did IOM and the IMU/RSI work together? (Prompts as needed: What do you think were the goals for the IMU's review of activities? How was the information the IMU produced used by IOM?)

21 . Were you satisfied with the information you received about $\mathrm{CCl}$ when you joined the program? What were the challenges to understanding CCl's approach, goals or processes when you joined the program?

22. Did you contribute to discussions about the $\mathrm{CCl}$ strategy (objectives and optic) during your time with the program?

23. Did changes to the strategy impact your work or understanding of CCl's purpose?

\section{USIP Questionnaire}

I. Please describe for me briefly your organization and your role as a partner of USIP. What work did you do with USIP and has your work changed over time?

2. USIP had the objective of countering violent extremism. Please describe in your own terms the meaning of this objective.

3. How did your organization work against violent extremism?

4. Were there changes in community cohesion that resulted from your work with USIP? If so, what was the most significant change in cohesion that you witnessed?

5. Do you believe that the quality of the activities you implemented with USIP improved over time? If so, then what were the most important ways that your organization learned to improve activities?

6. Monitoring and evaluation is usually used to check whether activities are successful. What, if anything, could have been done to make more use of monitoring and evaluation to improve the quality of activities?

7. What were the most lasting effects of your work with USIP after it was completed?

8. Were there any activities that had unexpected results? If so what were these results and why were they unexpected? [can be good or bad results] 
9. What lessons should be learned from your work with USIP for creating a new project to achieve the same objectives?

10. What was the most significant change created by your work with USIP?

\section{Stakeholder Questionnaire for Interviews and Focus Groups}

I. To start I would like to know about the project that took place in your area. What did the project do and how were you involved? (Interviewer prompt the respondent to discuss projects from $\mathrm{CCl}$ only)

2. Please tell me in your own words how you understood the purpose of the project?

3. To what extent did you have a say in what the project did or how the project was managed?

4. In your experience, what was the most significant change that the project created?

5. The project was intended to help people to work together to solve their own problems. Did the project lead the people to work together more than before the project started? If so, then what part of the project had the biggest effect on cooperation between the people?

6. The project was intended to give people resources to make them more capable of recovering from shocks or negative events that could threaten their survival. Thinking about the situation of the people in this area now compared to before the project, to what extent was there a change in people's abilities to recover from negative events because of the project? Which abilities of the people were particularly affected by the project?

7. Some of the activities of the project were intended to establish new relationships, or strengthen existing relationships between the local people and the government. To what extent did relationships between the people and the government change because of the project?

8. Did people's confidence in the government change because of the project? If so what did the project do to cause this change in confidence?

9. The project was also intended to reduce the influence of armed opposition groups such as the Taliban on people in this area. To what extent did the influence of armed opposition groups change as a result of the project?

10. To what extent did armed opposition groups or other people in this area oppose the work of the project? If there was opposition, then how was it overcome so that the work could go forward?

II. To what extent did the project create lasting changes to the situation of the people here after the end of the project? 


\section{ANNEX IV: SOURCES OF INFORMATION}

\section{Key Documents Reviewed}

\begin{tabular}{|c|c|c|}
\hline Reference & Title & Type \\
\hline DOC-0I & $\begin{array}{l}\text { Lessons Learned from the Afghanistan Community Cohesion } \\
\text { Initiative, Creative and OTI }\end{array}$ & Internal CCI Document \\
\hline DOC-02 & OTI Afghanistan Management Review 2013 (I8-28 June) & Internal CCI Document \\
\hline DOC-03 & Afghanistan Field Strategy Memo: Version 3.0 August 5, 2012 & Internal CCI Document \\
\hline DOC-04 & Entry Memos: Balkh, Jawzjan, Samangan, Hirat, Badghis & Internal $\mathrm{CCl}$ Document \\
\hline DOC-05 & Supporting Alternatives to Violence in Elections - May 2013 & Internal CCI Document \\
\hline DOC-06 & CCl Implementation Plan 2013-10-17 & Internal CCI Document \\
\hline DOC-07 & CCI SRS 2013-II-05 & Internal CCI Document \\
\hline DOC-08 & Afghanistan PPR Report I.2.13 & Internal CCI Document \\
\hline DOC-09 & PPMR Afghanistan July 2014 & Internal CCI Document \\
\hline DOC- 10 & CCI 2015 SRS Report & Internal CCI Document \\
\hline DOC-II & CCI Annual Report Oct 2013 - Sept 2014 FINAL & Published Report \\
\hline DOC-12 & OTI CCI M\&E Strategy Final 01232014 & Internal $\mathrm{CCl}$ Document \\
\hline DOC-13 & 2012 II I4 CCI Programming methodology and approach & Internal CCI Document \\
\hline DOC-14 & 2012.05 Objectives, Goals and Indicators, consolidated & Internal $\mathrm{CCl}$ Document \\
\hline DOC-I5 & $2012.12 .12 \mathrm{CCl}$ Theory of Change (I) & Internal CCI Document \\
\hline DOC-16 & CCl Annual Report Oct 2012 Sept 20137 Nov final & Internal CCI Document \\
\hline DOC-17 & $\mathrm{CCl}$ Program Evolution Document 07.26.13 & Internal CCI Document \\
\hline DOC-18 & $\mathrm{CCl}$ rationale for working in districts, 9.15 .2012 & Internal CCI Document \\
\hline DOC-19 & CCI Strategic Communications Strategy 140612 Final & Internal CCI Document \\
\hline DOC-20 & $\mathrm{CCl}$ Strategy 20I2-20I5 version June 2013 & Internal CCI Document \\
\hline DOC-2I & CCI SW Regional Strategy Updated June 9 & Internal CCI Document \\
\hline DOC-22 & Draft Strategy Document ASI II I3March20I2 & Internal CCI Document \\
\hline DOC-23 & OTI Afghanistan Entry Criteria-March 12 & Internal CCI Document \\
\hline DOC-24 & $\mathrm{CCl}$ Expansion Lessons Learned v5 & Internal CCI Document \\
\hline DOC-25 & CCI SCAPE v2(2) OTI eds 09III3.ppt & Internal CCI Document \\
\hline DOC-26 & Memo S Realignment July 2013 & Internal CCI Document \\
\hline DOC-27 & Operational Plan for Realization of the Revised CCI Strategy & Internal CCI Document \\
\hline DOC-28 & OTI-IOM Startup Meeting Minutes Sept 292013 Rough Version & Internal CCI Document \\
\hline DOC-29 & Balkh Entry Memo & Internal CCI Document \\
\hline DOC-30 & Brief Security Context Faryab and SarePul, 5.7.20I4 & Internal CCI Document \\
\hline DOC-3I & CCI Supporting Alternatives to Violence in Elections May 2013 & Internal CCI Document \\
\hline DOC-32 & CCl Creative Last Kick Strategy 20 May & Internal CCI Document \\
\hline DOC-33 & CCI CVE Strategy Final & Internal CCI Document \\
\hline DOC-34 & CCl-Afghanistan-Election-Audit-Observation-FINAL-REPORT (I) & Internal CCI Document \\
\hline DOC-35 & Innocent Heart Summary, Creative Associates PDU activity & Internal CCI Document \\
\hline DOC-36 & $\begin{array}{l}\text { Countering Violent Extremism: Midterm Insights," USIP Kabul } \\
\text { Office }\end{array}$ & Internal $\mathrm{CCl}$ Document \\
\hline DOC-37 & $\begin{array}{l}\text { 3ie Impact Evaluation Practice: A Guide for Grantees. New Delhi: } \\
\text { International Initiative for Impact Evaluation. }\end{array}$ & Published article \\
\hline
\end{tabular}




\begin{tabular}{l|l|l} 
Reference & \multicolumn{1}{c}{ Title } & \multicolumn{1}{c}{ Type } \\
\hline DOC-38 & $\begin{array}{l}\text { Afghanistan Program Strategic Re-Orientation (Afghanistan Field } \\
\text { Strategy Memo: Version 3.0 August 5, 20I2) }\end{array}$ & Internal CCI Document \\
\hline DOC-39 & $\begin{array}{l}\text { October 20I4 Afghanistan ROLLING ASSESSMENT MEMO and } \\
\text { SUMMARY of Strategic Framework Changes }\end{array}$ & Internal CCI Document \\
\hline DOC-40 & USAID/Afghanistan Mission Order 20I.05 & Published Document \\
\hline DOC-4I & $\begin{array}{l}\text { International Crisis Group Report: “Afghanistan: The Long, Hard } \\
\text { Road to the 2014 Transition" }\end{array}$ & Published article \\
\hline
\end{tabular}




\section{List of Focus Groups Discussions and Participants}

\begin{tabular}{|c|c|c|c|c|c|c|}
\hline FGD Code & $\begin{array}{c}\text { Participant } \\
\text { No. }\end{array}$ & $\begin{array}{c}\text { Participant } \\
\text { Type }\end{array}$ & Age & Occupation & Date & Location \\
\hline ADR-FGD-0I & 1 & Male youth & 18 & Student & $12-O c t-15$ & Herat - Adraskan \\
\hline ADR-FGD-0I & 2 & Male youth & 20 & Tailor & $12-O c t-15$ & Herat - Adraskan \\
\hline ADR-FGD-0I & 3 & Male youth & 21 & School teacher & $12-O c t-15$ & Herat - Adraskan \\
\hline ADR-FGD-0I & 4 & Male youth & 22 & School teacher & $12-O c t-15$ & Herat - Adraskan \\
\hline ADR-FGD-0I & 5 & Male youth & 32 & Deputy of the shura & $12-O c t-15$ & Herat - Adraskan \\
\hline ADR-FGD-0I & 6 & Male youth & 60 & School teacher & $12-O c t-15$ & Herat - Adraskan \\
\hline ADR-FGD-0I & 7 & Male youth & 23 & School teacher & $12-O c t-15$ & Herat - Adraskan \\
\hline ADR-FGD-0I & 8 & Male youth & 26 & Shopkeeper & $12-O c t-15$ & Herat - Adraskan \\
\hline ADR-FGD-02 & 1 & Male & 60 & Self-employed & $10-O c t-15$ & Herat - Adraskan \\
\hline ADR-FGD-02 & 2 & Male & 42 & Self-employed & $10-O c t-15$ & Herat - Adraskan \\
\hline ADR-FGD-02 & 3 & Male & 54 & Self-employed & $10-O c t-15$ & Herat - Adraskan \\
\hline ADR-FGD-02 & 4 & Male & 38 & Member of the shura & $10-O c t-15$ & Herat - Adraskan \\
\hline ADR-FGD-02 & 5 & Male & 56 & Farmer & $10-O c t-15$ & Herat - Adraskan \\
\hline ADR-FGD-02 & 6 & Male & 55 & Self-employed & $10-O c t-15$ & Herat - Adraskan \\
\hline ADR-FGD-02 & 7 & Male & 48 & Self-employed & $10-O c t-15$ & Herat - Adraskan \\
\hline ADR-FGD-02 & 8 & Male & 52 & Self-employed & $10-O c t-15$ & Herat - Adraskan \\
\hline ADR-FGD-03 & 1 & Female & 30 & Housewife/Homemaker & $12-O c t-15$ & Herat - Adraskan \\
\hline ADR-FGD-03 & 2 & Female & 55 & Head of the shura & $12-O c t-15$ & Herat - Adraskan \\
\hline ADR-FGD-03 & 3 & Female & 38 & Housewife/Homemaker & $12-O c t-15$ & Herat - Adraskan \\
\hline ADR-FGD-03 & 4 & Female & 32 & Member of the shura & $12-$ Oct- 15 & Herat - Adraskan \\
\hline ADR-FGD-03 & 5 & Female & 38 & Member of the shura & $12-O c t-15$ & Herat - Adraskan \\
\hline ADR-FGD-03 & 6 & Female & 28 & Housewife/Homemaker & $12-$ Oct-15 & Herat - Adraskan \\
\hline ADR-FGD-03 & 7 & Female & 30 & Member of the shura & $12-O c t-15$ & Herat - Adraskan \\
\hline BDG-FGD-0I & 8 & Male youth & 20 & High school student & $17-O c t-15$ & Badghis - Qadis \\
\hline BDG-FGD-0I & 2 & Male youth & 21 & College student & $17-O c t-15$ & Badghis - Qadis \\
\hline BDG-FGD-0I & 3 & Male youth & 23 & School student & $17-O c t-15$ & Badghis - Qadis \\
\hline BDG-FGD-0I & 4 & Male youth & 27 & School student & $17-O c t-15$ & Badghis - Qadis \\
\hline
\end{tabular}




\begin{tabular}{|c|c|c|c|c|c|c|}
\hline FGD Code & $\begin{array}{c}\text { Participant } \\
\text { No. }\end{array}$ & $\begin{array}{c}\text { Participant } \\
\text { Type }\end{array}$ & Age & Occupation & Date & Location \\
\hline BDG-FGD-0I & 5 & Male youth & 19 & $\begin{array}{l}\text { Member of youth shura in } \\
\text { Qadis }\end{array}$ & 17-Oct- 15 & Badghis - Qadis \\
\hline BDG-FGD-0I & 6 & Male youth & 21 & College student & $17-O c t-15$ & Badghis - Qadis \\
\hline BDG-FGD-0I & 7 & Male youth & 20 & Deputy of shura & 17-Oct-15 & Badghis - Qadis \\
\hline BDG-FGD-0I & 8 & Male youth & 21 & College student & $17-O c t-15$ & Badghis - Qadis \\
\hline BDG-FGD-02 & I & Female & 30 & School teacher & $14-O c t-15$ & Badghis - Qala-i-Naw \\
\hline BDG-FGD-02 & 2 & Female & 25 & Employee & 14-Oct-15 & Badghis - Qala-i-Naw \\
\hline BDG-FGD-02 & 3 & Female & 32 & Health clinic employee & 14-Oct-15 & Badghis - Qala-i-Naw \\
\hline BDG-FGD-02 & 4 & Female & 21 & Private tuition course teacher & 14-Oct-I5 & Badghis - Qala-i-Naw \\
\hline BDG-FGD-02 & 5 & Female & 25 & Employee & $14-O c t-15$ & Badghis - Qala-i-Naw \\
\hline BDG-FGD-02 & 6 & Female & 27 & School student & 14-Oct-I5 & Badghis - Qala-i-Naw \\
\hline BDG-FGD-02 & 7 & Female & 36 & School teacher & 14-Oct-I5 & Badghis - Qala-i-Naw \\
\hline BDG-FGD-02 & 8 & Female & 24 & Employee & 14-Oct-15 & Badghis - Qala-i-Naw \\
\hline BDG-FGD-03 & I & Male & 60 & $\begin{array}{l}\text { Acting Hajj and Religious } \\
\text { Affairs Director of the district }\end{array}$ & $13-O c t-15$ & Badghis - Qadis \\
\hline BDG-FGD-03 & 2 & Male & 49 & Head of Mullah's shura & $13-O c t-15$ & Badghis - Qadis \\
\hline BDG-FGD-03 & 3 & Male & 52 & $\begin{array}{c}\text { Department of Rural } \\
\text { Rehabilitation Social Worker }\end{array}$ & $13-O c t-15$ & Badghis - Qadis \\
\hline BDG-FGD-03 & 4 & Male & 47 & $\begin{array}{c}\text { Deputy of Qadis } \\
\text { Development Shura }\end{array}$ & 13-Oct-I5 & Badghis - Qadis \\
\hline BDG-FGD-03 & 5 & Male & 45 & Self-employed & $13-O c t-15$ & Badghis - Qadis \\
\hline BDG-FGD-03 & 6 & Male & 25 & $\begin{array}{l}\text { Employee of Dept of Rural } \\
\text { Rehabilitation }\end{array}$ & 13-Oct-I 5 & Badghis - Qadis \\
\hline BDG-FGD-03 & 7 & Male & 30 & Self-employed & $13-O c t-15$ & Badghis - Qadis \\
\hline BDG-FGD-03 & 8 & Male & 55 & Teacher & $13-O c t-15$ & Badghis - Qadis \\
\hline INJ-FGD-0 I & I & Male youth & 25 & Deputy of the shura & $15-O c t-15$ & Herat - Injil \\
\hline INJ-FGD-0I & 2 & Male youth & 20 & Student & 15-Oct-15 & Herat - Injil \\
\hline INJ-FGD-0I & 3 & Male youth & 26 & Teacher & 15-Oct-I5 & Herat - Injil \\
\hline INJ-FGD-0I & 4 & Male youth & 25 & Self-employed & I5-Oct-15 & Herat - Injil \\
\hline
\end{tabular}




\begin{tabular}{|c|c|c|c|c|c|c|}
\hline FGD Code & $\begin{array}{l}\text { Participant } \\
\text { No. }\end{array}$ & $\begin{array}{l}\text { Participant } \\
\text { Type }\end{array}$ & Age & Occupation & Date & Location \\
\hline INJ-FGD-0I & 5 & Male youth & 25 & Student & $15-O c t-15$ & Herat - Injil \\
\hline INJ-FGD-0I & 6 & Male youth & 22 & Student & $15-O c t-15$ & Herat - Injil \\
\hline INJ-FGD-0I & 7 & Male youth & 18 & Student & $15-O c t-15$ & Herat - Injil \\
\hline INJ-FGD-0I & 8 & Male youth & 18 & Student & $15-O c t-15$ & Herat - Injil \\
\hline INJ-FGD-02 & 1 & Male & 26 & Teacher & $15-O c t-15$ & Herat - Injil \\
\hline INJ-FGD-02 & 2 & Male & 18 & Student & $15-O c t-15$ & Herat - Injil \\
\hline INJ-FGD-02 & 3 & Male & 18 & Student & $15-$ Oct- 15 & Herat - Injil \\
\hline INJ-FGD-02 & 4 & Male & 48 & Member of the shura & $15-O c t-15$ & Herat - Injil \\
\hline INJ-FGD-02 & 5 & Male & 41 & Farmer & $15-O c t-15$ & Herat - Injil \\
\hline INJ-FGD-02 & 6 & Male & 51 & Farmer & 15-Oct-15 & Herat - Injil \\
\hline INJ-FGD-02 & 7 & Male & 65 & Farmer & $15-O c t-15$ & Herat - Injil \\
\hline INJ-FGD-02 & 8 & Male & 42 & Farmer & $15-O c t-15$ & Herat - Injil \\
\hline INJ-FGD-03 & 1 & Female & 21 & Student & $15-O c t-15$ & Herat - Injil \\
\hline INJ-FGD-03 & 2 & Female & 19 & Homemaker & $15-O c t-15$ & Herat - Injil \\
\hline INJ-FGD-03 & 3 & Female & 22 & College student & $15-O c t-15$ & Herat - Injil \\
\hline INJ-FGD-03 & 4 & Female & 27 & Teacher & $15-O c t-15$ & Herat - Injil \\
\hline INJ-FGD-03 & 5 & Female & 22 & Homemaker & 15-Oct-15 & Herat - Injil \\
\hline INJ-FGD-03 & 6 & Female & 22 & Student & $15-O c t-15$ & Herat - Injil \\
\hline INJ-FGD-03 & 7 & Female & 17 & Homemaker & $15-O c t-15$ & Herat - Injil \\
\hline INJ-FGD-03 & 8 & Female & 17 & Homemaker & $15-O c t-15$ & Herat - Injil \\
\hline KJK-FGD-0I & 1 & Male & 45 & $\begin{array}{l}\text { Kajaki Shura member and } \\
\text { project beneficiary }\end{array}$ & $15-O c t-15$ & Helmand - Lashkargah \\
\hline KJK-FGD-0I & 2 & Male & 36 & $\mathrm{CCl}$ beneficiary & $15-O c t-15$ & Helmand - Lashkargah \\
\hline KJK-FGD-0I & 3 & Male & 57 & Project beneficiary & $15-O c t-15$ & Helmand - Lashkargah \\
\hline KJK-FGD-0I & 4 & Male & 53 & $\mathrm{CCl}$ beneficiary & $15-O c t-15$ & Helmand - Lashkargah \\
\hline KJK-FGD-0I & 5 & Male & 56 & $\begin{array}{c}\text { Kajaki Shura member and } \\
\text { project beneficiary }\end{array}$ & $15-O c t-15$ & Helmand - Lashkargah \\
\hline KJK-FGD-0I & 6 & Male & 44 & Jobless & $15-O c t-15$ & Helmand - Lashkargah \\
\hline KJK-FGD-0I & 7 & Male & 36 & $\mathrm{CCl}$ beneficiary & $15-O c t-15$ & Helmand - Lashkargah \\
\hline
\end{tabular}




\begin{tabular}{|c|c|c|c|c|c|c|}
\hline FGD Code & $\begin{array}{c}\text { Participant } \\
\text { No. }\end{array}$ & $\begin{array}{c}\text { Participant } \\
\text { Type }\end{array}$ & Age & Occupation & Date & Location \\
\hline KJK-FGD-0I & 8 & Male & 29 & $\mathrm{CCl}$ beneficiary & $15-O c t-15$ & Helmand - Lashkargah \\
\hline KJK-FGD-02 & 1 & Male youth & 34 & NA & $23-O c t-15$ & Helmand - Lashkargah \\
\hline KJK-FGD-02 & 2 & Male youth & 25 & NA & $23-O c t-15$ & Helmand - Lashkargah \\
\hline KJK-FGD-02 & 3 & Male youth & 22 & NA & $23-O c t-15$ & Helmand - Lashkargah \\
\hline KJK-FGD-02 & 4 & Male youth & 20 & NA & $23-$ Oct- 15 & Helmand - Lashkargah \\
\hline KJK-FGD-02 & 5 & Male youth & 63 & NA & $23-O c t-15$ & Helmand - Lashkargah \\
\hline KJK-FGD-02 & 6 & Male youth & 18 & NA & $23-O c t-15$ & Helmand - Lashkargah \\
\hline KJK-FGD-02 & 7 & Male youth & 26 & NA & $23-O c t-15$ & Helmand - Lashkargah \\
\hline KJK-FGD-02 & 8 & Male youth & 27 & NA & $23-$ Oct- 15 & Helmand - Lashkargah \\
\hline KND-FGD-0I & I & Female & 40 & $\begin{array}{l}\text { Nahia I women shura } \\
\text { secretary }\end{array}$ & $8-O c t-15$ & Kandahar - Kandahar \\
\hline KND-FGD-0I & 2 & Female & 36 & $\begin{array}{c}\text { Nahia I women shura } \\
\text { member }\end{array}$ & $8-O c t-15$ & Kandahar - Kandahar \\
\hline KND-FGD-0I & 3 & Female & 23 & School teacher & $8-O c t-15$ & Kandahar - Kandahar \\
\hline KND-FGD-0I & 4 & Female & 44 & $\begin{array}{c}\text { Employee of Department of } \\
\text { Women Affairs }\end{array}$ & $8-O c t-15$ & Kandahar - Kandahar \\
\hline KND-FGD-0I & 5 & Female & 18 & $\begin{array}{c}\text { Nahia } 3 \text { women shura } \\
\text { member }\end{array}$ & $8-O c t-15$ & Kandahar - Kandahar \\
\hline KND-FGD-0I & 6 & Female & 22 & Jobless & $8-O c t-15$ & Kandahar - Kandahar \\
\hline KND-FGD-0I & 7 & Female & 22 & School teacher & $8-O c t-15$ & Kandahar - Kandahar \\
\hline KND-FGD-0I & 8 & Female & 23 & School teacher & $8-O c t-15$ & Kandahar - Kandahar \\
\hline KND-FGD-02 & 1 & Male & 41 & Elder & $13-O c t-15$ & Kandahar - District 8 \\
\hline KND-FGD-02 & 2 & Male & 54 & Representative of Nahia & $13-O c t-15$ & Kandahar - District 8 \\
\hline KND-FGD-02 & 3 & Male & 25 & Farmer & $13-O c t-15$ & Kandahar - District 8 \\
\hline KND-FGD-02 & 4 & Male & 40 & Jobless & $13-O c t-15$ & Kandahar - District 8 \\
\hline KND-FGD-02 & 5 & Male & 63 & Representative of Nahia & $13-O c t-15$ & Kandahar - District 8 \\
\hline KND-FGD-02 & 6 & Male & 59 & Elder & $13-O c t-15$ & Kandahar - District 8 \\
\hline KND-FGD-02 & 7 & Male & 48 & Tribal Elder & $13-O c t-15$ & Kandahar - District 8 \\
\hline KND-FGD-02 & 8 & Male & 71 & Tribal Elder & $13-O c t-15$ & Kandahar - District 8 \\
\hline
\end{tabular}




\begin{tabular}{|c|c|c|c|c|c|c|}
\hline FGD Code & $\begin{array}{c}\text { Participant } \\
\text { No. }\end{array}$ & $\begin{array}{c}\text { Participant } \\
\text { Type }\end{array}$ & Age & Occupation & Date & Location \\
\hline KND-FGD-03 & 1 & Male youth & 63 & Musician & $14-O c t-15$ & Kandahar - Kandahar Center \\
\hline KND-FGD-03 & 2 & Male youth & 28 & Musician & $14-O c t-15$ & Kandahar - Kandahar Center \\
\hline KND-FGD-03 & 3 & Male youth & 48 & Poet & $14-O c t-15$ & Kandahar - Kandahar Center \\
\hline KND-FGD-03 & 4 & Male youth & 56 & Social worker & $14-O c t-15$ & Kandahar - Kandahar Center \\
\hline KND-FGD-03 & 5 & Male youth & 22 & Civil activist & $14-O c t-15$ & Kandahar - Kandahar Center \\
\hline KND-FGD-03 & 6 & Male youth & 21 & Social worker & $14-O c t-15$ & Kandahar - Kandahar Center \\
\hline KND-FGD-03 & 7 & Male youth & 20 & Musician & $14-O c t-15$ & Kandahar - Kandahar Center \\
\hline KND-FGD-03 & 8 & Male youth & 23 & Poet & $14-O c t-15$ & Kandahar - Kandahar Center \\
\hline KUR-FGD-0I & 1 & Male & 28 & NA & $11-O c t-15$ & Kunar - Khas Kunar \\
\hline KUR-FGD-0I & 2 & Male & 42 & NA & $11-O c t-15$ & Kunar - Khas Kunar \\
\hline KUR-FGD-0I & 3 & Male & 55 & NA & $11-O c t-15$ & Kunar - Khas Kunar \\
\hline KUR-FGD-0I & 4 & Male & 36 & NA & II-Oct-15 & Kunar - Khas Kunar \\
\hline KUR-FGD-0I & 5 & Male & 40 & NA & $11-O c t-15$ & Kunar - Khas Kunar \\
\hline KUR-FGD-0I & 6 & Male & 40 & NA & $11-O c t-15$ & Kunar - Khas Kunar \\
\hline KUR-FGD-0I & 7 & Male & 60 & NA & $11-O c t-15$ & Kunar - Khas Kunar \\
\hline KUR-FGD-0I & 8 & Male & 42 & NA & $11-O c t-15$ & Kunar - Khas Kunar \\
\hline KUR-FGD-02 & 1 & Male youth & 18 & Student & $12-O c t-15$ & Kunar - Khas Kunar \\
\hline KUR-FGD-02 & 2 & Male youth & 28 & Carpenter & $12-O c t-15$ & Kunar - Khas Kunar \\
\hline KUR-FGD-02 & 3 & Male youth & 29 & NA & $12-O c t-15$ & Kunar - Khas Kunar \\
\hline KUR-FGD-02 & 4 & Male youth & 30 & NA & $12-O c t-15$ & Kunar - Khas Kunar \\
\hline KUR-FGD-02 & 5 & Male youth & 24 & NA & $12-O c t-15$ & Kunar - Khas Kunar \\
\hline KUR-FGD-02 & 6 & Male youth & 24 & NA & $12-O c t-15$ & Kunar - Khas Kunar \\
\hline KUR-FGD-02 & 7 & Male youth & 26 & Worker & $12-O c t-15$ & Kunar - Khas Kunar \\
\hline KUR-FGD-02 & 8 & Male youth & 27 & Worker & $12-O c t-15$ & Kunar - Khas Kunar \\
\hline KUR-FGD-03 & 1 & Female & 19 & Housewife & 9-Oct-15 & Kunar - Khas Kunar \\
\hline KUR-FGD-03 & 2 & Female & 22 & Housewife & $9-O c t-15$ & Kunar - Khas Kunar \\
\hline KUR-FGD-03 & 3 & Female & 18 & Housewife & $9-O c t-15$ & Kunar - Khas Kunar \\
\hline
\end{tabular}




\begin{tabular}{|c|c|c|c|c|c|c|}
\hline FGD Code & $\begin{array}{c}\text { Participant } \\
\text { No. }\end{array}$ & $\begin{array}{c}\text { Participant } \\
\text { Type }\end{array}$ & Age & Occupation & Date & Location \\
\hline KUR-FGD-03 & 4 & Female & 25 & Housewife & $9-O c t-15$ & Kunar - Khas Kunar \\
\hline KUR-FGD-03 & 5 & Female & 30 & Housewife & 9-Oct-I5 & Kunar - Khas Kunar \\
\hline KUR-FGD-03 & 6 & Female & 28 & Housewife & $9-O c t-15$ & Kunar - Khas Kunar \\
\hline KUR-FGD-03 & 7 & Female & 24 & Housewife & 9-Oct- I5 & Kunar - Khas Kunar \\
\hline KUR-FGD-03 & 8 & Female & 29 & Housewife & $9-O c t-15$ & Kunar - Khas Kunar \\
\hline LASH-FGD-0I & 1 & Male youth & 30 & Painter & $10-O c t-15$ & Helmand - Lashkargah \\
\hline LASH-FGD-0I & 2 & Male youth & 28 & Trainer & $10-O c t-15$ & Helmand - Lashkargah \\
\hline LASH-FGD-0I & 3 & Male youth & 25 & Jobless & $10-O c t-15$ & Helmand - Lashkargah \\
\hline LASH-FGD-0I & 4 & Male youth & 26 & Journalist & $10-O c t-15$ & Helmand - Lashkargah \\
\hline LASH-FGD-0I & 5 & Male youth & 22 & Official worker & $10-O c t-15$ & Helmand - Lashkargah \\
\hline LASH-FGD-0I & 6 & Male youth & 37 & Jobless & $10-O c t-15$ & Helmand - Lashkargah \\
\hline LASH-FGD-0I & 7 & Male youth & 28 & IRC worker & $10-O c t-15$ & Helmand - Lashkargah \\
\hline LASH-FGD-0I & 8 & Male youth & 22 & Student & $10-O c t-15$ & Helmand - Lashkargah \\
\hline LASH-FGD-02 & 1 & Male & 28 & Jobless & $17-O c t-15$ & Helmand - Lashkargah \\
\hline LASH-FGD-02 & 2 & Male & 30 & Teacher & 17-Oct-I5 & Helmand - Lashkargah \\
\hline LASH-FGD-02 & 3 & Male & 35 & Official worker & 17-Oct-15 & Helmand - Lashkargah \\
\hline LASH-FGD-02 & 4 & Male & 35 & Official worker & 17-Oct-15 & Helmand - Lashkargah \\
\hline LASH-FGD-02 & 5 & Male & 26 & Trainer & $17-O c t-15$ & Helmand - Lashkargah \\
\hline LASH-FGD-02 & 6 & Male & 29 & Teacher & $17-O c t-15$ & Helmand - Lashkargah \\
\hline LASH-FGD-02 & 7 & Male & 22 & Teacher & $17-O c t-15$ & Helmand - Lashkargah \\
\hline LASH-FGD-03 & $\mathrm{I}$ & Female & 56 & Student & 14-Oct-15 & Helmand - Lashkargah \\
\hline LASH-FGD-03 & 2 & Female & 33 & Teacher & 14-Oct- 15 & Helmand - Lashkargah \\
\hline LASH-FGD-03 & 3 & Female & 28 & Teacher & $14-O c t-15$ & Helmand - Lashkargah \\
\hline LASH-FGD-03 & 4 & Female & 29 & Teacher & 14-Oct- 15 & Helmand - Lashkargah \\
\hline LASH-FGD-03 & 5 & Female & 31 & Student & 14-Oct-I5 & Helmand - Lashkargah \\
\hline LASH-FGD-03 & 6 & Female & 27 & Student & 14-Oct-15 & Helmand - Lashkargah \\
\hline LASH-FGD-03 & 7 & Female & 22 & Student & 14-Oct-15 & Helmand - Lashkargah \\
\hline LASH-FGD-03 & 8 & Female & 20 & Teacher & 14-Oct-15 & Helmand - Lashkargah \\
\hline
\end{tabular}




\begin{tabular}{|c|c|c|c|c|c|c|}
\hline FGD Code & $\begin{array}{c}\text { Participant } \\
\text { No. }\end{array}$ & $\begin{array}{c}\text { Participant } \\
\text { Type }\end{array}$ & Age & Occupation & Date & Location \\
\hline NRS-FGD-0I & I & Male & 35 & Tribal elder & $25-O c t-15$ & Helmand - Nahar-e-Saraj \\
\hline NRS-FGD-0I & 2 & Male & 36 & Tribal elder & $25-O c t-15$ & Helmand - Nahar-e-Saraj \\
\hline NRS-FGD-0I & 3 & Male & 27 & Civil activist & 25-Oct-15 & Helmand - Nahar-e-Saraj \\
\hline NRS-FGD-0I & 4 & Male & 40 & Tribal elder & $25-O c t-15$ & Helmand - Nahar-e-Saraj \\
\hline NRS-FGD-0I & 5 & Male & 45 & Tribal elder & $25-O c t-15$ & Helmand - Nahar-e-Saraj \\
\hline NRS-FGD-0I & 6 & Male & 36 & Shopkeeper & $25-O c t-15$ & Helmand - Nahar-e-Saraj \\
\hline NRS-FGD-0I & 7 & Male & 38 & Tribal elder & $25-O c t-15$ & Helmand - Nahar-e-Saraj \\
\hline NRS-FGD-0I & 8 & Male & 39 & Tribal elder & $25-O c t-15$ & Helmand - Nahar-e-Saraj \\
\hline NRS-FGD-02 & I & Male youth & 22 & Student & $18-O c t-15$ & Helmand - Nahar-e-Saraj \\
\hline NRS-FGD-02 & 2 & Male youth & 23 & Student & $18-O c t-15$ & Helmand - Nahar-e-Saraj \\
\hline NRS-FGD-02 & 3 & Male youth & 35 & Teacher & 18-Oct-15 & Helmand - Nahar-e-Saraj \\
\hline NRS-FGD-02 & 4 & Male youth & 27 & Shopkeeper & 18-Oct-I5 & Helmand - Nahar-e-Saraj \\
\hline NRS-FGD-02 & 5 & Male youth & 23 & Shopkeeper & 18-Oct-15 & Helmand - Nahar-e-Saraj \\
\hline NRS-FGD-02 & 6 & Female youth & 25 & Shura member & $18-O c t-15$ & Helmand - Nahar-e-Saraj \\
\hline NRS-FGD-02 & 7 & Male youth & 22 & Jobless & $18-O c t-15$ & Helmand - Nahar-e-Saraj \\
\hline NRS-FGD-02 & 8 & Male youth & 25 & Jobless & $18-O c t-15$ & Helmand - Nahar-e-Saraj \\
\hline NRS-FGD-03 & $\mathrm{I}$ & Female & 22 & Student & 14-Oct-15 & Helmand - Nahia 2 \\
\hline NRS-FGD-03 & 2 & Female & 39 & Teacher & 14-Oct- 15 & Helmand - Nahia 2 \\
\hline NRS-FGD-03 & 3 & Female & 56 & Teacher & 14-Oct-I5 & Helmand - Nahia 2 \\
\hline NRS-FGD-03 & 4 & Female & 18 & Teacher & 14-Oct-I5 & Helmand - Nahia 2 \\
\hline NRS-FGD-03 & 5 & Female & 56 & NA & 14-Oct-I5 & Helmand - Nahia 2 \\
\hline NRS-FGD-03 & 6 & Female & 21 & NA & 14-Oct-I5 & Helmand - Nahia 2 \\
\hline NRS-FGD-03 & 7 & Female & 26 & Teacher & 14-Oct- I5 & Helmand - Nahia 2 \\
\hline NRS-FGD-03 & 8 & Female & 26 & Student & 14-Oct-15 & Helmand - Nahia 2 \\
\hline NRS-FGD-04 & 1 & Female & 35 & Teacher & 14-Oct-I5 & Helmand - Nahri - Saraj \\
\hline NRS-FGD-04 & 2 & Female & 22 & Teacher & $14-O c t-15$ & Helmand - Nahri - Saraj \\
\hline NRS-FGD-04 & 3 & Female & 29 & NA & $14-O c t-15$ & Helmand - Nahri - Saraj \\
\hline NRS-FGD-04 & 4 & Female & 56 & NA & $14-O c t-15$ & Helmand - Nahri - Saraj \\
\hline
\end{tabular}




\begin{tabular}{|c|c|c|c|c|c|c|}
\hline FGD Code & $\begin{array}{c}\text { Participant } \\
\text { No. }\end{array}$ & $\begin{array}{c}\text { Participant } \\
\text { Type }\end{array}$ & Age & Occupation & Date & Location \\
\hline NRS-FGD-04 & 5 & Female & 45 & NA & 14-Oct-15 & Helmand - Nahri - Saraj \\
\hline NRS-FGD-04 & 6 & Female & 38 & NA & $14-O c t-15$ & Helmand - Nahri - Saraj \\
\hline NRS-FGD-04 & 7 & Female & 30 & NA & $14-O c t-15$ & Helmand - Nahri - Saraj \\
\hline NRS-FGD-04 & 8 & Female & 25 & NA & 14-Oct-15 & Helmand - Nahri - Saraj \\
\hline PNJ-FGD-0I & I & Female & 30 & Council member & $8-O c t-15$ & Kandahar - Panjwai \\
\hline PNJ-FGD-0I & 2 & Female & 60 & Teacher & $8-O c t-15$ & Kandahar - Panjwai \\
\hline PNJ-FGD-0I & 3 & Female & 40 & NA & $8-O c t-15$ & Kandahar - Panjwai \\
\hline PNJ-FGD-0I & 4 & Female & 44 & Tailor & $8-O c t-15$ & Kandahar - Panjwai \\
\hline PNJ-FGD-0I & 5 & Female & 25 & Teacher & $8-O c t-15$ & Kandahar - Panjwai \\
\hline PNJ-FGD-0I & 6 & Female & 32 & Tailor & $8-O c t-15$ & Kandahar - Panjwai \\
\hline PNJ-FGD-0I & 7 & Female & 22 & Nurse & $8-O c t-15$ & Kandahar - Panjwai \\
\hline PNJ-FGD-0I & 8 & Female & 35 & Teacher & $8-O c t-15$ & Kandahar - Panjwai \\
\hline PNJ-FGD-02 & I & Male & 40 & DDA member & II-Oct-I5 & Kandahar - Panjwai \\
\hline PNJ-FGD-02 & 2 & Male & 42 & NA & $11-O c t-15$ & Kandahar - Panjwai \\
\hline PNJ-FGD-02 & 3 & Male & 32 & Farmer & II-Oct-I5 & Kandahar - Panjwai \\
\hline PNJ-FGD-02 & 4 & Male & 30 & $\begin{array}{c}\text { CDC member and self- } \\
\text { employed }\end{array}$ & II-Oct-I 5 & Kandahar - Panjwai \\
\hline PNJ-FGD-02 & 5 & Male & 22 & Jobless & II-Oct-I5 & Kandahar - Panjwai \\
\hline PNJ-FGD-02 & 6 & Male & 35 & Worker & II-Oct-I5 & Kandahar - Panjwai \\
\hline PNJ-FGD-02 & 7 & Male & 31 & DDA member & II-Oct-I5 & Kandahar - Panjwai \\
\hline PNJ-FGD-02 & 8 & Male & 26 & Elder & $11-O c t-15$ & Kandahar - Panjwai \\
\hline PNJ-FGD-02 & 9 & Male & 36 & Elder & II-Oct-I5 & Kandahar - Panjwai \\
\hline PNJ-FGD-03 & I & Male youth & 21 & Worker & II-Oct-I5 & Kandahar - Panjwai \\
\hline PNJ-FGD-03 & 2 & Male youth & 25 & NA & II-Oct-I5 & Kandahar - Panjwai \\
\hline PNJ-FGD-03 & 3 & Male youth & 45 & Team leader & II-Oct-I5 & Kandahar - Panjwai \\
\hline PNJ-FGD-03 & 4 & Male youth & 20 & Council member & II-Oct-I5 & Kandahar - Panjwai \\
\hline PNJ-FGD-03 & 5 & Male youth & 35 & Supervisor & II-Oct-I5 & Kandahar - Panjwai \\
\hline PNJ-FGD-03 & 6 & Male youth & 25 & Council member & $11-O c t-15$ & Kandahar - Panjwai \\
\hline
\end{tabular}




\begin{tabular}{|c|c|c|c|c|c|c|}
\hline FGD Code & $\begin{array}{c}\text { Participant } \\
\text { No. }\end{array}$ & $\begin{array}{c}\text { Participant } \\
\text { Type }\end{array}$ & Age & Occupation & Date & Location \\
\hline PNJ-FGD-03 & 7 & Male youth & 50 & Head of Council & II-Oct-15 & Kandahar - Panjwai \\
\hline SMG-FGD-0I & I & Female & 35 & Homemaker & $13-O c t-15$ & Samangan - Hazrat Sultan \\
\hline SMG-FGD-0I & 2 & Female & 32 & Homemaker & $13-O c t-15$ & Samangan - Hazrat Sultan \\
\hline SMG-FGD-0I & 3 & Female & 25 & Student & 13-Oct-15 & Samangan - Hazrat Sultan \\
\hline SMG-FGD-0I & 4 & Female & 45 & Deputy of the shura & 13-Oct-15 & Samangan - Hazrat Sultan \\
\hline SMG-FGD-0I & 5 & Female & 26 & Teacher & $13-O c t-15$ & Samangan - Hazrat Sultan \\
\hline SMG-FGD-0I & 6 & Female & 24 & Student & $13-O c t-15$ & Samangan - Hazrat Sultan \\
\hline SMG-FGD-0I & 7 & Female & 33 & Shura member & $13-O c t-15$ & Samangan - Hazrat Sultan \\
\hline SMG-FGD-0I & 8 & Female & 42 & Homemaker & 13-Oct-15 & Samangan - Hazrat Sultan \\
\hline SMG-FGD-02 & I & Male & 41 & Head of the shura & 13-Oct-15 & Samangan - Hazrat Sultan \\
\hline SMG-FGD-02 & 2 & Male & 52 & Malik of village & $13-O c t-15$ & Samangan - Hazrat Sultan \\
\hline SMG-FGD-02 & 3 & Male & 46 & Mullah & $13-O c t-15$ & Samangan - Hazrat Sultan \\
\hline SMG-FGD-02 & 4 & Male & 47 & Qawmi leader & $13-O c t-15$ & Samangan - Hazrat Sultan \\
\hline SMG-FGD-02 & 5 & Male & 28 & Treasurer/cashier of the shura & 13-Oct- I5 & Samangan - Hazrat Sultan \\
\hline SMG-FGD-02 & 6 & Male & 37 & Shura member & $13-O c t-15$ & Samangan - Hazrat Sultan \\
\hline SMG-FGD-02 & 7 & Male & 46 & NA & 13-Oct-I5 & Samangan - Hazrat Sultan \\
\hline SMG-FGD-02 & 8 & Male & 36 & Teacher & 13-Oct-15 & Samangan - Hazrat Sultan \\
\hline SMG-FGD-03 & I & Male youth & 36 & Teacher & I5-Oct-I5 & Samangan - Hazrat Sultan \\
\hline SMG-FGD-03 & 2 & Male youth & 34 & Teacher & $15-O c t-15$ & Samangan - Hazrat Sultan \\
\hline SMG-FGD-03 & 3 & Male youth & 30 & Teacher & I5-Oct-15 & Samangan - Hazrat Sultan \\
\hline SMG-FGD-03 & 4 & Male youth & 33 & Qawmi leader & 15-Oct-I5 & Samangan - Hazrat Sultan \\
\hline SMG-FGD-03 & 5 & Male youth & 27 & Student & I5-Oct-I5 & Samangan - Hazrat Sultan \\
\hline SMG-FGD-03 & 6 & Male youth & 35 & Shura member & I5-Oct-I5 & Samangan - Hazrat Sultan \\
\hline SMG-FGD-03 & 7 & Male youth & 36 & Shura treasurer & $15-O c t-15$ & Samangan - Hazrat Sultan \\
\hline SMG-FGD-03 & 8 & Male youth & 32 & Deputy to Village Council & 15-Oct-I5 & Samangan - Hazrat Sultan \\
\hline TRZ-FGD-0I & I & Female & 32 & Teacher & $13-O c t-15$ & Khost Center - Center \\
\hline TRZ-FGD-0I & 2 & Female & 20 & Teacher & 13-Oct- I5 & Khost Center - Center \\
\hline TRZ-FGD-0I & 3 & Female & 30 & NA & $13-O c t-15$ & Khost Center - Center \\
\hline
\end{tabular}




\begin{tabular}{|c|c|c|c|c|c|c|}
\hline FGD Code & $\begin{array}{c}\text { Participant } \\
\text { No. }\end{array}$ & $\begin{array}{c}\text { Participant } \\
\text { Type }\end{array}$ & Age & Occupation & Date & Location \\
\hline TRZ-FGD-0I & 4 & Female & 39 & NA & $13-O c t-15$ & Khost Center - Center \\
\hline TRZ-FGD-0I & 5 & Female & 38 & NA & $13-O c t-15$ & Khost Center - Center \\
\hline TRZ-FGD-0I & 6 & Female & 31 & NA & 13-Oct-15 & Khost Center - Center \\
\hline TRZ-FGD-0I & 7 & Female & 23 & NA & 13-Oct-15 & Khost Center - Center \\
\hline TRZ-FGD-0I & 8 & Female & 23 & Headmaster & $13-O c t-15$ & Khost Center - Center \\
\hline TRZ-FGD-02 & I & Male youth & 24 & Student & 12-Oct-15 & Khost Center - Terizi \\
\hline TRZ-FGD-02 & 2 & Male youth & 36 & NA & 12-Oct- I5 & Khost Center - Terizi \\
\hline TRZ-FGD-02 & 3 & Male youth & 28 & NA & $12-O c t-15$ & Khost Center - Terizi \\
\hline TRZ-FGD-02 & 4 & Male youth & 29 & Head of Youth Council & 12-Oct-15 & Khost Center - Terizi \\
\hline TRZ-FGD-02 & 5 & Male youth & 27 & NA & $12-O c t-15$ & Khost Center - Terizi \\
\hline TRZ-FGD-02 & 6 & Male youth & 23 & NA & $12-O c t-15$ & Khost Center - Terizi \\
\hline TRZ-FGD-02 & 7 & Male youth & 28 & NA & 12-Oct-I5 & Khost Center - Terizi \\
\hline TRZ-FGD-02 & 8 & Male youth & 38 & NA & $12-O c t-15$ & Khost Center - Terizi \\
\hline TRZ-FGD-03 & I & Male & 70 & NA & 13-Oct-15 & Khost Center - Terizi \\
\hline TRZ-FGD-03 & 2 & Male & 55 & NA & 13-Oct-15 & Khost Center - Terizi \\
\hline TRZ-FGD-03 & 3 & Male & 60 & NA & 13-Oct-I5 & Khost Center - Terizi \\
\hline TRZ-FGD-03 & 4 & Male & 42 & NA & 13-Oct-15 & Khost Center - Terizi \\
\hline TRZ-FGD-03 & 5 & Male & 68 & NA & 13-Oct-15 & Khost Center - Terizi \\
\hline TRZ-FGD-03 & 6 & Male & 45 & NA & 13-Oct-15 & Khost Center - Terizi \\
\hline TRZ-FGD-03 & 7 & Male & 40 & NA & 13-Oct-15 & Khost Center - Terizi \\
\hline TRZ-FGD-03 & 8 & Male & 38 & NA & 13-Oct-15 & Khost Center - Terizi \\
\hline
\end{tabular}


List of In-Depth Interviews with Local Stakeholders

\begin{tabular}{|c|c|c|c|c|c|c|}
\hline No. & Interview ID & Respondent Type & N Respondents & Interview Date & Location & Gender \\
\hline 1 & ADR-IDI-0I & Local stakeholder & I & 12 OCT 2015 & Herat - Adraskan & Male \\
\hline 2 & ADR-IDI-02 & Local stakeholder & I & 12 OCT 2015 & Herat - Adraskan & Male \\
\hline 3 & ADR-IDI-03 & Local stakeholder & I & 12 OCT 2015 & Herat - Adraskan & Male \\
\hline 4 & ADR-IDI-04 & Local stakeholder & I & 12 OCT 2015 & Herat - Adraskan & Male \\
\hline 5 & ADR-IDI-05 & Local stakeholder & I & 12 OCT 2015 & Herat - Adraskan & Male \\
\hline 6 & ADR-IDI-06 & Local stakeholder & I & 12 OCT 2015 & Herat - Adraskan & Male \\
\hline 7 & ADR-IDI-07 & Local stakeholder & I & 12 OCT 2015 & Herat - Adraskan & Male \\
\hline 8 & ADR-IDI-08 & Local stakeholder & $\mathrm{I}$ & 12 OCT 2015 & Herat - Adraskan & Male \\
\hline 9 & ADR-IDI-09 & Local stakeholder & I & 12 OCT 2015 & Herat - Adraskan & Male \\
\hline 10 & ADR-IDI- 10 & Local stakeholder & $\mathrm{I}$ & 13 OCT 2015 & Herat - Adraskan & Female \\
\hline 11 & ADR-IDI-II & Local stakeholder & I & 13 OCT 2015 & Herat - Adraskan & Female \\
\hline 12 & ADR-IDI-I 2 & Local stakeholder & 1 & 13 OCT 2015 & Herat - Adraskan & Female \\
\hline 13 & BDG-IDI-0I & Local stakeholder & 1 & II OCT 2015 & Badghis - Qala-i-Naw & Male \\
\hline 14 & BDG-IDI-02 & Local stakeholder & I & II OCT 2015 & Badghis - Qala-i-Naw & Male \\
\hline 15 & BDG-IDI-03 & Local stakeholder & I & 12 OCT 2015 & Badghis - Qadis & Male \\
\hline 16 & BDG-IDI-04 & Local stakeholder & $\mathrm{I}$ & 12 OCT 2015 & Badghis - Qadis & Male \\
\hline 17 & BDG-IDI-05 & Local stakeholder & I & II OCT 2015 & Badghis - Qala-i-Naw & Male \\
\hline 18 & BDG-IDI-06 & Local stakeholder & I & 14 OCT 2015 & Badghis - Qala-i-Naw & Female \\
\hline 19 & BDG-IDI-07 & Local stakeholder & I & 13 OCT 2015 & Badghis - Qala-i-Naw & Female \\
\hline 20 & BDG-IDI-08 & Local stakeholder & I & 19 OCT 2015 & Badghis - Qala-i-Naw & Male \\
\hline 21 & BDG-IDI-09 & Local stakeholder & $\mathrm{I}$ & 12 OCT 2015 & Badghis - Qala-i-Naw & Female \\
\hline 22 & BDG-IDI- 10 & Local stakeholder & I & 16 OCT 2015 & Badghis - Qala-i-Naw & Male \\
\hline 23 & BDG-IDI-I I & Local stakeholder & I & 14 OCT 2015 & Badghis - Qala-i-Naw & Male \\
\hline 24 & BDG-IDI-I2 & Local stakeholder & I & 13 OCT 2015 & Badghis - Qadis & Male \\
\hline 25 & INJ-IDI-0I & Local stakeholder & I & 10 OCT 2015 & Herat - City & Male \\
\hline 26 & INJ-IDI-02 & Local stakeholder & I & 15 OCT 2015 & Herat - Injil & Female \\
\hline 27 & INJ-IDI-03 & Local stakeholder & I & I5 OCT 2015 & Herat - Injil & Male \\
\hline 28 & INJ-IDI-04 & Local stakeholder & I & 10 OCT 2015 & Herat - City & Male \\
\hline
\end{tabular}




\begin{tabular}{|c|c|c|c|c|c|c|}
\hline No. & Interview ID & Respondent Type & N Respondents & Interview Date & Location & Gender \\
\hline 29 & INJ-IDI-05 & Local stakeholder & I & 15 OCT 2015 & Herat - Injil & Female \\
\hline 30 & INJ-IDI-06 & Local stakeholder & $\mathrm{I}$ & 15 OCT 2015 & Herat - Injil & Male \\
\hline 31 & INJ-IDI-07 & Local stakeholder & I & 17 OCT 2015 & Herat - Injil & Male \\
\hline 32 & INJ-IDI-08 & Local stakeholder & $\mathrm{I}$ & 10 OCT 2015 & Herat - City & Male \\
\hline 33 & INJ-IDI-09 & Local stakeholder & I & I5 OCT 2015 & Herat - Injil & Female \\
\hline 34 & INJ-IDI-I0 & Local stakeholder & $\mathrm{I}$ & 17 OCT 2015 & Herat - Injil & Male \\
\hline 35 & INJ-IDI-II & Local stakeholder & I & 15 OCT 2015 & Herat - Injil & Male \\
\hline 36 & INJ-IDI-I2 & Local stakeholder & $\mathrm{I}$ & 15 OCT 2015 & Herat - Injil & Male \\
\hline 37 & KJK-IDI-0I & Local stakeholder & I & 9 OCT 2015 & Helmand - Lashkargah & Male \\
\hline 38 & KJK-IDI-02 & Local stakeholder & I & 14 OCT 2015 & Helmand - Lashkargah & Male \\
\hline 39 & KJK-IDI-03 & Local stakeholder & I & 13 OCT 2015 & Helmand - Lashkargah & Male \\
\hline 40 & KJK-IDI-04 & Local stakeholder & I & 19 OCT 2015 & Helmand - Kajaki & Male \\
\hline 41 & KJK-IDI-05 & Local stakeholder & $\mathrm{I}$ & 14 OCT 2015 & Helmand - Kajaki & Male \\
\hline 42 & KJK-IDI-06 & Local stakeholder & I & 14 OCT 2015 & Helmand - Kajaki & Male \\
\hline 43 & KJK-IDI-07 & Local stakeholder & I & 14 OCT 2015 & Helmand - Kajaki & Male \\
\hline 44 & KJK-IDI-08 & Local stakeholder & I & 24 OCT 2015 & Helmand - Lashkargah & Male \\
\hline 45 & KJK-IDI-09 & Local stakeholder & I & 15 OCT 2015 & Helmand - Kajaki & Male \\
\hline 46 & KJK-IDI-IO & Local stakeholder & I & 14 OCT 2015 & Helmand - Kajaki & Female \\
\hline 47 & KJK-IDI-II & Local stakeholder & I & 14 OCT 2015 & Helmand - Nahr-e-Saraj & Female \\
\hline 48 & KJK-IDI-I 2 & Local stakeholder & 1 & 14 OCT 2015 & Helmand - Nahr-e-Saraj & Female \\
\hline 49 & KND-IDI-0I & Local stakeholder & I & 8 OCT 2015 & Kandahar - City & Male \\
\hline 50 & KND-IDI-02 & Local stakeholder & I & 16 OCT 2015 & Kandahar - City & Male \\
\hline 51 & KND-IDI-03 & Local stakeholder & I & 7 OCT 2015 & Kandahar - City & Male \\
\hline 52 & KND-IDI-04 & Local stakeholder & I & 8 OCT 2015 & Kandahar - City & Male \\
\hline 53 & KND-IDI-05 & Local stakeholder & I & 7 OCT 2015 & Kandahar - City & Female \\
\hline 54 & KND-IDI-06 & Local stakeholder & $\mathrm{I}$ & 7 OCT 2015 & Kandahar - City & Male \\
\hline 55 & KND-IDI-07 & Local stakeholder & I & 15 OCT 2015 & Kandahar - City & Male \\
\hline 56 & KND-IDI-08 & Local stakeholder & I & 10 OCT 2015 & Kandahar - City & Male \\
\hline 57 & KND-IDI-09 & Local stakeholder & 1 & 16 OCT 2015 & Kandahar - City & Male \\
\hline
\end{tabular}




\begin{tabular}{|c|c|c|c|c|c|c|}
\hline No. & Interview ID & Respondent Type & N Respondents & Interview Date & Location & Gender \\
\hline 58 & KND-IDI- 10 & Local stakeholder & I & II OCT 2015 & Kandahar - City & Male \\
\hline 59 & KND-IDI-II & Local stakeholder & I & 15 OCT 2015 & Kandahar - City & Female \\
\hline 60 & KND-IDI- 12 & Local stakeholder & I & 15 OCT 2015 & Kandahar - City & Female \\
\hline 61 & KUR-IDI-OI & Local stakeholder & I & 7 OCT 2015 & Kunar - Khas Kunar & Male \\
\hline 62 & KUR-IDI-02 & Local stakeholder & I & 6 OCT 2015 & Kunar - Khas Kunar & Male \\
\hline 63 & KUR-IDI-03 & Local stakeholder & I & 7 OCT 2015 & Kunar - Khas Kunar & Male \\
\hline 64 & KUR-IDI-04 & Local stakeholder & I & II OCT 2015 & Kunar - Khas Kunar & Male \\
\hline 65 & KUR-IDI-05 & Local stakeholder & $\mathrm{I}$ & 7 OCT 2015 & Kunar - Khas Kunar & Male \\
\hline 66 & KUR-IDI-06 & Local stakeholder & $\mathrm{I}$ & 6 OCT 2015 & Kunar - Asadabad & Male \\
\hline 67 & KUR-IDI-07 & Local stakeholder & I & 4 OCT 2015 & Kunar - Asadabad & Male \\
\hline 68 & KUR-IDI-08 & Local stakeholder & $\mathrm{I}$ & 10 OCT 2015 & Kunar - Khas Kunar & Male \\
\hline 69 & KUR-IDI-09 & Local stakeholder & I & 10 OCT 2015 & Kunar - Khas Kunar & Male \\
\hline 70 & KUR-IDI- I0 & Local stakeholder & $\mathrm{I}$ & 10 OCT 2015 & Kunar - Khas Kunar & Male \\
\hline 71 & KUR-IDI-II & Local stakeholder & 1 & 10 OCT 2015 & Kunar - Asadabad & Female \\
\hline 72 & KUR-IDI-I2 & Local stakeholder & 1 & 12 OCT 2015 & Kunar - Khas Kunar & Female \\
\hline 73 & KUR-IDI-I 3 & Local stakeholder & I & 13 OCT 2015 & Kunar - Khas Kunar & Female \\
\hline 74 & LASH-IDI-0I & Local stakeholder & I & 6 OCT 2015 & Helmand - Lashkargah & Female \\
\hline 75 & LASH-IDI-02 & Local stakeholder & I & 6 OCT 2015 & Helmand - Lashkargah & Female \\
\hline 76 & LASH-IDI-03 & Local stakeholder & I & 14 OCT 2015 & Helmand - Lashkargah & Male \\
\hline 77 & LASH-IDI-04 & Local stakeholder & 1 & 14 OCT 2015 & Helmand - Lashkargah & Male \\
\hline 78 & LASH-IDI-05 & Local stakeholder & I & 13 OCT 2015 & Helmand - Lashkargah & Male \\
\hline 79 & LASH-IDI-06 & Local stakeholder & 1 & 8 OCT 2015 & Helmand - Lashkargah & Male \\
\hline 80 & LASH-IDI-07 & Local stakeholder & I & 13 OCT 2015 & Helmand - Lashkargah & Male \\
\hline 81 & LASH-IDI-08 & Local stakeholder & I & 13 OCT 2015 & Helmand - Lashkargah & Male \\
\hline 82 & LASH-IDI-09 & Local stakeholder & I & 14 OCT 2015 & Helmand - Lashkargah & Male \\
\hline 83 & LASH-IDI-IO & Local stakeholder & I & 13 OCT 2015 & Helmand - Lashkargah & Male \\
\hline 84 & LASH-IDI-I I & Local stakeholder & $\mathrm{I}$ & 18 OCT 2015 & Helmand - Lashkargah & Male \\
\hline 85 & LASH-IDI-I 2 & Local stakeholder & I & 6 OCT 2015 & Helmand - Lashkargah & Female \\
\hline 86 & LASH-IDI-I 3 & Local stakeholder & I & I5 OCT 2015 & Helmand - Nahr-e-Saraj & Male \\
\hline
\end{tabular}




\begin{tabular}{|c|c|c|c|c|c|c|}
\hline No. & Interview ID & Respondent Type & N Respondents & Interview Date & Location & Gender \\
\hline 87 & NRS-IDI-0I & Local stakeholder & I & 14 OCT 2015 & Helmand - Nahr-e-Saraj & Male \\
\hline 88 & NRS-IDI-02 & Local stakeholder & $\mathrm{I}$ & 14 OCT 2015 & Helmand - Nahr-e-Saraj & Male \\
\hline 89 & NRS-IDI-03 & Local stakeholder & 1 & 15 OCT 2015 & Helmand - Nahr-e-Saraj & Male \\
\hline 90 & NRS-IDI-04 & Local stakeholder & $\mathrm{I}$ & 15 OCT 2015 & Helmand - Nahr-e-Saraj & Male \\
\hline 91 & NRS-IDI-05 & Local stakeholder & I & 14 OCT 2015 & Helmand - Nahr-e-Saraj & Male \\
\hline 92 & NRS-IDI-06 & Local stakeholder & I & 15 OCT 2015 & Helmand - Nahr-e-Saraj & Male \\
\hline 93 & NRS-IDI-07 & Local stakeholder & I & 15 OCT 2015 & Helmand - Nahr-e-Saraj & Male \\
\hline 94 & NRS-IDI-08 & Local stakeholder & $\mathrm{I}$ & 14 OCT 2015 & Helmand - Nahr-e-Saraj & Male \\
\hline 95 & NRS-IDI-09 & Local stakeholder & I & 14 OCT 2015 & Helmand - Nahr-e-Saraj & Male \\
\hline 96 & NRS-IDI- 10 & Local stakeholder & I & 14 OCT 2015 & Helmand - Nahr-e-Saraj & Female \\
\hline 97 & NRS-IDI-I I & Local stakeholder & I & 14 OCT 2015 & Helmand - Nahr-e-Saraj & Female \\
\hline 98 & NRS-IDI- I 2 & Local stakeholder & I & 14 OCT 2015 & Helmand - Nahr-e-Saraj & Female \\
\hline 99 & PNJ-IDI-0I & Local stakeholder & $\mathrm{I}$ & 14 OCT 2015 & Kandahar - Panjwai & Male \\
\hline 100 & PNJ-IDI-02 & Local stakeholder & 1 & 17 OCT 2015 & Kandahar - Panjwai & Male \\
\hline 101 & PNJ-IDI-03 & Local stakeholder & 1 & 14 OCT 2015 & Kandahar - Panjwai & Male \\
\hline 102 & PNJ-IDI-04 & Local stakeholder & I & 14 OCT 2015 & Kandahar - Panjwai & Male \\
\hline 103 & PNJ-IDI-05 & Local stakeholder & I & II OCT 2015 & Kandahar - Panjwai & Male \\
\hline 104 & PNJ-IDI-06 & Local stakeholder & I & 9 OCT 2015 & Kandahar - Panjwai & Male \\
\hline 105 & PNJ-IDI-07 & Local stakeholder & I & 9 OCT 2015 & Kandahar - Panjwai & Male \\
\hline 106 & PNJ-IDI-08 & Local stakeholder & 1 & 16 OCT 2015 & Kandahar - Panjwai & Male \\
\hline 107 & PNJ-IDI-09 & Local stakeholder & I & 13 OCT 2015 & Kandahar - Panjwai & Male \\
\hline 108 & PNJ-IDI- 10 & Local stakeholder & I & 14 OCT 2015 & Kandahar - Panjwai & Male \\
\hline 109 & PNJ-IDI-II & Local stakeholder & 1 & 12 OCT 2015 & Kandahar - Panjwai & Female \\
\hline 110 & PNJ-IDI-I 2 & Local stakeholder & 1 & 12 OCT 2015 & Kandahar - Panjwai & Female \\
\hline 111 & PNJ-IDI-I 3 & Local stakeholder & 1 & 12 OCT 2015 & Kandahar - Panjwai & Female \\
\hline 112 & SMG-IDI-0I & Local stakeholder & $\mathrm{I}$ & II OCT 2015 & Samangan - Hazrat Sultan & Male \\
\hline 113 & SMG-IDI-03 & Local stakeholder & I & 12 OCT 2015 & Samangan - Hazrat Sultan & Female \\
\hline 114 & SMG-IDI-04 & Local stakeholder & I & I5 OCT 2015 & Samangan - Hazrat Sultan & Male \\
\hline 115 & SMG-IDI-05 & Local stakeholder & 1 & 8 OCT 2015 & Samangan - Hazrat Sultan & Male \\
\hline
\end{tabular}




\begin{tabular}{|c|c|c|c|c|c|c|}
\hline No. & Interview ID & Respondent Type & N Respondents & Interview Date & Location & Gender \\
\hline 116 & SMG-IDI-06 & Local stakeholder & I & 9 OCT 2015 & Samangan - Hazrat Sultan & Male \\
\hline 117 & SMG-IDI-07 & Local stakeholder & I & 9 OCT 2015 & Samangan - Hazrat Sultan & Male \\
\hline 118 & SMG-IDI-08 & Local stakeholder & I & 10 OCT 2015 & Samangan - Hazrat Sultan & Male \\
\hline 119 & SMG-IDI-09 & Local stakeholder & I & II OCT 2015 & Samangan - Hazrat Sultan & Male \\
\hline 120 & SMG-IDI-12 & Local stakeholder & I & II OCT 2015 & Samangan - Hazrat Sultan & Female \\
\hline 121 & SMG-IDI-I4 & Local stakeholder & 1 & 12 OCT 2015 & Samangan - Hazrat Sultan & Male \\
\hline 122 & SMG-IDI-I5 & Local stakeholder & I & 12 OCT 2015 & Samangan - Hazrat Sultan & Female \\
\hline 123 & SMG-IDI-I7 & Local stakeholder & I & 8 OCT 2015 & Samangan - Hazrat Sultan & Male \\
\hline 124 & TRZ-IDI-0I & Local stakeholder & $\mathrm{I}$ & 9 OCT 2015 & Khost - Terezayi & Male \\
\hline 125 & TRZ-IDI-02 & Local stakeholder & 1 & 10 OCT 2015 & Khost - Terezayi & Male \\
\hline 126 & TRZ-IDI-03 & Local stakeholder & I & 8 OCT 2015 & Khost - Terezayi & Male \\
\hline 127 & TRZ-IDI-04 & Local stakeholder & I & 9 OCT 2015 & Khost - Terezayi & Male \\
\hline 128 & TRZ-IDI-05 & Local stakeholder & $\mathrm{I}$ & 8 OCT 2015 & Khost - Terezayi & Male \\
\hline 129 & TRZ-IDI-06 & Local stakeholder & 1 & 10 OCT 2015 & Khost - Terezayi & Female \\
\hline 130 & TRZ-IDI-07 & Local stakeholder & 1 & 12 OCT 2015 & Khost - Terezayi & Male \\
\hline 131 & TRZ-IDI-08 & Local stakeholder & I & 10 OCT 2015 & Khost - Terezayi & Female \\
\hline 132 & TRZ-IDI-09 & Local stakeholder & $\mathrm{I}$ & II OCT 2015 & Khost - Terezayi & Male \\
\hline 133 & TRZ-IDI-I0 & Local stakeholder & I & 9 OCT 2015 & Khost - Mondazay & Female \\
\hline 134 & TRZ-IDI-I I & Local stakeholder & 1 & II OCT 2015 & Khost - Terezayi & Male \\
\hline 135 & TRZ-IDI- I 2 & Local stakeholder & I & 10 OCT 2015 & Khost - Center & Male \\
\hline
\end{tabular}


Interviews with USAID Officials, IP Management, and IP Staff

\begin{tabular}{|c|c|c|c|c|c|}
\hline No. & Transcript Code & Respondent Type & N Respondents & Interview Date & Location \\
\hline I & BDG-IOM-0I & IP staff - IOM & 1 & 14 OCT 2015 & Kabul - City \\
\hline 2 & BDG-IOM-02 & IP staff - IOM & $\mathrm{I}$ & 6 OCT 2015 & Badghis - Qala-i-Naw \\
\hline 3 & BDG-IOM-03 & IP staff - IOM & 1 & 6 OCT 2015 & Badghis - Qala-i-Naw \\
\hline 4 & BDG-IOM-04 & IP staff - IOM & I & 5 OCT 2015 & Herat - City \\
\hline 5 & BDG-IOM-05 & IP staff - IOM & 1 & 6 OCT 2015 & Badghis - Qala-i-Naw \\
\hline 6 & BDG-IOM-06 & IP staff - IOM & I & 5 OCT 2015 & Herat - City \\
\hline 7 & BLK-IOM-0I & IP staff - IOM & I & 29 OCT 2015 & Kabul - City \\
\hline 8 & HLM-CR-OI & IP staff - Creative & 1 & 9 OCT 2015 & Helmand - Lashkargah \\
\hline 9 & HLM-CR-02 & IP staff - Creative & 1 & 10 OCT 2015 & Helmand - Lashkargah \\
\hline 10 & HLM-CR-03 & IP staff - Creative & 1 & 10 OCT 2015 & Helmand - Lashkargah \\
\hline 11 & HLM-CR-04 & IP staff - Creative & 1 & 10 OCT 2015 & Helmand - Lashkargah \\
\hline 12 & HLM-CR-05 & IP staff - Creative & 1 & 10 OCT 2015 & Helmand - Lashkargah \\
\hline 13 & HLM-CR-06 & IP staff - Creative & 1 & 9 OCT 2015 & Helmand - Lashkargah \\
\hline 14 & HRT-IOM-0I & IP staff - IOM & 1 & 4 OCT 2015 & Herat - City \\
\hline 15 & HRT-IOM-02 & IP staff - IOM & $\mathrm{I}$ & 4 OCT 2015 & Herat - City \\
\hline 16 & HRT-IOM-03 & IP staff - IOM & 1 & 4 OCT 2015 & Herat - City \\
\hline 17 & HRT-IOM-04 & IP staff - IOM & $\mathrm{I}$ & 4 OCT 2015 & Herat - City \\
\hline 18 & HRT-IOM-05 & IP staff - IOM & 1 & 5 OCT 2015 & Herat - City \\
\hline 19 & HRT-IOM-06 & IP staff - IOM & 1 & 5 OCT 2015 & Herat - City \\
\hline 20 & HRT-IOM-07 & IP staff - IOM & 1 & 5 OCT 2015 & Herat - City \\
\hline 21 & HRT-IOM-08 & IP staff - IOM & 1 & 26 OCT 2015 & Kabul - City \\
\hline 22 & KBL-IOM-0I & IP management - IOM & I & 30 SEP 2015 & Kabul \\
\hline 23 & KBL-IOM-02 & IP management - IOM & 1 & 30 SEP 2015 & Kabul \\
\hline 24 & KBL-IOM-02 & IP management - IOM & I & 2 SEP 2015 & Kabul \\
\hline 25 & KBL-IOM-03 & IP staff - IOM & 2 & 30 SEP 2015 & Kabul \\
\hline 26 & KBL-IOM-06 & IP staff - IOM & 2 & I OCT 2015 & Kabul \\
\hline 27 & KBL-IOM-07 & IP management - IOM & 1 & I OCT 2015 & Kabul \\
\hline 28 & KBL-IOM-08 & IP staff - IOM & I & I OCT 2015 & Kabul \\
\hline
\end{tabular}




\begin{tabular}{|c|c|c|c|c|c|}
\hline No. & Transcript Code & Respondent Type & N Respondents & Interview Date & Location \\
\hline 29 & KBL-IOM-09 & IP staff - IOM & I & I OCT 2015 & Kabul \\
\hline 30 & KBL-IOM-I0 & IP staff - IOM & 1 & I OCT 2015 & Kabul \\
\hline 31 & KBL-IOM-II & IP management - IOM & I & 7 ОСТ 2015 & Kabul \\
\hline 32 & KBL-IOM-I2 & IP management - IOM & 1 & 7 OCT 2015 & Kabul \\
\hline 33 & KBL-RSI-0I & IP management - RSI & 2 & 27 SEP 2015 & Kabul \\
\hline 34 & KBL-RSI-02 & IP staff - RSI & 1 & 8 NOV 2015 & Kabul - City \\
\hline 35 & KBL-RSI-03 & IP staff - RSI & 1 & 8 NOV 2015 & Kabul - City \\
\hline 36 & KBL-RSI-03 & IP management - RSI & 1 & 7 OCT 2015 & Kabul \\
\hline 37 & KBL-USAID-0I & Mission leadership & 1 & 27 SEP 2015 & Kabul \\
\hline 38 & KBL-USAID-02 & Mission leadership & 1 & 27 SEP 2015 & Kabul \\
\hline 39 & KBL-USAID-03 & Mission leadership & 1 & I NOV 2015 & Kabul \\
\hline 40 & KBL-USIP-IO & USIP management & 1 & 4 OCT 2015 & Kabul \\
\hline 41 & KBL-USIP-II & USIP management & 1 & 4 OCT 2015 & Kabul \\
\hline 42 & KBL-USIP-I 2 & USIP management & 2 & 4 OCT 2015 & Kabul \\
\hline 43 & KBL-USIP-I 3 & USIP management & 1 & 4 OCT 2015 & Kabul \\
\hline 44 & KBL-USIP-I 4 & USIP management & $1>$ & 4 OCT 2015 & Kabul \\
\hline 45 & KHT-CR-OI & IP staff - Creative & 1 & 7 OCT 2015 & Khost - Mandozay \\
\hline 46 & KHT-CR-03 & IP staff - Creative & 1 & II OCT 2015 & Kabul - City \\
\hline 47 & KHT-CR-04 & IP staff - Creative & 1 & 9 OCT 2015 & Khost - Center \\
\hline 48 & KHT-CR-05 & IP staff - Creative & 1 & 9 OCT 2015 & Khost - Center \\
\hline 49 & KHT-CR-06 & IP staff - Creative & I & 9 OCT 2015 & Khost - Center \\
\hline 50 & KHT-CR-07 & IP staff - Creative & 1 & 29 OCT 2015 & Kabul - Bagrami \\
\hline 51 & KHT-CR-08 & IP staff - Creative & 1 & 9 OCT 2015 & Khost - Center \\
\hline 52 & KHT-RSI-OI & IP staff - RSI & 1 & 5 OCT 2015 & Kabul - City \\
\hline 53 & KND-CR-0I & IP staff - Creative & 1 & 16 OCT 2015 & Kandahar - City \\
\hline 54 & KND-CR-02 & IP staff - Creative & I & 13 OCT 2015 & Kandahar - City \\
\hline 55 & KND-CR-03 & IP staff - Creative & 1 & 14 OCT 2015 & Kandahar - City \\
\hline 56 & KND-CR-04 & IP staff - Creative & I & 12 OCT 2015 & Kandahar - City \\
\hline 57 & KND-CR-05 & IP staff - Creative & 1 & 15 OCT 2015 & Kandahar - City \\
\hline
\end{tabular}




\begin{tabular}{|c|c|c|c|c|c|}
\hline No. & Transcript Code & Respondent Type & N Respondents & Interview Date & Location \\
\hline 58 & KND-CR-06 & IP staff - Creative & $\mathrm{I}$ & 15 OCT 2015 & Kandahar - City \\
\hline 59 & KND-CR-07 & IP staff - Creative & 1 & 12 OCT 2015 & Kandahar - City \\
\hline 60 & KUR-CR-0I & IP staff - Creative & I & 8 OCT 2015 & Kunar - Center \\
\hline 61 & KUR-CR-02 & IP staff - Creative & 1 & 5 OCT 2015 & Nangarhar - Jalalabad \\
\hline 62 & KUR-CR-03 & IP staff - Creative & I & 6 OCT 2015 & Kunar - Center \\
\hline 63 & KUR-CR-04 & IP staff - Creative & 1 & 4 OCT 2015 & Nangarhar - Jalalabad \\
\hline 64 & KUR-CR-05 & IP staff - Creative & I & 6 OCT 2015 & Kunar - Center \\
\hline 65 & KUR-CR-06 & IP staff - Creative & 1 & 30 OCT 2015 & Kabul - City \\
\hline 66 & SMG-IOM-0I & IP staff - IOM & $\mathrm{I}$ & 5 OCT 2015 & Samangan - Aybak \\
\hline 67 & SMG-IOM-02 & IP staff - IOM & 1 & 5 OCT 2015 & Samangan - Aybak \\
\hline 68 & SMG-IOM-03 & IP staff - IOM & 1 & 6 OCT 2015 & Samangan - Aybak \\
\hline 69 & SMG-IOM-04 & IP staff - IOM & 1 & 6 OCT 2015 & Samangan - Aybak \\
\hline 70 & SMG-IOM-05 & IP staff - IOM & I & I5 OCT 2015 & Kabul - City \\
\hline 71 & SMG-IOM-06 & IP staff - IOM & 1 & 25 OCT 2015 & Kabul - City \\
\hline 72 & SMG-IOM-08 & IP staff - IOM & 1 & 25 OCT 2015 & Kabul - City \\
\hline 73 & WAS-CR-OI & IP management - Creative & 3 & 3 SEP 2015 & Washington \\
\hline 74 & WAS-CR-02 & IP management - Creative & $\mathrm{I}$ & I5 SEP 2015 & Phone \\
\hline 75 & WAS-CR-03 & IP staff - Creative & 1 & 21 SEP 2015 & Phone \\
\hline 76 & WAS-CR-04 & IP management - Creative & $\mathrm{I}$ & 17 SEP 2015 & Phone \\
\hline 77 & WAS-IOM-0I & IP management - IOM & 1 & 2 SEP 2015 & Washington \\
\hline 78 & WAS-IOM-03 & IP management - IOM & $\mathrm{I}$ & 2 SEP 2015 & Washington \\
\hline 79 & WAS-IOM-04 & IP management - IOM & 1 & 2 SEP 2015 & Washington \\
\hline 80 & WAS-IOM-04 & IP management - IOM & $\mathrm{I}$ & 30 SEP 2015 & Washington \\
\hline 81 & WAS-IOM-05 & IP management - IOM & 1 & 30 SEP 2015 & Washington \\
\hline 82 & WAS-USAID-0I & USAID-OAPA & $\mathrm{I}$ & 31 AUG 2015 & Kabul \\
\hline 83 & WAS-USAID/OTI-0I & CCI-OTI & 1 & 8 SEP 2015 & Phone \\
\hline 84 & WAS-USAID/OTI-02 & CCI-OTI & $\mathrm{I}$ & 31 AUG 2015 & Washington \\
\hline 85 & WAS-USAID/OTI-03 & CCI-OTI & 1 & 31 AUG 2015 & Washington \\
\hline 86 & WAS-USAID/OTI-04 & OTI Washington & 2 & 31 AUG 2015 & Washington \\
\hline
\end{tabular}




\begin{tabular}{|c|c|c|c|c|c|}
\hline No. & Transcript Code & Respondent Type & N Respondents & Interview Date & Location \\
\hline 87 & WAS-USAID/OTI-05 & OTI Washington & I & 31 AUG 2015 & Washington \\
\hline 88 & WAS-USAID/OTI-06 & $\mathrm{CCl}-\mathrm{OTI}$ & $\mathrm{I}$ & I SEP 2015 & Washington \\
\hline 89 & WAS-USAID/OTI-07 & OTI Washington & 1 & I SEP 2015 & Washington \\
\hline 90 & WAS-USAID/OTI-08 & $\mathrm{CCl}-\mathrm{OTI}$ & $\mathrm{I}$ & 2 SEP 2015 & Washington \\
\hline 91 & WAS-USAID/OTI-09 & OTI Washington & 1 & 4 SEP 2015 & Washington \\
\hline 92 & WAS-USAID/OTI-I0 & $\mathrm{CCl}-\mathrm{OTI}$ & 1 & 4 SEP 2015 & Washington \\
\hline 93 & WAS-USAID/OTI-II & OTI Washington & 1 & 17 SEP 2015 & Phone \\
\hline 94 & WAS-USAID/OTI-I 2 & $\mathrm{CCl}-\mathrm{OTI}$ & 1 & 22 SEP 2015 & Phone \\
\hline 95 & WAS-USAID/OTI-I3 & $\mathrm{CCl}-\mathrm{OTI}$ & 1 & 27 SEP 2015 & Washington \\
\hline 96 & WAS-USAID/OTI-I4 & $\mathrm{CCl}-\mathrm{OTI}$ & 1 & 6 NOV 2015 & Phone \\
\hline 97 & WAS-USAID/OTI-I5 & $\mathrm{CCl}-\mathrm{OTI}$ & 1 & 9 NOV 2015 & Phone \\
\hline 98 & WAS-USIP-0I & USIP management & 4 & 2 SEP 2015 & Washington \\
\hline 99 & WAS-USIP-05 & USIP management & 1 & 4 SEP 2015 & Phone \\
\hline
\end{tabular}




\section{Interviews with USIP Partners}

\begin{tabular}{|c|c|c|c|c|c|}
\hline No. & Transcript Code & USIP Grantee & N Respondents & Interview Date & Location \\
\hline I & HLM-USIP-OI & Bost Radio & I & 27 OCT 2015 & Helmand - \\
\hline 2 & HRT-USIP-OI & Sanayee Development Organization (SDO) & I & 19 OCT 2015 & Kabul - City \\
\hline 3 & HRT-USIP-02 & $\begin{array}{l}\text { Afghanistan Youth National and Social Organization } \\
\text { (AYNSO) }\end{array}$ & I & 18 OCT 2015 & Herat - City \\
\hline 4 & HRT-USIP-03 & $\begin{array}{l}\text { Afghanistan Youth National and Social Organization } \\
\text { (AYNSO) }\end{array}$ & I & 18 OCT 2015 & Herat - City \\
\hline 5 & HRT-USIP-04 & $\begin{array}{c}\text { Welfare and Support Afghan Women Disability } \\
\text { Organization (WSAWDO) }\end{array}$ & I & 18 OCT 2015 & Herat - City \\
\hline 6 & HRT-USIP-05 & Social Development and Advocacy Organization (SDAO) & I & 18 OCT 2015 & Herat - City \\
\hline 7 & KBL-USIP-0I & School of Leadership Afghanistan (SOLA) & I & 3 NOV 2015 & Kabul - City \\
\hline 8 & KBL-USIP-02 & Equality for Peace and Democracy & I & 4 OCT 2015 & Kabul - City \\
\hline 9 & KBL-USIP-03 & The Liaison Office (TLO) & I & 4 OCT 2015 & Kabul - City \\
\hline 10 & KBL-USIP-04 & Sanayee Development Organization (SDO) & I & 6 OCT 2015 & Kabul - City \\
\hline II & KBL-USIP-05 & Saba Media & I & 6 OCT 2015 & Kabul - City \\
\hline 12 & KBL-USIP-06 & $\begin{array}{l}\text { Afghanistan Youth National and Social Organization } \\
\text { (AYNSO) }\end{array}$ & I & 6 OCT 2015 & Kabul - City \\
\hline 13 & KBL-USIP-07 & Wadan & I & 6 OCT 2015 & Kabul - City \\
\hline 14 & KBL-USIP-08 & Tadbeer & I & 6 OCT 2015 & Kabul - City \\
\hline 15 & KBL-USIP-09 & Bond Street Theater Co. & I & 6 OCT 2015 & Kabul - City \\
\hline 16 & KHT-USIP-OI & Awoshtoon Cultural Society (ACS) & I & 13 OCT 2015 & Kabul - City \\
\hline 17 & KHT-USIP-02 & Pajhwok Afghan News & I & I5 OCT 2015 & Khost - Center \\
\hline 18 & KHT-USIP-03 & Peace Radio & I & 16 OCT 2015 & Khost - Center \\
\hline 19 & KND-USIP-0I & Hewad Radio and TV & I & 8 OCT 2015 & Kabul - City \\
\hline 20 & KND-USIP-02 & Hindara Media and Youth Development Organization & I & 17 OCT 2015 & Kandahar - City \\
\hline 21 & KND-USIP-03 & Hindara Media and Youth Development Organization & I & 17 OCT 2015 & Kandahar - City \\
\hline 22 & KND-USIP-04 & Hewad TV & I & 17 OCT 2015 & Kandahar - City \\
\hline 23 & KND-USIP-05 & Kandahar Film and Theater & I & 18 OCT 2015 & Kandahar - City \\
\hline 24 & KND-USIP-06 & Nial Academy & I & 18 OCT 2015 & Kandahar - City \\
\hline
\end{tabular}




\begin{tabular}{c|c|c|c|c|c}
\hline No. & Transcript Code & USIP Grantee & I & I2 OCT 20I5 & Kabul - City \\
\hline 25 & KUR-USIP-0I & Saba Story Radio & I & I3 OCT 20I5 & Kunar - Asadabad \\
\hline 26 & KUR-USIP-02 & OSCAR & I & I5 OCT 20I5 & Nangarhar - Jalalabad \\
\hline 27 & KUR-USIP-03 & AABRAR & I & I4 OCT 20I5 & Kunar - Asadabad \\
\hline 28 & KUR-USIP-04 & Badloon Radio & I & 29 OCT 2015 & Nangarhar - Pachai \\
\hline 29 & KUR-USIP-05 & Nangarhar Theater Co & & \\
\hline
\end{tabular}




\section{ANNEX V: DISCLOSURE OF ANY CONFLICTS OF INTEREST}

Disclosure of Conflict of Interest for USAID Evaluation Team Members

\begin{tabular}{|c|c|}
\hline Name & Samuel Schueth \\
\hline Title & Senior Evaluation Expert/Team Leader \\
\hline Organization & Social Impact, Inc. \\
\hline Evaluation Position? & - Team Leader $\square$ Team member \\
\hline $\begin{array}{l}\text { Evaluation Award Number(contract } \\
\text { or other instrument) }\end{array}$ & $\begin{array}{l}\text { Contract \# AID-OAA-I-13-00006 } \\
\text { Task Order \# AID-OAA-TO-15-00018 \#11 }\end{array}$ \\
\hline $\begin{array}{l}\text { USAID Project(s) Evaluated(Include } \\
\text { project name(s), implementer } \\
\text { name(s) and award number(s), if } \\
\text { applicable) }\end{array}$ & $\begin{array}{l}\text { USAID/Afghanistan Rule of Law Stabilization Program, } \\
\text { Informal Component, Checchi Consulting and } \\
\text { Company, AID-0-14-0005 }\end{array}$ \\
\hline $\begin{array}{l}\text { I have real or potential conflicts of } \\
\text { interest to disclose. }\end{array}$ & $\square$ Yes $\quad \mathrm{X}$ No \\
\hline 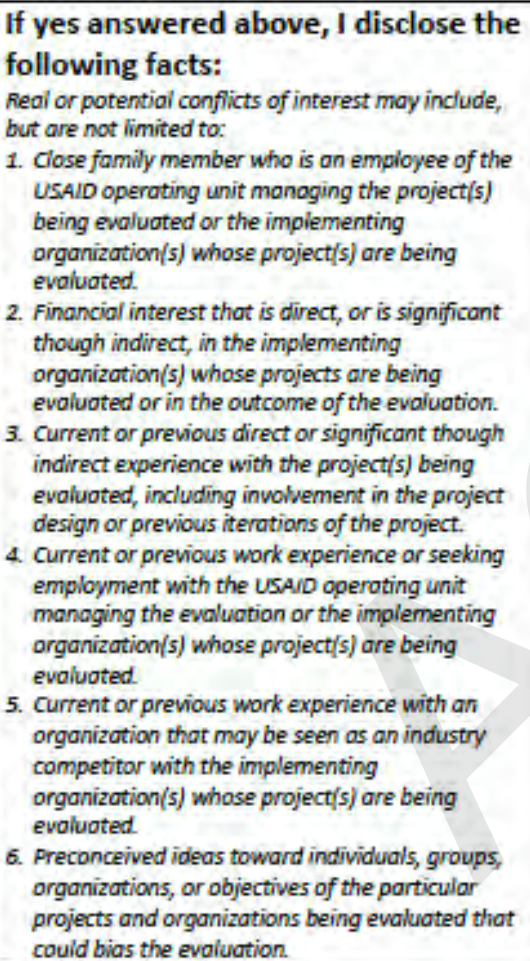 & \\
\hline
\end{tabular}

I certify (1) that I have completed this disclosure form fully and to the best of my ability and (2) that I will update this disclosure form promptly if relevant circumstances change. If I gain access to proprietary information of other companies, then I agree to protect their information from unauthorized use or disclosure for as long as it remains proprietary and refrain from using the information for any purpose other than that for which it was furnished.

\begin{tabular}{|l|l|}
\hline Signature & Salf Sat \\
\hline Date & 23 July 2015 \\
\hline
\end{tabular}


U.S. Agency for International Development

I 300 Pennsylvania Avenue, NW

Washington, DC 20523 